Bert Rürup Uwe H. Schneider (Hrsg.)

Bearbeitet von: Thomas Kemmler,

Thomas Steinbacher

\title{
Umwelt und Technik in den Europäischen Gemeinschaften
}

Teil I: Die grenzüberschreitende Entsorgung von Abfällen 


\author{
Bert Rürup Uwe H. Schneider (Hrsg.) \\ Bearbeitet von: Thomas Kemmler, Thomas Steinbacher
}

\title{
Umwelt und Technik in den Europäischen Gemeinschaften
}

Aufgrund der Einheitlichen Europäischen Akte erhielt die Europäische Gemeinschaft den Auftrag und die Kompetenz, einen ökologischen qualifizierten Binnenmarkt zu schaffen. Problematisch ist, ob und in welchem Umfang dazu auch die Schaffung eines gemeinsamen europäischen Abfallmarktes gehört. Vor diesem Hintergrund ist es notwendig, die rechtlichen und volkswirtschaftlichen Aspekte der grenzüberschreitenden Abfallentsorgung eingehend $\mathrm{zu}$ untersuchen. Maßgebender Gesichtspunkt war, daß dieses Thema im Spannungsfeld zwischen Ökonomie, Technik, Recht und Ökologie einerseits und im Spannungsfeld zwischen nationalem und europäischem.Recht andererseits eingebettet ist.

Bert Rürup und Uwe H. Schneider sind Professoren für Volkswirtschaftslehre und Rechtswissenschaft an der Technischen Hochschule Darmstadt. Gemeinsam betreuen sie das vom Land Hessen geförderte Forschungsprojekt "Umwelt und Technik als Gegenstand europäischer Steuerungspolitiken". 
Umwelt und Technik in den Europäischen Gemeinschaften Teil I: Die grenzüberschreitende Entsorgung von Abfällen Bearbeitet von: Thomas Kemmler, Thomas Steinbacher 


\section{Sozialökonomische Schriften}

Herausgegeben von Bert Rürup

Band 6

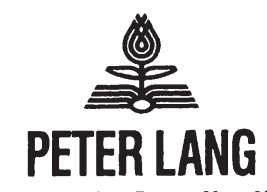

Frankfurt am Main - Berlin B Bem - New York - Paris - Wien

Downloaded from PubFactory at 01/11/2019 08:13:45AM

via free access 


\title{
Bert Rürup \\ Uwe H. Schneider \\ (Hrsg.)
}

\section{Umwelt und Technik \\ in den \\ Europäischen Gemeinschaften}

\author{
Teil l:
}

Die grenzüberschreitende Entsorgung von Abfällen

Bearbeitet von:

Thomas Kemmler, Thomas Steinbacher

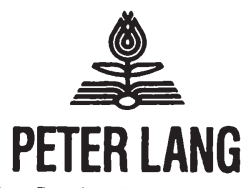

Frankfurt am Main · Berlin · Bem - New York · Paris - Wien

Bert Rürup and Uwe H. Schneider - 978-3-631-75109-1 
Umwelt und Technik in den Europäischen Gemeinschaften / Bert Rürup ; Uwe H. Schneider (Hrsg.). - Frankfurt am Main ; Berlin ; Bern ; New York ; Paris ; Wien : Lang, 1993

NE: Rürup, Bert [Hrsg.]

Open Access: The online version of this publication is published on www.peterlang.com and www.econstor.eu under the international Creative Commons License CC-BY 4.0. Learn more on how you can use and share this work: http://creativecommons.org/ licenses/by/4.0.

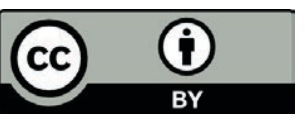

This book is available Open Access thanks to the kind support of ZBW - Leibniz-Informationszentrum Wirtschaft.

Teil 1. Die grenzüberschreitende Entsorgung von Abfällen / bearb. von: Thomas Kemmler ; Thomas Steinbacher. - 1993 (Sozialökonomische Schriften ; Bd. 6) ISBN 3-631-44735-3

NE: Kemmler, Thomas; GT

\author{
ISSN 0172-1747 \\ ISBN 3-631-44735-3 \\ ISBN 978-3-631-75109-1 (eBook) \\ (C) Verlag Peter Lang GmbH, Frankfurt am Main 1993 \\ Alle Rechte vorbehalten.
}

Das Werk einschließlich aller seiner Teile ist urheberrechtlich geschützt. Jede Verwertung außerhalb der engen Grenzen des Urheberrechtsgesetzes ist ohne Zustimmung des Verlages unzulässig und strafbar. Das gilt insbesondere für Vervielfältigungen, Übersetzungen, Mikroverfilmungen und die Einspeicherung und Verarbeitung in elektronischen Systemen. 


\section{Vorwort}

Dem Start des europäischen Binnenmarktes wurde in Politik, Wirtschaft, Wissenschaft und in der interessierten Öffentlichkeit mit großem Interesse entgegengesehen. Mit ziemlicher Sicherheit wird die innergemeinschaftliche grenzüberschreitende Abfallverbringung und -entsorgung nicht unbeeinflußt von diesem Ereignis bleiben.

Zwei Studenten des Wirtschaftsingenieurwesens an der Technischen Hochschule Darmstadt trugen den Wunsch an die Herausgeber heran, eine gemeinsame Studienarbeit zur Problematik der grenzüberschreitenden Abfallentsorgung im Rahmen der Europäischen Gemeinschaft zu erstellen. Das Ergebnis dieser bemerkenswerten Arbeiten liegt in leicht überarbeiteter in Form dieser Veröffentlichung vor. Im Hinblick auf die Aktualität der Ausführungen ist zu beachten, daß die Arbeit im Wintersemester 1990/91 abgeschlossen wurde.

Die rechtlichen Aspekte der grenzüberschreitenden Abfallentsorgung standen im Vordergrund der Betrachtungen, doch setzt - wie die Verfasser darlegen - das Abfallrecht Rahmenbedingungen, die auch von betriebs- und volkswirtschaftlicher Relevanz sind.

An die Darstellung europäischen und des bundesdeutschen Abfallrechts sowie der für die Abfallentsorgung möglicherweise relevanten Bestimmungen des EWGVertrages zu den Grundfreiheiten im Binnenmarkt schließt sich die Untersuchung der sich u.U. ergebenden Konflikte zwischen den abfallrechtlichen Regelungen auf gemeinschaftlicher und bundesdeutscher Ebene und den Regelungen zum Binnenmarkt an. Die Autoren nehmen dabei insbesondere Stellung zur Frage der Wareneigenschaft von Abfällen und der Dienstleistungseigenschaft von Abfallentsorgung. Weiterhin werden die EWG-Vertragliche Legitimation von Beschränkungen der Grundfreiheiten untersucht und Maßnahmentypen zur Beschränkung des innergemeinschaftlichen Exports und Imports von Abfällen hinsichtlich ihrer Vereinbarkeit mit dem EWG-Vertrag beurteilt. Zuletzt versuchen die beiden Verfasser einen kurzen Ausblick auf die weitere Entwicklung zu geben.

Darmstadt, Dezember 1992

Prof. Dr. Dr. h.c. B. Rürup 
Bert Rürup and Uwe H. Schneider - 978-3-631-75109-1

Downloaded from PubFactory at 01/11/2019 08:13:45AM

via free access 


\section{Inhaltsverzeichnis}

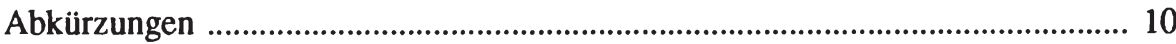

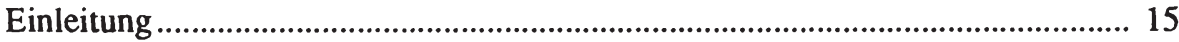

1. Gegenstand und Zielsetzung der Untersuchung ..................................... 15

2. Bedeutung der grenzüberschreitenden Abfallentsorgung .......................... 18

a) Volkswirtschaftliche Bedeutung ........................................................ 19

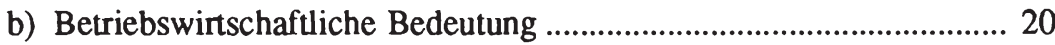

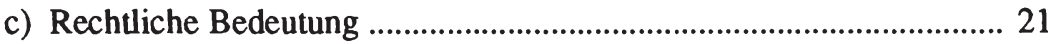

3. Gang der Untersuchung und ausgeklammerte Fragen ............................. 22

A. Rechtsgrundlagen mit Relevanz für die grenzüberschreitende Abfallentsorgung in der Gemeinschaft ................................................................ 25

I. Internationale Übereinkommen und Empfehlungen ................................. 25

1. Baseler Konvention über die Überwachung der grenzüberschreitenden Verbringung gefährlicher Abfälle und ihrer Beseitigung ....... 26

2. Empfehlung des Rates der OECD über die grenzüberschreitende Verbringung von gefährlichen Abfällen ........................................... 28

II. Recht der Europäischen Wirtschaftsgemeinschaft .................................. 28

1. Rechtsgrundlagen der Verwirklichung des Binnenmarktes im EWG-Vertrag

- Primäres Gemeinschaftsrecht - ..................................................... 29

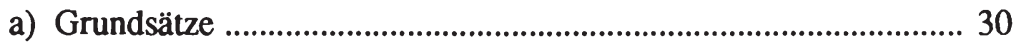

b) Zeitplan zur Verwirklichung des Binnenmarktes ......................... 31

c) Grundlagen der Gemeinschaft ................................................... 31

aa) Der freie Warenverkehr ....................................................... 31

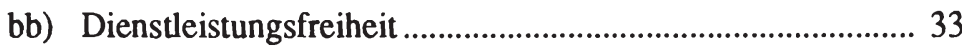

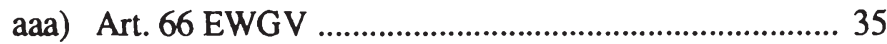

bbb) Art. 90 Abs. 2 EWGV ............................................... 35

d) Politik der Gemeinschaft,

Allgemeine und Schlußbestimmungen des Vertrags ..................... 36

2. Richtlinien

- Sekundäres Gemeinschaftsrecht - ............................................... 38

a) Richtlinie des Rates über Abfälle, 75/442/EWG .......................... 41

b) Richtlinie des Rates über giftige und gefährliche Abfälle, 78/319/EWG

c) Richtlinie des Rates über die Beseitigung polychlorierter Biphenyle und Terphenyle, 76/403/EWG 
d) Richtlinie des Rates über die grenzüberschreitende Verbringung gefährlicher Abfälle, 84/631/EWG

aa) Abschließende Wirkung ........................................................ 45

bb) Notifizierungsverfahren................................................... 47

aaa) Einfuhr giftiger und gefährlicher Abfälle ................... 48

bbb) Transit giftiger und gefährlicher Abfälle ..................... 50

ccc) Ausfuhr giftiger und gefährlicher Abfälle .................... 51

e) Richtlinie des Rates über Abfälle aus der Titanoxid-Produktion,

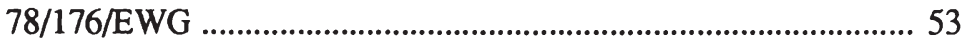

f) Zusammenfassender Überblick über das Abfallrecht der EG ....... 54

III. Recht der Abfallentsorgung in der Bundesrepublik Deutschland ............ 56

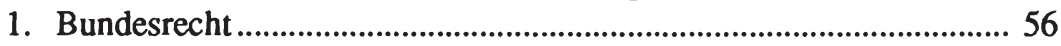

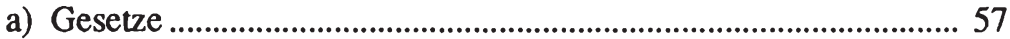

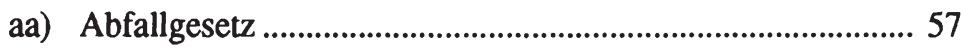

aaa) Abfallbegriff ............................................................... 57

bbb) Abfallarten .............................................................. 59

ccc) Rangfolge der Entsorgungsarten ................................ 59

ddd) Grundsatz der öffentlichen Abfallentsorgung ............. 60

eee) Grundsatz der Inlandsentsorgung ................................ 61

fff) Grenzüberschreitende Abfallverbringung .................... 62

bb) Bundes-Immissionsschutzgesetz ............................................ 63

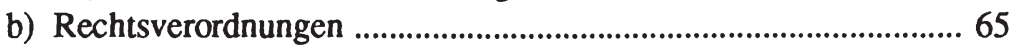

aa) Abfallbestimmungs-Verordnung ........................................... 66

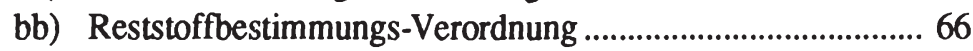

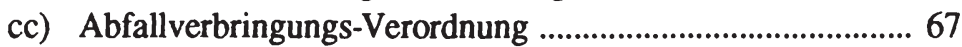

dd) Abfall- und Reststoffüberwachungs-Verordnung ................. 69

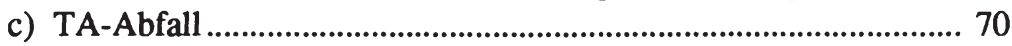

d) Verwaltungs-, Verfahrens- und Raumordnungsrecht ..................... 71

2. Landesrecht am Beispiel des Hessischen Abfallgesetzes .................... 73

a) Allgemeine Regelungen ............................................................... 73

b) Regelungen zur grenzüberschreitenden Abfallentsorgung ............ 74

3. Kommunales Satzungsrecht ................................................................ 75

B. Konflikte aus unterschiedlichen Zwecksetzungen und systematischen

Unterschieden der Regelungssysteme .......................................................... 77

I. Integrationsgebot des EWG-Vertrags.................................................. 77

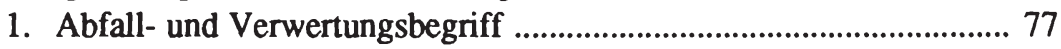

a) Präzisierung des Abfallbegriffs ..................................................... 78

aa) Objektiver Abfallbegriff ..................................................... 78

bb) Subjektiver Abfallbegriff ...................................................... 79

b) Verwertungsbegriff ................................................................... 81

2. Anwendbarkeit der Bestimmungen zum Warenverkehr oder zur Dienstleistungsfreiheit 


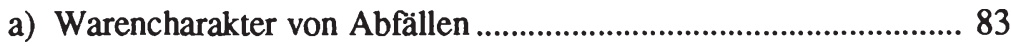

b) Abfallentsorgung als Dienstleistung ............................................ 87

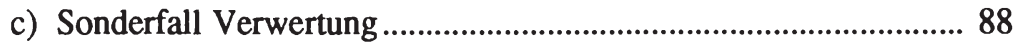

d) Schlußfolgerung ............................................................................... 88

II. EWG-Vertragliche Legitimation von Beschränkungen

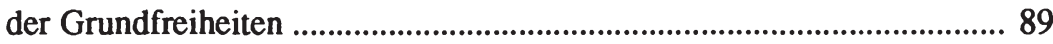

1. Ausnahme von Dienstleistungsbereichen ......................................... 90

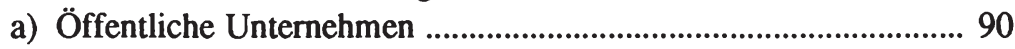

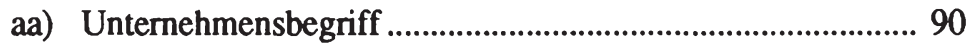

bb) Allgemeines wirtschaftliches Interesse ................................ 91

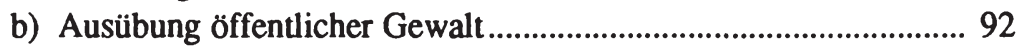

2. Beschränkung der Warenverkehrsfreiheit ....................................... 93

III. Maßnahmentypen zur Beschränkung der grenzüberschreitenden Abfallentsorgung in der Gemeinschaft .............................................. 94

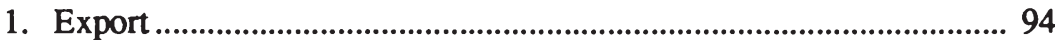

a) Grundsatz der Inlandsentsorgung ..............................................96

aa) Ausschluß der Anwendbarkeit des EWG-Vertrags ............... 97

bb) Rechtfertigung eines Verstoßes gegen die Art. 59 ff. EWGV ............................................ 99

cc) Sekundäres Gemeinschaftsrecht ........................................ 100

b) Anschluß und Benutzungszwang .......................................... 103

aa) Private Haushalte ........................................................... 104

bb) Gewerbliche Abfallerzeuger ........................................... 105

c) EG-weite Wirkungen von nationalen Abfallvermeidungsgeboten .................................................................................. 106

aa) Vermeidungsgebote in Form von Produktionsregelungen . 106

bb) Produktbezogene Maßnahmen zur Abfallvermeidung ....... 107

d) Verpflichtung im Ausland zumindest eine gleichwertige Anlage aufzusuchen ................................................... 107

aa) Umweltpolitischer Nutzen .............................................. 108

bb) Schutz der inländischen Umwelt ...................................... 109

2. Import ......................................................................................... 110

a) Mitgliedstaatliche Entsorgungsgarantien .................................... 111

aa) Beschränkung der Abfalleinfuhr ....................................... 112

bb) Rechtfertigung durch zwingende Erfordemisse ................. 113

cc) Umweltpolitische Rechtfertigung ....................................... 114

dd) Bundesdeutsche Praxis ...................................................... 115

b) Stützung nationaler Abfallvermeidungsgebote durch Importbeschränkungen ..................................................... 116

C. Entwicklungen und Ausblick ....................................................................... 119

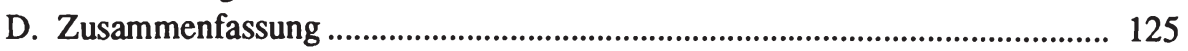

E. Literaturverzeichnis ................................................................................ 129 


\section{Abkürzungen}

a.A. ................................. anderer Ansicht

a.a.O............................ am angegebenen Ort

a.F. alte Fassung

AbfBestV Verordnung zur Bestimmung von Abfällen nach $\S 2$ Abs. 2 des Abfallgesetzes

AbfallHE Kommissionsvorschlag für eine Richtlinie des Rates über die zivilrechtliche Haftung für die durch Abfälle verursachten Schäden

AbfG Gesetz über die Vermeidung und Entsorgung von Abfällen

AbfRestÜberwV Verordnung über das Einsammeln und Befördern sowie die Überwachung von Abfällen und Reststoffen

AbfVerbrV Verordnung über die grenzüberschreitende Verbringung von Abfällen

ABl Amtsblatt der Europäischen Gemeinschaften

Abs. Absatz

amtl. amtlich

Anh. Anhang

Anm. Anmerkung

Art. Artikel

Aufl. Auflage

Az. Aktenzeichen

BAnz. Bundesanzeiger

Bd. Band

Bek Bekanntmachung

ber. berichtigt

bes. besonders

BGB Bürgerliches Gesetzbuch

BGBl. Bundesgesetzblatt

$\mathrm{BGH}$ Bundesgerichtshof

BGHZ Entscheidungen des Bundesgerichtshofs in Zivilsachen 
Gesetz zum Schutz vor schädlichen Umwelteinwirkungen durch Luftverunreinigung, Geräusche, Erschütterungen und ähnliche Vorgänge

BImSchV Verordnung über genehmigungsbedürftige Anlagen

BMU Bundesministerium für Umwelt, Naturschutz und Reaktorsicherheit

BR Drucks. Drucksachen des Bundesrates

BReg. Bundesregierung

bspw beispielsweise

BT Drucks. Drucksachen des Bundestages BVerfGE Bundesverfassungsgerichtsentscheidung bzw. beziehungsweise

DB Der Betrieb

d.h. das heißt

DDR Deutsche Demokratische Republik

ders. derselbe

Diss. Dissertation

DVB1 Deutsches Verwaltungsblatt

EEA Einheitliche Europäische Akte

EG Europäische Gemeinschaft(en)

EuGH Europäischer Gerichtshof

EuGHE Entscheidung des Europäischen Gerichtshofs

EuZW Europäische Zeitschrift für Wirtschaftsrecht

EWG Europäische Wirtschaftsgemeinschaft

EWGV Vertrag zur Gründung der Europäischen Wirtschaftsgemeinschaft

FAZ Frankfurter Allgemeine Zeitung

ff. folgende

Fn Fußnote

FR Frankfurter Rundschau

GBI. Gesetzblatt

geänd. geändert

GewArch Gewerbearchiv

GG Grundgesetz

ggf. gegebenenfalls

$\mathrm{GmbH}$ Gesellschaft mit beschränkter Haftung 
GmBl. .Gemeinsames Ministerialblatt

GVB1. ..Gesetz- und Verordnungsblatt für das Land Hessen

h.A herrschende Auffassung

h.L herrschende Lehre

h.M. herrschende Meinung

HAbfAG Gesetz über die Vermeidung, Verminderung, Verwertung und Beseitigung von Abfällen und die Sanierung von Altlasten (Hessisches Abfallwirtschafts- und Altlastengesetz)

$\mathrm{HB}$ .Handelsblatt

HEK Hessische Gesellschaft für Entsorgung kommunaler Abfälle

HGB Handelsgesetzbuch

Hrsg. .Herausgeber

hrsg. herausgegeben

i.d.R in der Regel

i.S. im Sinne

i.V. $\mathrm{m}$. in Verbindung mit insbes. insbesondere

$\mathrm{JZ}$ Juristenzeitung

KABV Kommunaler Abfallentsorgungsverband Saar

Lfg. Lieferung

lit. litera

Lit. Literatur

m.w.N. mit weiteren Nachweisen

NJW Neue Juristische Wochenschrift

NRW Nordrhein-Westfalen

$\mathrm{NuR}$ Natur und Recht

NVwZ Neue Zeitschrift für Verwaltungsrecht

OECD Organization for Economic Cooperation and Development

o.V. ohne Verfasser 


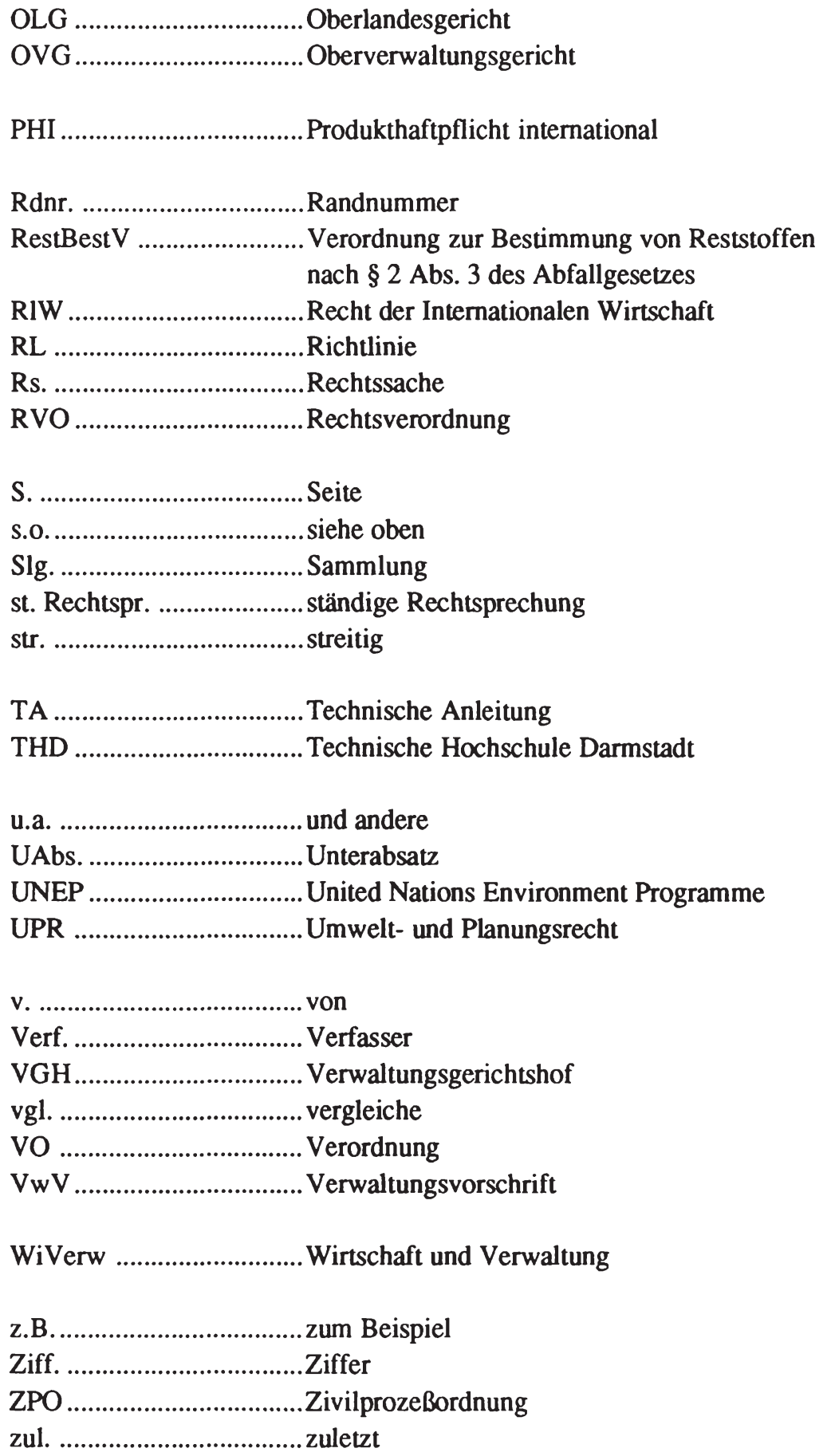


Bert Rürup and Uwe H. Schneider - 978-3-631-75109-1

Downloaded from PubFactory at 01/11/2019 08:13:45AM

via free access 


\section{Einleitung}

\section{Gegenstand und Zielsetzung der Untersuchung}

Die Erhaltung und Verbesserung der natürlichen Umwelt haben in den letzten Jahren eine zentrale Bedeutung in der gesellschaftlichen Wertorientierung der Bürger der Bundesrepublik Deutschland erlangt. Dieser Sachverhalt findet seinen Ausdruck in einer hohen Sensibilisierung aller gesellschaftlichen Kreise in Fragen der Ökologie. Der hohe Stellenwert ökologischer Belange zeigt sich nicht nur in der ständigen Berichterstattung der Medien, sondern auch in der Diskussion umweltpolitischer Fragen auf allen politischen Ebenen. Folge dieser Entwicklung sind umfangreiche Rechtsetzungsaktivitäten in der Bundesrepublik wie auch in zunehmendem Maße durch die Europäische Gemeinschaft.

In der Bundesrepublik Deutschland liegen die wesentlichen Grundlagen der Umweltpolitik im Umweltprogramm der Bundesregierung von $1971^{1}$. In diesem Grundsatzprogramm wurde der Schutz der menschlichen Gesundheit und der natürlichen Umwelt als oberstes Ziel der Umweltpolitik in der Bundesrepublik Deutschland festgelegt und das Verursacherprinzip für die Übernahme von Kosten aus Umweltbelastungen eingeführt. Einer der herausragenden Gründe, die zur Ausarbeitung dieses Programms führten, waren die zu jener Zeit erstmals vermehrt sichtbar gewordenen schwerwiegenden Umweltbeeinträchtigungen, die von einer nicht sachgerechten Abfallentsorgung verursacht werden. Damals existierten bei der Entsorgung von Abfällen nahezu keine rechtlich und organisatorisch geregelte Sammlung, Abfuhr und Beseitigung von Abfallstoffen gleich welcher Art. Die rechtlichen Vorschriften waren wegen fehlender bundeseinheitlicher Regelungen zersplittert und in weiten Teilen lückenhaft. So gab es bis zum Inkrafttreten des Abfallgesetzes von 1972 beispielsweise keine gesetzlichen Bestimmungen, die eine Beseitigung von Abfällen in dafür geeigneten und zugelassenen Anlagen vorschrieben. Die damit einhergehenden Mißstände, wie wilde Müllablagerung verbunden mit Luft-, Boden- und Grundwasserverunreinigungen, verschärften sich durch den Anstieg der Abfallmengen so sehr, daß der unverkennbare Handlungsbedarf eine Reaktion des bundesdeutschen Gesetzgebers hervorrufen mußte. Sie erfolgte in Form des Abfallgesetzes von 1972. Dieses neue Abfallgesetz bewirkte vorallem bei der grenzüberschreitenden Abfallverbringung einschneidende Ände-

1 Bundestags-Drucksache VI/2710 vom 14. 10. 1971. 
rungen. Die Bundesrepublik Deutschland, bis dahin ein Abfallimportland, wurde aufgrund der nunmehr vorgeschriebenen hohen Standards bei der Abfallentsorgung und den daraus resultierenden Kapazitätsengpässen und Kostensteigerungen zum größten Abfallexporteur innerhalb der Europäischen Gemeinschaft.

Die damalige Situation in der Bundesrepublik Deutschland, gekennzeichnet durch hohe Entsorgungskosten und knappe Deponierungs- und Beseitigungskapazitäten, besteht bis heute fort. Sie verschärft sich sogar weiter, denn noch immer wachsen die anfallenden Abfallmengen. Bestrebungen zu Kapazitätsausweitungen bei Abfallentsorgungsanlagen stoßen wegen des gestiegenen Umweltbewußtseins und den daraus resultierenden langwierigen und komplizierten Genehmigungsverfahren auf erhebliche Schwierigkeiten. Als Folge davon ist die Bundesrepublik bis zum heutigen Tag ein Land mit umfangreichem Abfallexport geblieben. Dieser sogenannte „Mülltourismus" ist jedoch vom Gesetzgeber nicht gewünscht, er widerspricht dem im Abfallgesetz formulierten umweltpolitischen Ziel in Form des Grundsatzes der Entsorgung im Entstehungsland.

Um den legalen Abfallexport, den das Abfallgesetz bei Vorliegen bestimmter Voraussetzungen zuläßt, zu verringern bzw. in Zukunft gänzlich einzustellen, wird auf verschiedenen Wegen versucht, auf die Ursachen für den Abfallexport einzuwirken. So soll durch die kürzlich erfolgte Änderung des Bundes-Immissionsschutzgesetzes (3. Änderungsgesetz zum Bundes-Immissionsschutzgesetz) eine Erhöhung der Abfallverbrennungskapazitäten erreicht werden. Eine weitere Maßnahme zur Abfallreduzierung bzw. zur der Erleichterung der Entsorgung ist die neue Verpackungsverordnung des Bundesministers für Umwelt, Naturschutz und Reaktorsicherheit. Durch diese Verordnung wird beispielsweise der Handel verpflichtet werden, Verpackungsabfälle der von ihm vertriebenen Produkte zurückzunehmen. Ziel der Regelung ist es, die Hersteller zum Einsatz von umweltfreundlicheren, d.h. weniger aufwendigen sowie leichter beseitigbaren Verpackungen zu bewegen. Eine solche Maßnahme ist vor dem Hintergrund zu sehen, daß von 1984 bis 1987 das Gewicht des angefallenen Hausmülls und des hausmüllähnlichen gewerblichen Abfalls nahezu unverändert geblieben ist, während sein Schüttvolumen im gleichen Zeitraum bei ohnehin knappem Deponieraum um ungefähr 10 Millionen Kubikmeter zugenommen hat.

Der weitaus größte Abfallverursacher insgesamt gesehen ist jedoch das produzierende Gewerbe. Das im Zusammenhang mit der Vollendung des EG-Binnenmarktes prognostizierte zusätzliche Wirtschaftswachstum verleiht diesem Sachverhalt eine besondere Brisanz. Die Steigerung des wirtschaftlichen Wachstums geht mit hoher Wahrscheinlichkeit mit einem weiteren Wachstum der Abfallmengen einher und als 
Folge davon dürfte auch der Umfang der grenzüberschreitenden Abfallentsorgung weiter zunehmen. Die Vereinigung der beiden deutschen Staaten hat außerdem jetzt schon zu einer deutlichen Zunahme der Abfallmengen und zur weiteren Verschärfung der Probleme geführt.

Vor diesem Hintergrund erhält die Diskussion, ob und in welchem Umfang Abfälle und Abfallentsorgung unter das Liberalisierungsgebot des EWG-Vertrags zum Waren- und Dienstleistungsverkehr fallen, ein besonderes Gewicht. Die Auffassungen darüber gehen ebenso wie die über die sich daraus ergebenden Konsequenzen weit auseinander. Die EG-Kommission hat ihre Haltung zu diesem Komplex in einem Strategiepapier dargelegt. Sie hat darin ihre Auffassung verdeutlicht, daß die Lösung der Abfallentsorgungsproblematik wegen der höchst unterschiedlichen Entsorgungsstandards und Entsorgungskosten in den einzelnen EG-Mitgliedstaaten auf Gemeinschaftsebene angegangen werden muß. Dabei sei - so die Kommission eine Verträglichkeit der Regelungen mit den Grundfreiheiten des EWG-Vertrags unabdingbar. In diesem Zusammenhang wird außerdem immer wieder darauf hingewiesen, daß unterschiedliche rechtliche Regelungen der Mitgliedstaaten die Funktionsfähigkeit des Gemeinsamen Marktes beeinträchtigen können. Uneinheitliche Entsorgungsstandards und Umwelthaftungsbestimmungen sind dazu geeignet, Investitions- und Abfallströme in die Mitgliedstaaten mit den großzügigsten Regelungen zu lenken. Eine derartige Entwicklung ist aber aus wettbewerbs- und umweltpolitischen Gründen keinesfalls wünschenswert. Es ist daher zu vermuten, daß hier in Zukunft verstärkte und umfassende Rechtsetzungsaktivitäten in Form von sekundärem EG-Recht zu erwarten sind. Erste deutliche Anhaltspunkte sind die Neufassung der EG-Abfallrichtlinie und der Kommissionsvorschlag zu einer Richtlinie zur Haftungsregelung zivilrechtlicher Ansprüche für durch Abfälle verursachte Schäden.

Aus den ökonomischen und ökologischen Aspekten der grenzüberschreitenden Abfallentsorgung ergibt sich ein Spannungsfeld, das auch zwischen den Rechtssystemen der Bundesrepublik Deutschland und der Europäischen Wirtschaftsgemeinschaft besteht. Um es aufzuzeigen werden nachfolgend die Wirkungen des primären Gemeinschaftsrechts zum Gemeinsamen Markt im EWG-Vertrag auf die abfallrechtlichen Regelungen des Umweltrechts untersucht. Die Regelungen des Abfallrechts in Form des nationalen Rechts der Bundesrepublik und des sekundären Gemeinschaftsrechts werden den Regelungen des Binnenmarktrechts gegenübergestellt. Notwendige Voraussetzung dafür ist die Klärung des Verhältnisses der genannten Regelungssysteme zueinander. Der Untersuchung der Frage des Warencharakters von Abfall bzw. des Dienstleistungscharakters der Abfallentsorgung im Zusammenhang mit dem Liberalisierungsgebot des EWG-Vertrags kommt bei der 
Gegenüberstellung eine zentrale Bedeutung zu. Auf dieser Grundlage werden schließlich die möglichen Auswirkungen der rechtlichen Regelungen zur Errichtung des EG-Binnenmarktes auf die grenzüberschreitende Abfallentsorgung auf dem Gebiet der EG betrachtet.

\section{Bedeutung der grenzüberschreitenden Abfallentsorgung}

Das Thema Abfallentsorgung hat sich für Wissenschaft, Wirtschaft und Politik zu einer der großen aktuellen Herausforderungen entwickelt, da die Lösung der anstehenden Probleme alle Menschen heute und in der Zukunft unmittelbar betrifft. Die $\mathrm{zu}$ lösenden Aufgabenstellungen sind jedoch komplex und umfangreich, sie weisen vielfältige Interdependenzen auf. $\mathrm{Zu}$ ihrer Bewältigung ist daher eine interdisziplinäre Zusammenarbeit zwischen unterschiedlichsten wissenschaftlichen Disziplinen, sowie mit Politik und Praxis unerläßlich ${ }^{2}$. Aufgabe der Politik ist es dabei, neue Erkenntnisse der Forschung aufzugreifen, den daraus resultierenden Handlungsbedarf frühzeitig zu erkennen und Handlungsmöglichkeiten entsprechend zu nutzen.

Die Behandlung der Altlastenproblematik ist ein Beispiel dafür, welche fächerübergreifende Kooperation hierzu notwendig ist. Das Aufspüren solcher Altlasten erfordert die Zusammenarbeit von Geologen, Chemikern, Raumplanern, Ingenieuren, Biologen und Medizinern. Bei der Sanierung von Altlasten und von veralteten Abfallbeseitigungsanlagen oder der Ausarbeitung zukunftsorientierter Konzepte zur Vermeidung und Verwertung von Abfällen ergibt sich darüber hinaus zusätzlich die Notwendigkeit der Mitarbeit von Juristen, Volkswirten und Betriebswirten.

Thema ist hier jedoch nicht generell die Bewältigung der Abfallproblematik, vielmehr wird ein Teilaspekt herausgegriffen, dem eine besondere rechtliche Bedeutung zukommt: die grenzüberschreitende Abfallentsorgung. Untersucht wird dabei der Einfluß des dem bundesdeutschen Recht überlagerten Rechtssystems der EWG. Die Bedeutung der grenzüberschreitenden Abfallentsorgung beschränkt sich aber nicht nur auf rechtliche Aspekte, sondern sie weist ebenso vielfältige volkswirtschaftliche und betriebswirtschaftliche Aspekte auf. Diese sind bei der Untersuchung zu berücksichtigen.

2 Böhme in THD-Intern Nr. 4 vom 17. 5. 1990, S. 1-2. 


\section{a) Volkswirtschaftliche Bedeutung}

Einen besonderen Stellenwert für die grenzüberschreitende Abfallentsorgung hat das im Hinblick auf die Vollendung des EG-Binnenmarktes zu erwartende Wirtschaftswachstum und die wahrscheinlich damit einhergehende weitere Steigerung der Abfallmengen. Als Folge davon ist auch eine weitere Zunahme der grenzüberschreitenden Abfallverbringung zu erwarten. Parallel zu dieser Entwicklung dürften weitere Fortschritte in der Umwelttechnik und dort besonders in der Abfallentsorgungstechnik erreicht werden. Die Umwelttechnik, die bereits heute einen sehr bedeutenden Wirtschaftsfaktor darstellt, wird sehr wahrscheinlich ihren bislang erkennbaren positiven Wachstumstrend beibehalten. Insbesondere in der Bundesrepublik Deutschland existiert auf diesem Gebiet aufgrund der hohen Entsorgungsstandards ein leistungsfähiger Industriesektor. Der Export von Entsorgungstechnik sowie von Technologie für abfallärmere Produkte und Produktionsverfahren stellt in der Bundesrepublik bereits heute einen wichtigen volkswirtschaftlichen Faktor dar.

Aus der Gesamtperspektive der Europäischen Gemeinschaft gesehen könnte die grenzüberschreitende Abfallentsorgung dabei helfen, durch die Wahrnehmung komparativer Vorteile eine effektivere und effizientere Gestaltung der Entsorgung von Abfällen zu erreichen. Beispiele dafür sind: die gemeinsame Nutzung und Auslastung der geeignetesten Entsorgungsanlagen, die Senkung der Erschließungskosten von Standorten oder die Schaffung von Know how für Überwachungs- und Kontrollverfahren. Zusätzlich dazu wird es auch durch Vermeidung von Parallelinvestitionen möglich, die Abfallentsorgung im europäischen Rahmen volkswirtschaftlich effizienter zu gestalten.

Bei der grenzüberschreitenden Abfallentsorgung dürfen keinesfalls die landesspezifischen volkswirtschaftlichen Kosten der Abfallentsorgung unterschätzt werden. Aus der Sicht der Abfallimportländer kann es nicht ausreichen, die mit der Abfallentsorgung verbundenen Einnahmen losgelöst von einer später möglichen Altlastenproblematik zu sehen. Es besteht vielmehr immer die Gefahr, daß einem Gemeinwesen durch Altlastensanierung beträchtliche Kosten entstehen. Sie schlagen sich zwangsläufig negativ in der volkswirtschaftlichen Bilanz nieder. Die Einnahmen können durch die Kosten aus Sanierung oder negativen Auswirkungen auf die Menschen und die Umwelt um ein Vielfaches übertroffen werden. Solche "Altlastenkosten“ sind zu bedenken, wenn Abfallimporte lediglich unter dem Gesichtspunkt der zu erwartenden Einnahmen genehmigt werden. Seitens der Abfallexportländer werden so Teile der volkswirtschaftlichen Kosten für die Abfallentsorgung bzw. deren Folgebelastungen in andere Länder verlagert. 


\section{b) Betriebswirtschaftliche Bedeutung}

Die grenzüberschreitende Abfallentsorgung weist vielfältige und vielschichtige betriebswirtschaftlichen Aspekte auf. Zuerst ist die Entscheidung zur Nutzung einer ausländischen Abfallentsorgungsanlage aber eine Kostenfrage. Ein Unternehmer wird sich für diesen Entsorgungsweg nur dann entscheiden, wenn die Kosten des Transportes und der Entsorgung im Ausland unter denen der Inlandsentsorgung liegen. Ein weiterer Grund für die Wahl einer Abfallentsorgung im Ausland ist, daß aus Engpaßgründen eine Entsorgung im Inland nicht möglich ist.

Zwischen abfallverursachenden Unternehmen und Unternehmen der Abfallwirtschaft ist hinsichtlich strategischer Investitionsentscheidungen zu unterscheiden: Die abfallverursachenden Unternehmen der Bundesrepublik Deutschland haben ein großes Interesse daran, die Entwicklungen bei der grenzüberschreitenden Abfallentsorgung möglichst früh zu erkennen. Nur dann können sie frühzeitig zwischen Strategiealternativen zur Sicherung der Entsorgung der im Unternehmen anfallenden Abfälle wählen. Sollte ihnen die Nutzung ausländischer Entsorgungsmöglichkeiten zukünftig verwehrt sein, so müssen die möglichen Beschränkungswirkungen auf die Produktionsmengen abfallverursachender Produkte ebenso wie die höheren Kosten der inländischen Entsorgung bei der Unternehmensplanung berücksichtigt werden. Gegenüber Wettbewerbern in Ländern mit niedrigeren Entsorgungsstandards könnte sich dadurch eine Verschlechterung der Wettbewerbsposition ergeben. Zur Lösung dieser Schwierigkeit stehen den Unternehmen dabei verschiedene Strategiealternativen zur Verfügung. Es bietet sich die konsequente Investition in abfallärmere Produktionsverfahren ebenso an wie die Nutzung aller bekannten Verwertungsmöglichkeiten und die Suche nach neuen. Eine weitere Strategie besteht im Eingehen von Entsorgungskooperationen mit anderen Unternehmen zum Betrieb gemeinsamer Entsorgungseinrichtungen oder zur Vermarktung wiederverwertbarer Produktionsabfälle. Eine Alternative, die viel kurzfristiger verwirklicht werden kann, ist das Konkurrieren um knappe Entsorgungskapazitäten über die Bezahlung höherer Preise. Ein Abfallverursacher könnte auf diesem Weg versuchen, sich Entsorgungskapazitäten zu sichern, was aber nur auf einem echten Entsorgungsmarkt ohne direkte oder indirekte staatliche Entsorgungsgarantien vorstellbar ist. Verschiedentlich wird auch die Verlagerung von Produktionsstätten in Länder mit weniger strengen Umweltauflagen in Erwägung gezogen und in der Praxis vereinzelt auch beschritten.

Die Entsorgungswirtschaft in der Bundesrepublik Deutschland muß für den Fall einer zunehmenden Einschränkung der grenzüberschreitenden Abfallentsorgung innerhalb der Europäischen Gemeinschaft Entscheidungen hinsichtlich der Schaffung 
weiterer Kapazitäten z.B. bei Recyclinganlagen treffen. Es bestünden dann wahrscheinlich große zusätzliche Absatzchancen hinsichtlich Know how oder Anlagen für die bereits erwähnten abfallärmeren Produktionsverfahren sowie für neue Verwertungsverfahren. Würde der umgekehrte Fall eintreten, daß die Beschränkungen der grenzüberschreitenden Abfallentsorgung innergemeinschaftlich fallen, so müßte die bundesdeutsche Entsorgungswirtschaft wegen der in vielen EG-Mitgliedstaaten niedrigeren Entsorgungskosten mit einer deutlichen Verschlechterung ihrer Wettbewerbssituation rechnen. Eine mögliche Reaktion auf eine solchermaßen veränderte Situation wäre die Verfolgung von Nischenstrategien. Denkbar ist etwa die Beschränkung auf das Angebot europaweit gesetzlich vorgeschriebener Entsorgungsleistungen mit hohem Standard, die bislang aber nicht flächendeckend verfügbar sind. Sollte sich jedoch abzeichnen, da $B$ die grenzüberschreitende Abfallentsorgung innerhalb der Europäischen Gemeinschaft durch eine gemeinschaftsweite Angleichung der Entsorgungsstandards auf hohem Niveau ihre Kostenvorteile verlieren wird, so dürfte dies die Inlandsnachfrage nach Entsorgungsleistungen in der Bundesrepublik erhöhen und zusätzliche Chancen für Know howund Entsorgungstechnologie-Export in andere Mitgliedstaaten eröffnen.

Vor dem Hintergrund der langwierigen Genehmigungsverfahren für großtechnische Anlagen in der Bundesrepublik ist daher die Klärung der zukünftigen rechtlichen Rahmenbedingungen, für die abfallverursachenden Unternehmen und gleichermaBen für die Entsorgungswirtschaft in der Bundesrepublik von größter Bedeutung.

\section{c) Rechtliche Bedeutung}

Die rechtlichen Aspekte, die sich im Zusammenhang mit der innergemeinschaftlichen, grenzüberschreitenden Abfallentsorgung ergeben, sind nicht weniger vielfältig als die volks- und betriebswirtschaftlichen. Das Spannungsverhältnis zwischen Ökonomie und Ökologie, das sich auch zwischen den für die grenzüberschreitende Abfallentsorgung relevanten Regelungen des Abfallrechts und dem Integrationsrecht des EWG-Vertrags wiederfindet, ist sogar im EWG-Vertrag selbst seit Inkrafttreten der Einheitlichen Europäischen Akte am 1. Juli 1987 durch die Ergänzung der Art. 130r-t angelegt. Im EWG-Vertrag findet sich nunmehr auch eine ausdrückliche Ermächtigung an die EWG, in umweltpolitischen Fragen tätig zu werden.

Ein weiterer wichtiger Gesichtspunkt ist die Entwicklung der Rechtslage zur grenzüberschreitenden Abfallentsorgung. Nach Inkrafttreten des Abfallgesetzes der Bundesrepublik Deutschland von 1972 hat diese sich - wie bereits erwähnt - von einem Abfallimportland zu einem Abfallexportland entwickelt. Um diese umweltpolitisch 
unerwünschte Entwicklung zu korrigieren, wurde und wird das bundesdeutsche Recht laufend fortentwickelt. Nun zeigt sich aber, daß diese Anstrengungen hinfällig werden könnten, da zumindest Teile des bundesdeutschen Abfallrechts nicht mit dem überlagerten sekundären und primären Gemeinschaftsrecht vereinbar zu sein scheinen. Es könnte dadurch zu einem ähnlich bedeutungsvollen Einschnitt kommen wie 1972 durch das bundesdeutsche Abfallgesetz, denn mit dem 31. Dezember 1992 ist ein Zeitpunkt festgelegt, ab dem die Marktfreiheiten des EWG-Vertrags hergestellt sein müssen. Eine isolierte nationale Lösung der Abfallentsorgungsproblematik ist sehr unwahrscheinlich, da sich durch die Rechtsetzungsaktivtäten der Gemeinschaft der nationale Handlungsspielraum oft nur noch auf die Wahl der Mittel bei der Umsetzung von EG-Richtlinien beschränkt. Außerdem müssen sich alle mitgliedstaatlichen Maßnahmen an ihrer Vereinbarkeit mit primärem und sekundärem EG-Recht messen lassen. Der Anspruch der Gemeinschaft in der Frage der Regelung der Abfallentsorgung äußert sich in der Tendenz zu einer umfassenden und abschließenden Gestaltung des Abfallrechts auf gemeinschaftlicher Ebene. Dabei deuten sich in jüngster Zeit allerdings auch Legitimationsschwierigkeiten der Gemeinschaft selbst an. Bei Maßnahmen, die dazu dienen sollen, zu befürchtende umweltpolitisch nicht gewollte Entwicklungen zu verhindern, könnte sich deren Legitimationsbasis als zu schmal erweisen. Der Grund mag darin liegen, daß die EWG bei ihrer Gründung primär auf wirtschaftliche Gesichtspunkte ausgerichtet war. Die Europäische „Wirtschafts- und Umweltgemeinschaft" ist dagegen erst in der Entstehung. Bei ihrer Entwicklung ist allerdings in jüngster Zeit eine zunehmende Dynamik unverkennbar. Die Fortentwicklungen im Abfallrecht, insbesondere die Regelung der grenzüberschreitenden Abfallentsorgung sind darüber hinaus ein anschauliches Beispiel dafür, wie Rechtsetzungsaktivitäten zunehmend im europäischen Rahmen vollzogen werden. Widersprechende nationale Regelungen auf Gebieten, auf denen die Gemeinschaft die alleinige Rechtsetzungskompetenz beansprucht, sind nahezu unmöglich.

\section{Gang der Untersuchung und ausgeklammerte Fragen}

In der Untersuchung werden die für das Gebiet der Bundesrepublik Deutschland und das der Europäischen Gemeinschaft geltenden speziellen Regelungen des Umweltrechts zur Abfallentsorgung dargestellt. Es sind Regelungen auf internationaler, gemeinschaftsrechtlicher und bundesdeutscher Ebene. Darüber hinaus werden solche allgemeinen Regelungen zur Errichtung des EG-Binnenmarktes berücksichtigt, die eine Relevanz für die grenzüberschreitende Abfallentsorgung innerhalb des Gebiets der Gemeinschaft aufweisen könnten. Im Rechtssystem der Bundesrepublik werden als Beispiel für Bestimmungen des Landesrechts, diejenigen des 
Hessischen Abfallgesetzes betrachtet. Sowohl zu den speziellen wie zu den allgemeinen Regelungen wird die Rechtsprechung der nationalen Gerichte und des Europäischen Gerichtshofs berücksichtigt. Aufbauend auf dieser Darstellung ist zu klären, ob Abfälle und Abfallentsorgung vom Integrationsgebot des EWG-Vertrags erfaßt sind.

Auf der Grundlage der Bestandsaufnahme und der Klärung der Frage nach der Relevanz des Binnenmarktrechts werden die speziellen Regelungen zur Abfallentsorgung den anzuwendenden allgemeinen Regelungen zur Errichtung des EGBinnenmarktes gegenübergestellt. Dabei wird eine problemorientierte Vorgehensweise anhand der rechtlichen Fragen gewählt, welche sich im Zusammenhang mit verschiedenen Beschränkungsformen des innergemeinschaftlichen Exports und Imports von Abfall ergeben. Das Verhältnis und das Ineinandergreifen der Rechtssysteme der Bundesrepublik Deutschland und der Europäischen Gemeinschaft stehen dabei im Mittelpunkt der Betrachtungen.

Ausgeklammert bleiben alle Fragen, die sich bei der Abfallentsorgung auf hoher See ergeben oder den Import aus bzw. den Export in Nicht-EG-Mitgliedstaaten betreffen. 
Bert Rürup and Uwe H. Schneider - 978-3-631-75109-1

Downloaded from PubFactory at 01/11/2019 08:13:45AM

via free access 


\section{A. Rechtsgrundlagen mit Relevanz für die grenzüberschreitende Abfallentsorgung in der Gemeinschaft}

Bei der grenzüberschreitenden Abfallentsorgung ist eine Vielzahl nationaler, europäischer und internationaler umweltrechtlicher Regelungen im Zusammenhang zu sehen. Nachfolgend werden diejenigen Regelungen des besonderen Umweltrechts ${ }^{3}$ dargestellt, die den Regelungsbereich Abfall und Abfallentsorgung abdecken. Es wird dabei sowohl die internationale und europäische, als auch die nationale Ebene - am Beispiel der Bundesrepublik Deutschland - betrachtet.

Die Darstellung von Regelungen auf der internationalen Ebene beschränkt sich auf solche, denen sich die Europäische Gemeinschaft bzw. ihre Mitgliedstaaten unterwerfen. Auf europäischer Ebene werden die seitens der Europäischen Wirtschaftsgemeinschaft ergangenen Rechtsakte des Abfallrechts erfaßt. Die nationale Regelungsebene wird anhand des Abfallrechts der Bundesrepublik Deutschland dargestellt. Hierbei finden auch angrenzende Teilgebiete des besonderen Umweltrechts Berücksichtigung, sofern sie für die grenzüberschreitende Abfallentsorgung bedeutsam sind.

Die grenzüberschreitende Abfallverbringung und -entsorgung innerhalb der Gemeinschaft unterliegt neben den Regelungen des Umweltrechts möglicherweise zusätzlich dem Liberalisierungsgebot des EWG-Vertrags zur Errichtung des EGBinnenmarktes. Es ist daher erforderlich, auch diesbezügliche Regelungen in die Darstellung des Gemeinschaftsrechts einzubeziehen.

\section{Internationale Übereinkommen und Empfehlungen}

Internationale Übereinkommen, die von der Gemeinschaft bzw. von den Mitgliedstaaten geschlossen werden, erstrecken sich nur auf die Außenbeziehungen der $\mathrm{Ge}$ meinschaft. Das Gebiet der Gemeinschaft ist davon ausgenommen, die Beziehungen der Mitgliedstaaten untereinander werden durch das Gemeinschaftsrecht geregelt. Es besteht aber die Möglichkeit, daß solche Übereinkünfte durch eine Umsetzung in Gemeinschaftsrecht auch Innenwirkung erlangen können. Bilaterale Abkommen zwischen den Mitgliedstaaten sind unabhängig davon möglich, doch ist davon aus-

3 Vgl. zum Aufbau und Abgrenzung des Umweltrechts Kloepfer, § 1, Rdnr. 40-42. 
zugehen, daß dabei wie bei der mitgliedstaatlichen Gesetzgebung das Gemeinschaftsrecht zu beachten ist.

Zur grenzüberschreitenden Abfallverbringung und -entsorgung bestehen zwei internationale Abkommen, die von der Europäischen Gemeinschaft und einem Teil der Mitgliedstaaten unterzeichnet wurden. Das ist zum einen die „Baseler Konvention über die Überwachung der grenzüberschreitenden Verbringung gefährlicher Abfälle und ihrer Beseitigung“" und zum anderen die „Empfehlung des Rates der OECD über die grenzüberschreitende Verbringung von gefährlichen Abfällen". Daneben existieren eine Reihe von internationalen Transport- und Kennzeichnungsvereinbarungen für gefährliche Güter, die auch auf den Transport gefährlicher Abfälle Anwendung finden ${ }^{4}$.

\section{Baseler Konvention über die Überwachung der grenzüberschreitenden Verbringung gefährlicher Abfälle und ihrer Beseitigung 5}

Diese im Rahmen des UNEP initiierte Konvention wurde von der Europäischen Gemeinschaft und acht Mitgliedstaaten am 2. März 1989 in Basel unterzeichnet ${ }^{6}$. Die Bundesrepublik Deutschland hat bislang nur eine Absichtserklärung abgegeben, dieses Abkommen nach genauer inhaltlicher Prüfung ebenfalls zu unterzeichnen und die darin enthaltenen Bestimmungen mit der Abgabe dieser Erklärung vom Oktober 1989 einzuhalten ${ }^{7}$.

Ziel des Abkommens ist es, den potentiellen Risiken aus der grenzüberschreitenden Verbringung und Beseitigung von gefährlichen Abfällen möglichst wirksam und umfassend zu begegnen ${ }^{8}$. Um diesem Ziel näher zu kommen, soll die grenzüberschreitende Verbringung weltweit einer wirksamen Überwachung und Kontrolle unterworfen werden ${ }^{9}$. Ein noch zu bildendes Sekretariat ${ }^{10}$ soll dabei den Informationsaustausch gewährleisten, den Transfer von Abfallentsorgungstechnologie orga-

4 Vgl. die Übersichten in der Studie der Europäischen Stiftung zur Verbesserung der Lebens- und Arbeitsbedingungen über den Transport gefährlicher Abfälle, S. 113-115 und S. 275-278. Vgl. auch Anhang zur Richtlinie 84/631/EWG nach Art. 8 Abs. 2.

5 Global Convention on the Control of Transboundary Movements of Hazardous Wastes and their disposal, Basel 1989. Orginaltext in Environmental Policy and Law 18/1988/ S. 194.

6 Bull. EG 3-1989, Ziff. 2.1.113, S. 40.

7 FAZ vom 14. 5. 1990; vgl. zur Kritik an dieser Entscheidung Bernsdorf, in Spill/Wingert (Hrsg.), S. 115-117.

8 Vgl. 1. Erwägungsgrund der Baseler Konvention.

9 Vgl. 11. und 24. Erwägungsgrund der Baseler Konvention.

10 Vgl. Art. 16 der Baseler Konvention. 
nisieren und Beschwerden entgegennehmen. Alle internationalen Abfalltransporte müssen von den Unterzeichnerstaaten dem Sekretariat und den Transitstaaten gemeldet werden. Die Europäische Gemeinschaft beabsichtigt, die Richtlinie über die grenzüberschreitende Verbringung gefährlicher Abfälle ${ }^{11}$ in ihren Bestimmungen für die Ausfuhr in Drittstaaten an dieses Abkommen anzupassen ${ }^{12}$. Daraus wird deutlich, daß nicht die innergemeinschaftliche Verbringung betroffen ist. Dennoch soll nachfolgend ein kurzer Überblick über den Inhalt der Baseler Konvention gegeben werden.

Im einzelnen sieht die Baseler Konvention vor, den Import und Export sowie den Transit gefährlicher Abfälle nur dann zu erlauben, wenn alle vom Transport betroffenen Staaten informiert sind und der Verbringung und Beseitigung zugestimmt haben ${ }^{13}$. Gänzlich ausgeschlossen bleibt nach Art. 4 Abs. 5 der Konvention der Export $^{14}$ in Staaten, welche dieser Konvention nicht zugestimmt haben. Es besteht jedoch die Möglichkeit, mit solchen Staaten bilaterale Abkommen unter Wahrung der Bestimmungen der Konvention zu schließen ${ }^{15}$. Ebenso ist durch die zuständigen Behörden die Ausfuhr in solche Staaten nicht zu gestatten, die ein Einfuhrverbot verhängt haben oder in denen eine umweltgerechte ${ }^{16}$ Entsorgung der Abfälle nicht gewährleistet erscheint. Bei illegal vorgenommenen Abfallexporten besteht seitens des Abfallexporteurs, des Erzeugers oder des Exportstaates nach Art. 9 Abs. 2 der Konvention eine Rückführungsverpflichtung in den Exportstaat, wenn auf anderem Weg keine den Bestimmungen dieser Konvention und denen des Empfängerstaates gemäße Entsorgung gewährleistet werden kann. Die Illegalität bestimmt sich aus Vorschriften der Konvention ${ }^{17}$ und den Vorschriften der von Verbringung und Entsorgung betroffenen Staaten. Die Verpflichtung zur Rücknahme gilt für bereits vollzogene illegale Abfallexporte wie für gescheiterte Versuche. Gleiches ergibt sich für den Fall, daß die Vereinbarungen bezüglich der Beseitigung im Empfangsstaat nicht eingehalten werden können ${ }^{18}$. Der Herkunftsstaat und die Transitstaaten dürfen eine aus diesen Gründen gegebenenfalls notwendig werdende Rückführung in den Herkunftsstaat nicht behindern.

11 Vgl. unten Kapitel A.II.2.d).

12 Pernice, NVwZ 1990, S. 414, 417.

13 Vgl. Art. 6 und Art. 4 Abs. 11 der Baseler Konvention.

14 Der Transit ist unter Beachtung der Bestimmungen des Art. 7 zulässig.

$15 \mathrm{Vgl}$. zur Kritik an dieser Bestimmung in Art. 11 der Baseler Konvention, Bernsdorf in Spill/Wingert (Hrsg.), S. 113-120.

16 Vgl. zu den Kriterien Art. 4 Abs. 9 lit a-e.

17 Vgl. Art. 9 Abs. 1 der Baseler Konvention.

18 Vgl. Art. 8 der Baseler Konvention und Grabitz, Art. 130s, Rdnr. 249 und 249d. 
Der Rat der Europäischen Gemeinschaften hat am 2.4. 1990 im Zusammenhang mit seinem Beschluß zur OECD-Empfehlung über die grenzüberschreitende Verbringung von gefährlichen Abfällen den Mitgliedstaaten, welche die Baseler Konvention bisher nicht unterzeichnet haben, dringend empfohlen, dies bald nachzuholen ${ }^{19}$.

\section{Empfehlung des Rates der OECD über die grenzüberschreitende Verbringung von gefährlichen Abfällen}

Die Empfehlung des Rates der OECD stützt sich in ihren Bestimmungen weitgehend auf die Baseler Konvention über die Überwachung der grenzüberschreitenden Verbringung gefährlicher Abfälle und ihrer Beseitigung. Bedeutsamste Abweichung ist die ausdrücklich formulierte Zulässigkeit von Abfallexporten in Nichtsignatarstaaten. Voraussetzung dafür ist, daß keine weniger strengen Überwachungsmaßnahmen angewendet werden. Die OECD-Empfehlung verpflichtet die Mitgliedstaaten der OECD dazu, Behörden bzw. andere Körperschaften zu benennen, welche die grenzüberschreitende Verbringung von gefährlichen Abfällen überwachen. Alle Mitgliedstaaten müssen durch geeignete Maßnahmen gewährleisten, daß die erforderlichen Informationen über geplante grenzüberschreitende Verbringungen von gefährlichen Abfällen bei den zuständigen Stellen der Transitstaaten und des Empfängerstaates rechtzeitig genutzt werden können. Der Rat der Europäischen Gemeinschaften hat am 2. 4. 1990 beschlossen, die OECD-Empfehlung für die EWG anzunehmen ${ }^{20}$.

\section{Recht der Europäischen Wirtschaftsgemeinschaft}

Der Vertrag zur Gründung der Europäischen Wirtschaftsgemeinschaft ${ }^{21}$ wurde 1957 von den sechs Gründungsmitgliedern ${ }^{22}$ geschlossen. Mit dem Inkrafttreten des EWG-Vertrags ist die Gemeinschaft als solche erstanden, gleichzeitig wurde ihr in Form des EWG-Vertrags eine „Verfassung“ gegeben ${ }^{23}$. Aus dieser Verfassung, d.h. dem primären Gemeinschaftsrecht, bestimmt sich die Aufgabe der EWG. Im EWGVertrag sind die Organe der EWG benannt, und es sind die Rechtsakte festgelegt, welche durch diese Organe bei der Ausübung der ihnen übertragenen Gewalt

19 EuZW 1990, S. 270.

20 EuZW 1990, S. 270.

21 Vertrag zur Gründung der Europäischen Wirtschaftsgemeinschaft vom 25. 3. 1957, BGBI. II S. 766.

22 Belgien, Bundesrepublik Deutschland, Frankreich, Italien, Luxemburg, Niederlande.

23 Vgl. zum Verfassungscharakter des primären Gemeinschaftsrechts, Ipsen, § 2, Rdnr. 33. 
ergehen können. Aus diesen Rechtsakten setzt sich das sekundäre Gemeinschaftsrecht zusammen.

Das für die grenzüberschreitende Abfallentsorgung relevante Gemeinschaftsrecht findet sich auf beiden Ebenen des EG-Rechts. Auf der obersten Ebene ist das Binnenmarktrecht im EWG-Vertrag angesiedelt, auf der Ebene darunter das sekundäre Gemeinschaftsrecht in Form der Abfallrichtlinien. Dem sekundären wie dem primären Gemeinschaftsrecht kommt gegenüber widersprechendem mitgliedstaatlichen Recht ein Anwendungsvorrang $\mathrm{zu}^{24}$.

\section{Rechtsgrundlagen der Verwirklichung des Binnenmarktes im EWG-Vertrag - Primäres Gemeinschaftsrecht -}

Das durch den EWG-Vertrag begründete Recht verleiht der Gemeinschaft Kompetenzen auf wirtschaftspolitischem und umweltpolitischem Gebiet. Somit hat sie umfangreiche die Rechtsetzungsbefugnisse, die für eine grenzüberschreitende Abfallentsorgung innerhalb der Gemeinschaft von Belang sein könnten.

Für die bestehenden und zukünftigen Regelungen des sekundären Gemeinschaftsrechts ist es von großer Tragweite, welche Ermächtigungsgrundlage aus dem EWGVertrag zu ihrer Abstützung herangezogen wurde bzw. wird. Die Organe der Gemeinschaft müssen sich bei ihrer Tätigkeit auf eine Ermächtigungsgrundlage stützen. Je nach Abstützung sind für den Erlaß neuer Regelungen andere Mehrheiten bei der Beschlußfassung erforderlich und verschiedene Beteiligungsformen des Europäischen Parlaments vorgesehen. Es bestehen darüber hinaus - was im $\mathrm{Zu}$ sammenhang mit der innergemeinschaftlichen Abfallentsorgung von besonderer Bedeutung ist - Unterschiede in der Zulässigkeit weitergehender mitgliedstaatlicher Schutzmaßnahmen.

Für den Fall, daß Abfälle Waren sind und/oder Abfallentsorgung eine Dienstleistung darstellt, so unterliegt die innergemeinschaftliche, grenzüberschreitende Abfallentsorgung ${ }^{25}$ zusätzlich zu den bestehenden speziellen Regelungen des sekundären Gemeinschaftsrechts denen des EWG-Vertrags, d.h. dem primären Gemeinschaftsrecht zum Gemeinsamen Markt und zur Verwirklichung des Binnenmarktes ${ }^{26}$.

24 Rojahn in v. Münch, Art. 24, Rdnr. 41-45; BVerfGE 31, 174; Ipsen § 10, Rdnr. 56. Vgl. unten Kapitel A.II.2..

25 Die Auswirkungen auf die innerstaatliche Abfallverbringung und die in Drittstaaten werden hier nicht untersucht, vgl. dazu v. Wilmowsky, S. 50.

26 Vgl. zu den beiden Begriffsinhalten Müller-Graff, S. 8-13 und Beutler u.a., S. 47-48. 
Damit könnten sich Kollisionen von Bestimmungen des Abfallrechts der Bundesrepublik Deutschland aber auch des sekundären Gemeinschaftsrechts mit dem primären Gemeinschaftsrecht ergeben. In diesem Fall würde der Vorrang des primären Gemeinschaftsrechts greifen und das widersprechende nationale Recht bezüglich der grenzüberschreitenden Abfallentsorgung innerhalb der Gemeinschaft fände keine Anwendung. Der Gemeinschaftsgesetzgeber ist gleichermaßen an die Bestimmungen des EWG-Vertrags gebunden, so da $B$ widersprechendes sekundäres $\mathrm{Ge}-$ meinschaftsrecht ebenfalls keinen Bestand haben kann. Mit der Festlegung des Termins zur Vollendung des Binnenmarktes ist für den Fall der Erfassung der grenzüberschreitenden Abfallentsorgung vom Liberalisierungsgebot des EWG-Vertrags ein Zeitpunkt vorgegeben, zu dem gegebenenfalls der freie Waren- und Dienstleistungsverkehr auch für den Bereich der Abfallentsorgung innerhalb der Gemeinschaft durch die Gemeinschaft und die Mitgliedstaaten gewährleistet sein müßte ${ }^{27}$.

\section{a) Grundsätze}

Im einzelnen sind für grenzüberschreitende Abfallentsorgung auf dem Gebiet der Gemeinschaft folgende Festlegungen, die in den Grundsätzen des EWG-Vertrags formuliert sind, von Bedeutung:

In Art. 2 EWGV wird als Aufgabe der Gemeinschaft die Errichtung eines Gemeinsamen Marktes und die sukzessive Annäherung der Wirtschaftspolitik der Mitgliedstaaten festgelegt. Es wird in Politik, Wirtschaft und Rechtswissenschaft diskutiert $^{28}$, ob die damit verbundenenen Zielsetzungen auch die Schaffung eines gemeinsamen Marktes für Abfälle einschließt. Art. 3 EWGV nennt neben anderen Tätigkeiten der Gemeinschaft bei der Bewältigung dieser Aufgabe „... die Abschaffung der Zölle und mengenmäßiger Beschränkungen bei der Ein- und Ausfuhr von Waren sowie aller sonstigen Maßnahmen gleicher Wirkung zwischen den Mitgliedstaaten;“29 "die Beseitigung der Hindernisse für den den freien Personen-, Dienstleistungs- und Kapitalverkehr zwischen den Mitgliedstaaten“30 und „die Angleichung der innerstaatlichen Rechtsvorschriften, soweit dies für das ordnungsmäßige Funktionieren des Gemeinsamen Marktes erforderlich ist ${ }^{\text {“31. }}$.

27 Die Frage der Relevanz dieser Bestimmungen für die Abfallentsorgung wird im Anschluß zunächst nicht abschließend geprüft, sie wird nachfolgend im Kapitel B. eingehend untersucht.

28 Vgl. v. Wilmowsky, NVWZ 1991, S.1.

29 Art. 3 lit. a EWGV.

30 Art. 3 lit. c EWGV, vgl. hierzu die korrespondierenden Artikel im Kapitel des EWGVertrag „Grundlagen der Gemeinschaft“, unten Kapitel A.II.1.c)aa) und bb).

31 Art. 3 lit. h EWGV. Vgl. unten Kapitel A.II.1.d). 
Art. 4 Abs. 1 EWGV bindet die Gemeinschaftsorgane dabei an das Prinzip der begrenzten Einzelermächtigung, d.h. jeder von Gemeinschaftsorganen erlassene Rechtsakt bedarf einer Ermächtigungsgrundlage im EWG-Vertrag ${ }^{32}$.

\section{b) Zeitplan zur Verwirklichung des Binnenmarktes}

Mit der Einheitlichen Europäischen Akte wurde der Art. 8a in den ersten Teil des EWG-Vertrags eingefügt. Er nennt als zusätzliche Aufgabe der Gemeinschaft die Verwirklichung eines Binnenmarktes ${ }^{33}$ auf dem Gebiet der Gemeinschaft zum 31. Dezember 1992. Zu diesem Zeitpunkt müssen gemäß Art. 8a EWGV die vier Grundfreiheiten gewährleistet sein. In Art. 8a EWGV werden die Ermächtigungsgrundlagen aufgezählt (Art. 8b, 8c, 28, 57 II, 59, 70 I, 84, 99, 100a und 100b), die der Gemeinschaft bei der Verwirklichung des Ziels eines Binnnenmarktes zur Verfügung stehen. Für den Bereich der Abfallentsorgung kommt davon nur Art. 100a EWGV in Frage.

\section{c) Grundlagen der Gemeinschaft}

Der zweite Teil des EWG-Vertrags schreibt die Grundlagen der Gemeinschaft fest. Die Grundlagen der Gemeinschaft werden durch die Grundfreiheiten des EWGVertrags gelegt. Namentlich sind dies „der freie Warenverkehr“34 und „die Freizügigkeit, der freie Dienstleistungs- und Kapitalverkehr'355 (weitere Grundlagen sind die Landwirtschaft ${ }^{36}$ und der Verkehr ${ }^{37}$ ). Von den Bestimmungen zu den Grundlagen der Gemeinschaft könnten für die grenzüberschreitende Abfallentsorgung solche aus den Bereichen Warenverkehr und Dienstleistungsverkehr relevant sein.

\section{aa) Der freie Warenverkehr}

Der erste Titel des zweiten Teils des EWG-Vertrags beinhaltet die Bestimmungen zum freien Warenverkehr. Art. 30 EWGV im zweiten Kapitel des ersten Titels des EWG-Vertrags verbietet den Mitgliedstaaten „mengenmäßige Einfuhrbeschrän-

32 Vgl. zu den Ermächtigungsgrundlagen im Abfallrecht unten Kapitel A.II.1.d).

33 Vgl. zu den beiden Begriffsinhalten „Binnenmarkt“ und „Gemeinsamer Markt“ MüllerGraff, S. 8-13 und Beutler u.a., S. 47-48.

34 1. Titel im 2. Teil des EWGV.

35 3. Titel im 2. Teil des EWGV.

36 2. Titel im 2. Teil des EWGV.

37 4. Titel im 2. Teil des EWGV. 
kungen sowie alle Maßnahmen gleicher Wirkung“38 im innergemeinschaftlichen Warenverkehr. In Art. 34 EWGV wird ein gleichlautendes Verbot für Ausfuhrbeschränkungen formuliert ${ }^{39}$. Dadurch wird der freie Verkehr von Waren aus den Mitgliedstaaten und allen legal eingeführten Waren auf dem Gebiet der Gemeinschaft geschützt und der Bezug zur Aufgabe der EWG und ihrer Organe gemäß Art. 2 EWGV hergestellt.

Die Grundlage für eine Definition des oben genannten Begriffs „Maßnahmen gleicher Wirkung" wurde durch den EuGH im Fall „Dassonville" 40 gegeben ${ }^{41}$. Danach ist unter Maßnahmen gleicher Wirkung zu verstehen, „... jede (wie auch immer geartete $^{42}$ ) Handelsregelung der Mitgliedstaaten, die geeignet ist, den innergemeinschaftlichen Warenverkehr unmittelbar, tatsächlich oder potentiell zu behindern ${ }^{\prime 4}$.

Eine Beschränkung des Warenverkehrs durch einseitige mitgliedstaatliche Maßnahmen ist nur auf der Grundlage von Art. 36 EWGV möglich. Geschützt werden durch Art. 36 EWGV unter anderem die „... öffentliche Sittlichkeit, Ordnung und Sicherheit, ... die Gesundheit und das Leben von Menschen, Tieren und Pflanzen ...". Der in Art. 36 EWGV enthaltene Katalog ist abschließend. Wird eines der in Art. 36 EWGV genannten Rechtsgüter durch Gemeinschaftsrecht abschließend geregelt, so ist eine Berufung auf Art. 36 EWGV ausgeschlossen ${ }^{44}$.

Für den Fall, daß oder soweit keine Gemeinschaftsregelung besteht, hat der EuGH die Dassonville-Formel durch die „Cassis“-Rechtsprechung ${ }^{45}$ für unterschiedslos anwendbare Einfuhrregelungen eingeschränkt. Liegen im Sinne dieser Rechtsprechung „Zwingende Erfordernisse“ (entsprechend der rule of reason) vor, so fallen unterschiedslos anwendbare Einfuhrregelungen nicht unter die Maßnahmen gleicher Wirkung ${ }^{46}$. Im Fall der Ausfuhr ist aus der neueren Rechtsprechung des

38 Die Abgrenzung der Begriffe „mengenmäßige Einfuhrbeschränkungen“ sowie „Maßnahmen gleicher Wirkung" war nur bis zum Ablauf der Übergangszeit am 1. 1. 1970 (gemäß Art. 33 Abs. 7) in Bezug auf die Sanktionsfolgen von praktischer Bedeutung, Matthies in Grabitz Art. 31, Rdnr. 3. Gleiches gilt für die Art. 31-33, Matthies in Grabitz Art. 31-33, Rdnr. 1.

39 Für Art. 35 gilt hinsichtlich der Begriffsabgrenzung das für die Art. 31-33 gesagte.

40 Rs. 8/74 - Dassonville, Slg. 1974/837, S. 852.

41 Matthies in Grabitz, Art. 30, Rdnr. 12.

42 Hinzufügung d. Verf..

43 Matthies in Grabitz, Art. 30, Rdnr. 12. Der Nachweis einer tatsächlichen Behinderung ist nicht erforderlich, st. Rechtspr..

44 Matthies in Grabitz, Art. 36, Rdnr. 9.

45 Rs. 120/78, Slg. 1979/649, S. 285.

46 Matthies in Grabitz, Art. 30, Rdnr. 6. 
EuGH abzuleiten, daß sich Art. 34 EWGV nur auf solche nationale Maßnahmen erstrecken soll, die durch spezifische Beschränkungen der Ausfuhr der nationalen Produktion oder dem nationalen Binnenmarkt einen Vorteil gegenüber der Produktion oder dem Handel andere Mitgliedstaaten verschaffen ${ }^{47}$.

Gerichtet ist das Verbot in Art. 30 und Art. 34 EWGV ausschließlich an die Mitgliedstaaten. Der Gemeinschaftsgesetzgeber ist aber ebenfalls verpflichtet, bei seinen Rechtsetzungsaktivitäten keine Handelsbeschränkungen einzuführen, denn seine Aufgabe ist gemäß Art. 3 lit. a EWGV in den Grundsätzen der Gemeinschaft die Herstellung und Gewährleistung des freien Warenverkehrs.

Bei der Abfallentsorgung und dabei insbesondere im Zusammenhang mit der Wiederverwertung wird die Frage aufgeworfen, ob und in welchem Umfang Abfällen überhaupt der Warencharakter im Sinne des Art. 9 EWGV zukommt. Diese Frage wird in Kapitel B.I. aufgegriffen.

\section{bb) Dienstleistungsfreiheit}

$\mathrm{Zu}$ den Grundlagen der Gemeinschaft zählt auch die Dienstleistungsfreiheit. Für den Fall, daß die Tätigkeiten im Rahmen der Abfallentsorgung den Dienstleistungen i.S. von Art. 60 EWGV zugeordnet werden können, finden auf solche Tätigkeiten die Bestimmungen der Art. 59-66 EWGV Anwendung. Art. 60 Abs. 1 EWGV stellt den Auffangtatbestand für solche Leistungen dar, die nicht unter die Vorschriften des Waren- oder Kapitalverkehrs ${ }^{48}$ fallen. Die Regelungen über den freien Warenverkehr und über die Dienstleistungen schließen einander in der Anwendung gegenseitig aus, da Artikel 60 des EWG-Vertrags die Dienstleistungen den anderen Grundfreiheiten gegenüberstellt: „... Leistungen, ... soweit sie nicht den Vorschriften über den freien Waren- und Kapitalverkehr und über die Freizügigkeit der Personen unterliegen “49. Damit ist ausgeschlossen, daß auf ein und den selben Vorgang gleichzeitig die Bestimmungen zum Warenverkehr und zur Dienstleistungsfreiheit Anwendung finden.

47 Beutler, u.a. S. 287, dort wird diese Differenzierung kritisiert.

48 D.h. aber nach Auffassung d. Verf. keinesfalls, daß Art. 60 EWGV nicht gleichberechtigt neben den anderen Freiheiten steht.

49 Vgl. Studie der Europäische Stiftung zur Verbesserung der Lebens- und Arbeitsbedingungen über den Transport gefährlicher Abfälle, 1987, S. 11. 
Bei den Regelungen zur Freiheit des Dienstleistungsverkehrs ist davon auszugehen, $\mathrm{da} ß$ es dabei nicht nur um die Aufhebung und das Verbot diskriminierender Bestimmungen der Mitgliedstaaten geht, sondern um die Beseitigung der Beschränkungen schlechthin ${ }^{50}$. Die Dienstleistungsfreiheit innerhalb der EWG gilt unmittelbar, d.h. es bedarf keiner vorhergehenden Angleichung mitgliedstaatlichen Rechts. Sie gilt sowohl für Erbringer als auch Empfänger von Dienstleistungen ${ }^{51}$. Diese Bestimmungen dürfen aber nicht dahingehend mißverstanden werden, daß vorhandene Berufs- oder Kontroll- und Aufsichtsregelungen ${ }^{52}$, die für In- und Ausländer gleichermaßen gelten und erfüllbar sind, abgeschafft werden müßten. Doch darf z.B. vom Dienstleistungserbringer kein ständiger Inlandsaufenthalt verlangt werden $^{53}$. Ziel ist es vielmehr, daß Dienstleistungen aus anderen Mitgliedstaaten der Gemeinschaft unter den gleichen Bedingungen angeboten werden können, wie dies für inländische der Fall ist, ohne dabei „... die Güte oder Qualität zu senken“54. Das schließt auch die folgenden Anforderungen bei Errichtung und Betrieb von Abfallentsorgungsanlagen mit ein:

- Genehmigungspflichten für Errichtung und Betrieb von Abfallentsorgungsanlagen

- Verbot von Entsorgungsverfahren und Festlegung von technischen Standards für Entsorgungsverfahren

- Begrenzung der jeweils in inländischen Anlagen entsorgbaren Abfallmengen

- Verbot der Beseitigung bestimmter Abfallarten und Zuordnung von Abfallarten zu speziellen Entsorgungsverfahren (wie z.B. in der TA-Abfall ${ }^{55}$ )

Bei der Klärung der Frage inwieweit die Tätigkeit der Abfallentsorgung überhaupt als Dienstleistung angesehen werden kann, ist zu untersuchen, ob sie nicht von vornherein von der Anwendung der Bestimmungen des EWG-Vertrags zur Dienstleistungsfreiheit ausgenommen sind. Zuerst sind demnach die im EWG-Vertrag vorgesehenen Bereichsausnahmen von der Dienstleistungsfreiheit zu prüfen:

50 Randelzhofer in Grabitz, Art. 59, Rdnr. 2.

51 Vgl. zur Rechtsprechung Randelzhofer in Grabitz Art. 59, Rdnr. 9, m. w. N.

52 Z.B. in Form von Erfordernissen an die Ausbildung der mit Entsorgungstätigkeiten betrauten Arbeitnehmer.

53 Randelzhofer in Grabitz, Art. 59, Rdnr. 3.

54 Randelzhofer in Grabitz, Art. 59, Rdnr. 11.

55 Vgl. unten Kapitel A.III.1.c). 
Art. 66 EWGV stellt einen Zusammenhang zwischen den Bestimmungen zur Dienstleistungsfreiheit und den Art. 55-58 EWGV im Vertragsteil zur Niederlassungsfreiheit her. Art. 55 EWGV nimmt solche Tätigkeiten, die in einem Mitgliedstaat mit der Ausübung öffentlicher Gewalt verbunden sind, in diesem Staat von der Anwendung der Bestimmungen des Vertragskapitels über die Dienstleistungsfreiheit aus. In der Bundesrepublik Deutschland liegt die staatliche Verantwortlichkeit für die Entsorgung gemäß $\S 3$ Abs. 2, Satz 1 AbfG bei den nach Landesrecht zuständigen Körperschaften des öffentlichen Rechts. Die Tatsache, daß die staatlichen Träger Tätigkeiten, die im Rahmen der Abfallentsorgung anfallen, gemäß $\S 3$ Abs. 2 Satz $2 \mathrm{AbfG}^{56}$ von privaten Unternehmen erbringen lassen können, ist für die Zuordnung der Beseitigungspflicht nicht von Belang. Die „Müllabfuhr" zählt in der Bundesrepublik Deutschland zum Gebiet öffentlicher Verwaltung 57 und für Abfälle besteht nach $\S 3$ Abs. 2 AbfG eine öffentliche Entsorgungspflicht ${ }^{58}$. Daraus könnte geschlossen werden, daß Abfallentsorgung in der Bundesrepublik als Ausübung öffentlicher Gewalt angesehen werden muß und somit gemäß Art. 55 EWGV von den Bestimmungen zum freien Dienstleistungsverkehr ausgenommen wäre. Die Dienstleistungsfreiheit nach dem EWG-Vertrag könnte aber zumindest für die grenzüberschreitende Entsorgung derjenigen Abfälle bestehen, bei denen sich die zuständigen öffentlichen Körperschaften entsprechend $\S 3 \mathrm{Abs} .3 \mathrm{AbfG}$ von ihrer Entsorgungspflicht entbunden haben ${ }^{59}$.

\section{bbb) Art. 90 Abs. 2 EWGV}

Art. 90 Abs. 2 S. 1 EWGV befreit „Unternehmen, die mit Dientsleistungen von allgemeinem wirtschaftlichen Interesse betraut sind" von der Anwendung der Bestimmungen des EWG-Vertrags soweit, wie dies zur Erfüllung der ihnen übertragenen besonderen Aufgaben notwendig ist. Die Mitgliedstaaten haben ebenfalls die Möglichkeit, sich bei Maßnahmen, welche die Funktionsfähigkeit solcher Unternehmen gewährleisten sollen, auf diese Vertragsbestimmung zu berufen. Dienstleistungen von allgemeinem wirtschaftlichen Interesse sind anerkanntermaßen Versorgungsleistungen und Leistungen zur Schaffung von Infrastruktur, ob die Abfallentsorgung dazu zählt, ist bislang nicht geklärt.

56 Vgl. unten Kapitel A.III.1.a)aa).

57 BGH, 17. 2. 1983, DVBl. 1983, S. 1061, 1062; BGH, 24. 10. 174, BGHZ 63, S. 119 , 122; BGH, 24. 1. 1950, BGHZ 40, S. 355, 360; vgl. auch v. Wilmowsky, S. 142.

58 Vgl. unten Kapitel A.III.1.a)aa).

59 Vgl. unten Kapitel A.III.1.a)aa). 


\section{d) Politik der Gemeinschaft, Allgemeine und Schlußbestimmungen des Vertrags}

In den beiden Kapiteln des EWG-Vertrags „Politik der Gemeinschaft“, sowie „Allgemeine und Schlußbestimmungen“ finden sich die einschlägigen Artikel, die als Handlungsermächtigungen für Regelungen des sekundären Gemeinschaftsrechts zur Abfallentsorgung herangezogen werden könnten. Sie bilden die notwendigen Voraussetzungen bei Gesetzgebungsaktivitäten der Gemeinschaftsorgane. Auf dem Gebiet des Abfallrechts im Rahmen des besonderen Umweltrechts waren dies in der Vergangenheit die Art. 100 und 235 EWGV. Durch die Einheitliche Europäische Akte kamen die Art. 100a und 130s EWGV hinzu.

Entscheidend für die Anwendung eines bestimmten Artikels ist die objektive Sachnähe der zu schaffenden Regelung zum Komplex „Umweltschutz“ oder zum Komplex „Abbau von Handelshemmnissen"60. Die Anwendung von Art. 100 und Art. 100a EWGV kommt nach dieser vom EuGH entwickelten Formel für solche Regelungsbereiche in Frage, die in erster Linie die Herstellung oder Sicherung der Funktionsfähigkeit des Gemeinsamen Marktes bzw. Binnenmarktes betreffen und nur in zweiter Linie Fragen des Umweltschutzes regeln.

Neben dieser wirtschaftspolitischen Kompetenz der EWG besitzt die Gemeinschaft gemäß den durch die Einheitliche Europäische Akte eingefügten Art. 130r-t EWGV erstmals eine ausdrückliche Kompetenz in umweltpolitischen Fragen. Art. 130s EWGV ist die Handlungsermächtigung des Rates. Das Tätigwerden der Gemeinschaft wird aber im Vertrag selbst in Art. 130r Abs. 4 Satz 1 EWGV auf solche Fälle begrenzt ${ }^{61}$, in denen die in Art. 130r Nr. 1 EWGV genannten Ziele auf Gemeinschaftsebene besser erreicht werden können ${ }^{62}$. Auf dem Gebiet der Abfallentsorgung dürfte der Art. 130s EWGV für die Zukunft die relevante Ermächtigungsgrundlage darstellen. Dies deutet sich auch mit der Richtlinie des Rates zur Begrenzung von Schadstoffemissionen aus Großfeuerungsanlagen ${ }^{63}$ an. Sie wurde auf Art. 130s EWGV abgestützt. Dies geschah, obwohl die Betreiber von Großfeuerungsanlagen miteinander im Wettbewerb stehen können. Die Umweltbelastungen, die potentiell von solchen Anlagen ausgehen, sind jedoch so erheblich, daß hier eine

60 Grabitz, Art. 130s, Rdnr. 21.

61 Die Bedeutung dieser Einschränkung ist allerdings strittig, vgl. Grabitz, Art. 130r, Rdnr. 21-23.

62 Es besteht darüber hinaus auch eine Außenkompetenz der Gemeinschaft, auf die hier jedoch nicht weiter eingegangen wird.

63 Richtlinie des Rates zur Begrenzung von Schadstoffemisionen aus Großfeuerungsanlagen 88/609/EWG vom 24. 11. 1988, ABl. Nr. L 336, S. 1. 
objektive Sachnähe zum Umweltschutz ohne Zweifel besteht ${ }^{64}$. Diese Sachnähe dürfte auch für Regelungen zum Abfall und zur Abfallentsorgung gelten.

Gemäß dem Prinzip der begrenzten Einzelermächtigung kommt die bisher vorgenommene Abstützung von Richtlinien zum Abfall und zur Abfallentsorgung auf Art. 235 EWGV nach Inkrafttreten der Einheitlichen Europäischen Akte nicht mehr in Frage. Diese Einzelermächtigung ist in der Umweltpolitik mit Art. 130s EWGV nunmehr vorhanden, Art. 235 EWGV ist demgegenüber subsidiär. Art. 235 EWGV ist nur für solche Fälle als Generalermächtigung des Rates vorgesehen, in denen ein Tätigwerden der Gemeinschaft erforderlich wird, um ein Ziel im Gemeinsamen Markt zu erreichen, für das der EWG-Vertrag keine ausdrückliche Einzelermächtigung beinhaltet.

Gemäß der vom EuGH zur Frage der Abgrenzung von Art. 100, Art. 100a und Art. 130s EWGV entwickelten Formel ${ }^{65}$ läßt sich demnach zusammenfassen: Art. 100 und Art. 100a EWGV kommen nur für solche Regelungsbereiche in Frage, die in erster Linie die Herstellung oder Sicherung der Funktionsfähigkeit des Gemeinsamen Markt betreffen und nur in zweiter Linie Fragen des Umweltschutzes regeln. Auf Art. 130s EWGV ist in solchen Fällen zurückzugreifen, in denen eine objektive Sachnähe zum Umweltschutz gegeben ist. Die Abgrenzung und Rangposition von Art. 100, Art. 100a und Art. 130s EWGV zueinander bleibt in der Literatur dennoch weiter umstritten. Eine Klärung wird allgemein von einer laufenden Klage vor dem EuGH erwartet ${ }^{66}$.

Hinsichtlich der Beteiligung des Europäischen Parlaments und der erforderlichen Mehrheiten bei der Beschlußfassung des Rates ergeben sich Unterschiede je nach der vorgesehenen Abstützung einer Richtlinie auf einen bestimmten Artikel des EWG-Vertrags. Zusätzlich ist die Zulässigkeit weitergehender mitgliedstaatlicher Schutzmaßnahmen unterschiedlich geregelt. Das Parlament wird bei der geplanten Abstützung einer Richtlinie auf Art. 100a, Art. 130s oder Art. 235 EWGV grundsätzlich angehört. Soll Art. 100 EWGV herangezogen werden, so ist die Anhörung des Parlaments nur vorgesehen, wenn die Umsetzung der Richtlinie eine Änderung mitgliedstaatlicher Rechtsvorschriften erfordern würde. Bei der Beschlußfassung des Rates ist bei der vorgesehenen Abstützung einer Richtlinie auf Art. 100 und

64 Grabitz, Art. 130, Rdnr. 21-23.

65 Vgl. Grabitz, Art. 130s, Rdnr. 21. Siehe zur Anwendung von EWGV-Artikeln zur Abstützung von Umweltrechtsakten ebenda Rdnr. 21-23.

$66 \mathrm{Vgl}$. zu den unterschiedlichen Ansichten: Kloepfer § Rdnr. 7-15; Grabitz, Art. 130s, Rdnr. 20-22; Langeheine in Grabitz, Art. 100a, Rdnr. 92-94 und Art. 100, Rdnr. 72; und zur Klage Pernice: NVwZ 1990, S. 205-206. 
Art. 235 EWGV Einstimmigkeit erforderlich. Dient Art. 100a EWGV als Ermächtigungsgrundlage, ist eine qualifizierte Mehrheit zur Beschlußfassung ausreichend. Bei Heranziehung des Art. 130s EWGV legt der Rat fest, für welche Beschlüsse eine qualifizierte Mehrheit ausreicht.

Art. 100 und Art. 100a EWGV verwehren den Mitgliedstaaten beim Vorliegen bestimmter Voraussetzungen weitergehende Schutzmaßnahmen im Umweltschutz. Erfolgt die Abstützung auf Art. 130s EWGV, dann sind diese auf der Grundlage von Art. 130t EWGV prinzipiell möglich ${ }^{67}$.

\section{Richtlinien - Sekundäres Gemeinschaftsrecht -}

Auf dem Gebiet des besonderen Umweltrechts haben die Legislativ- und Judikativorgane der EWG seit der Gründung der Gemeinschaft umfangreiche Rechtsetzungsaktivitäten entfaltet. Voraussetzung dafür, daß diese Rechtsetzungshandlungen in das nationale Recht der Mitgliedstaaten einwirken können, ist die Übertragung ${ }^{68}$ nationaler Hoheitsrechte auf einem sachlich umgrenzten Gebiet ${ }^{69}$ an die EWG. Die rechtliche Grundlage für diese Übertragung bildet im Rechtssystem der Bundesrepublik Deutschland Art. 24 I GG. Dort findet sich die Ermächtigung an den Bund $^{70}$, entsprechende Rechtshandlungen vorzunehmen. Erfolgt ist die Übertragung auf dieser Grundlage mit Inkrafttreten des Zustimmungsgesetzes zum EWG-Vertrag ${ }^{71}$. Mit Inkrafttreten dieses Gesetzes verzichtete die Bundesrepublik Deutschland auf die Ausschließlichkeit ihrer Hoheitsrechte gegenüber der EWG und duldet die Ausübung von Hoheitsgewalt durch die Organe ${ }^{72}$ der EWG ${ }^{73}$. Damit können die Rechtshandlungen der Gemeinschaftsorgane unmittelbar in den natio-

$67 \mathrm{Vgl.} \mathrm{zu}$ den inhaltlichen Beschränkungen solcher Schutzmaßnahmen durch den EWGVertrag Götz, JZ 1989, S. 1021.

68 Im Wortlaut von Art. 24 I GG wird zwar von der Übertragung nationaler Hoheitsrechte gesprochen, schlüssiger und anschaulicher erscheint es jedoch wie Ipsen, § 2, Rdnr. 15 16, von einem „Verzicht auf die Ausschließlichkeit von Hoheitsrechten“ und der „Duldung der Ausübung von Hoheitsgewalt durch Organe einer überstaatlichen Organisation" zu sprechen. Vgl. zu Art. 24 I GG allgemein Rojahn in v. Münch, Art. 24, Rdnr. 6, S. 9-15.

69 Vgl. dazu das „Prinzip der begrenzten Einzelermächtigung“ in Art. 4 Abs. 1 EWGV.

70 Und nur an diesen - nicht an die Länder.

71 Zustimmungsgesetz zum EWG-Vertrag vom 27. 7. 1957, BGBl. II, S. 445.

72 Vgl. zu den Organen Art. 4 Abs. 1 EWGV.

73 Ipsen, § 2, S. 57-61. 
nalen Rechtsraum hineinwirken und die Staatsorgane von Mitgliedstaaten wie auch den Einzelnen innerhalb des räumlichen Geltungsbereichs des Vertrags ${ }^{74}$ binden.

Neben der Übertragung der Hoheitsrechte an die EWG und der Regelung der verfassungsrechtlichen Fragen der Gemeinschaft ${ }^{75}$ bleibt noch zu klären, ob und wie die auf dieser rechtlichen Basis von der Gemeinschaft geschaffenen Rechtsnormen des sekundären Gemeinschaftsrechts im Kollisionsfall Vorrang vor dem mitgliedstaatlichen Recht entfalten können. Begründet wird die Kollisionsnorm noch unterschiedlich $^{76}$, entscheidend ist aber, da $B$ in der europarechtlichen Theorie weitestgehende Einigkeit darüber besteht, daß sekundäres Gemeinschaftsrecht im Falle der Kollision mit einfachen nationalen Gesetzen ${ }^{77}$ und Verordnungen der Mitgliedstaaten Vorrang hat ${ }^{78}$. Für den hier betrachteten Problemkreis ist diese Kollisionsnorm ausreichend, um die auftretenden Fragen klären zu können ${ }^{79}$.

Die Rechtsakte, die durch die Organe der EWG bei der Ausübung der ihnen übertragenen Gewalt ergehen können, sind in Art. 189 EWGV aufgezählt. Aus diesen Rechtsakten setzt sich das sekundäre Gemeinschaftsrecht zusammen. In Art. 189 Abs. 2 EWGV sind Richtlinien neben Verordnungen, Entscheidungen, Empfehlungen und Stellungnahmen als mögliche Rechtshandlungen der Gemeinschaft aufgeführt ${ }^{80}$. Sie werden gemäß Art. 189 Abs. 1 EWGV von einem Gemeinschaftsorgan der EWG - dem Rat oder der Kommission - erlassen ${ }^{81}$. Richtlinien entfalten ihre Wirkung gegenüber Einzelnen in einem zweistufigen Verfahren. Zunächst ergeht auf der gemeinschaftsrechtlichen Ebene eine Richtlinie. Diese bindet zu Anfang nur den bzw. die Mitgliedstaat(en), an den oder die sie sich richtet. Die Richtlinie erlangt ihre Wirkung gegenüber dem Einzelnen erst dann, wenn sie entsprechend der festgelegten Frist in nationales Recht umgesetzt ist ${ }^{82}$. Verbindlichkeit

74 Vgl. zum räumlichen Geltungsbereich Art. 227 EWGV.

75 Vgl. hierzu Pernice, NVwZ 1990, S. 201, 202.

76 Rojahn in v. Münch, Art. 24, Rdnr. 42.

77 Vgl. zur Kollision mit dem Grundgesetz der Bundesrepublik Deutschland Rojahn in v. Münch, Art. 24, Rdnr. 45-48.

78 Der Anwendungsvorrang reicht aus, eine Nichtigkeit widersprechenden mitgliedstaatlichen Rechts ist nicht notwendig.

79 Vgl. für eine ausführliche Darstellung möglicher Kollisionsfälle Spetzler, RIW 1990, S. 286, 286-290.

80 Vgl. zum Instrumentarium der anderen Gemeinschaften die Aufstellung bei Beutler u.a., S. 178 .

81 Verordnungen sind seitens der Gemeinschaft im Abfallrecht bisher nicht ergangen; zu den rechtlich unverbindlichen Handlungen der EG vgl. Grabitz Art. 130, Rdnr. 100-113c und Rdnr. 249-249d.

82 Vgl. zur unmittelbaren Wirkung von nicht fristgemäß oder inhaltlich nicht korrekt umgesetzten Richtlinien Oldenburg, m. w. N.. 
besteht bei der Umsetzung von Richtlinien in nationales Recht der Mitgliedstaaten nur hinsichtlich des Ziels bzw. des Ergebnisses ${ }^{83}$, d.h. den Mitgliedstaaten bleibt Wahlfreiheit bei der Auswahl der Mittel, mit denen sie das vorgegebene Ziel erreichen wollen. Es besteht allerdings bei der Richtliniengebung durchaus die Möglichkeit, so weitgehende und detaillierte Normierungen vorzunehmen, daß diese Freiheit faktisch nicht mehr existiert ${ }^{84}$. Ihre formale Rechtsnatur als Richtline verliert sie dadurch dennoch nicht. Voraussetzung ist aber, daß die Sicherung der Funktionsfähigkeit der Gemeinschaft diese Einschränkung der Wahlfreiheit rechtfertigt. Richtlinien unterscheiden sich damit von den Verordnungen, die sowohl für die Mitgliedstaaten als auch dem Einzelnen gegenüber unmittelbar verbindlich sind. Durch Richtlinien soll in der Regel eine Rechtsangleichung erreicht werden, während Verordnungen eine Rechtsvereinheitlichung zur Folge haben. Entscheidungen binden dagegen immer nur bestimmte Mitgliedstaaten oder Personen; Empfehlungen und Stellungnahmen sind unverbindlich.

Art.189 EWGV stellt für sich genommen allerdings keine Ermächtigungsnorm dar, er ordnet lediglich die Organzuständigkeit für die zuvor genannten Rechtshandlungen im Katalog des Art. 189 Abs. 2 EWGV. Als Ermächtigungsnormen für die Tätigkeit auf dem Gebiet des Abfallrechts im Rahmen des besonderen Umweltrechts ${ }^{85}$ kommen die Art. 100, Art. 100a und Art. 130s EWGV in Frage. Die bislang ergangenen Richtlinien im Abfallrecht wurden auf Art. 100 EWGV abgestützt oder es wurde eine Doppelabstützung auf Art. 100 und Art. 235 EWGV ${ }^{86}$ vorgenommen. Von der Abstützungsmöglichkeit auf Art. 130s EWGV wurde erstmals bei der Neufassung der Abfallrichtlinie 75/442/EWG Gebrauch gemacht.

83 Der Begriff „Ergebnis“ verdeutlicht bessser die Absicht die hinter dem Instrument der Richtlinie steht; z.B. in der französischen Fassung des Art. 189 EWGV wurde der Begriff ,résultat" verwendet. Ipsen, § 21, Rdnr. 28.

84 Vgl. Grabitz Art. 189, Rdnr. 59; Kloepfer, § 6, Rdnr. 25; zum abschließenden Charakter derartiger Richtlinien, unten Kapitel A.II.2.d)aa), dort zur Richtlinie über die grenzüberschreitende Verbringung giftiger und gefährlicher Abfälle.

85 Vgl. Beyerlin, UPR 1989, S. 361, 361.

86 Vgl. hierzu Offermann-Clas, DVB1. 1981, S. 1125, 1127. Die Abstützung von Abfallrichtlinien ist für die Art der Beschlußfassung bei der Verabschiedung solcher Richtlinien und für den verbleibenden Regelungsspielraum hinsichtlich strengerer mitgliedstaatlicher Schutzmaßnahmen von größter Bedeutung, da diesbezüglich in den Artikeln deutliche Unterschiede bestehen. 


\section{a) Richtlinie des Rates über Abfälle, 75/442/EWG ${ }^{87}$}

Die Richtlinie über Abfälle ist die grundlegende Richtlinie zum Regelungsbereich Abfall und Abfallentsorgung. Sie enthält die Bestimmungen der Begriffe Abfall (Art. 1 lit. a) und Beseitigung bzw. Entsorgung ${ }^{88}$ (Art. 1 lit. b). Sie schafft damit die notwendigen begrifflichen und definitorischen Voraussetzungen bei der Klärung der Frage, ob Abfälle und Abfallentsorgung dem Liberalisierungsgebot des EWGVertrags unterliegen.

Am 7. Juni 1990 stimmte der Rat der EWG einer Änderung der (Abfall-)Richtlinie 75/442/EWG zu ihrer Verstärkung zu. Der Wortlaut der verabschiedeten Fassung ist bis zum Ende der Bearbeitung der vorliegenden Veröffentlichung nicht zugänglich gewesen und die publizierten Informationen in verschiedenen Quellen lassen durchaus widersprüchliche Interpretationen $z u^{89}$. Wegen der grundsätzlichen Bedeutung der sich abzeichnenden Änderung wird dennoch auf diese zur endgültigen Neufassung der Richtlinie erhältlichen Sekundärinformationen zurückgegriffen, damit sie in die weiteren Überlegungen einfließen können. Die hier gegebene Darstellung der geänderten Richtlinie stützt sich im wesentlichen auf die diesbezügliche Pressemitteilung des Rates der Europäischen Gemeinschaften ${ }^{90}$ und den der Neufassung der Richtlinie zugrundeliegenden Kommissionsvorschlag ${ }^{91}$.

Abfall im Sinne des Art. 1 des Neuentwurfs der Richtlinie 75/442/EWG ist ,jeder Stoff oder Gegenstand, dessen sich sein Besitzer entledigt oder sich aus den in An hang I aufgeführten Gründen entledigen muß“. Beseitigung ist „das Einsammeln, die Verbringung und Behandlung der Abfälle, insbesondere derjenigen in Anhang II". Ob und inwieweit sich die äußerst wichtige Definition des Begriffs Abfall im bundesdeutschen Recht und im Recht der Gemeinschaft deckt, war zumindest bei der bislang gültigen Fassung der Richtlinie in der Literatur nicht unumstrit-

87 Richtline des Rates vom 15. 7. 1975 über Abfälle, ABl. Nr. L 194 vom 25. 7. 1975, S. 47.

88 In der Mitteilung des Rates an die Presse Nr. 6715/90 (Presse 81) zur Neufassung der Richtlinie 75/442/EWG wird nunmehr ebenfalls von Entsorgung gesprochen.

89 Es wurden Veröffentlichungen bis Ende Januar 1991 berücksichtigt.

90 Mitteilung des Rates der Europäischen Gemeinschaften - Generalsekretariat - an die Presse Nr. 6715/90 (Presse 81), S. 4.

91 Geänderter Vorschlag für eine Richtlinie des Rates zur Änderung der Richtlinie 75/442/EWG, ABl. Nr. C 295/3 vom 19. 11. 1988 und ABl. Nr. C 326/6, vom 30. 12. 1989. 
ten ${ }^{22}$. Dagegen kann bei der Begriffsbestimmung der Beseitigung in Art. 1 lit. $\mathrm{b}$ der Richtlinie 75/442/EWG (a.F.) und der Entsorgung in § 1 Abs. 2 AbfG von einer Übereinstimmung mit dem Recht der Bundesrepublik Deutschland ausgegangen werden.

Die bislang in Art. 2 der Richtlinie enthaltene Ermächtigung der Mitgliedstaaten, für bestimmte Gruppen von Abfällen, die keiner weitergehenden Gemeinschaftsregelung unterliegen, besondere Bestimmungen zu erlassen, ist zugunsten einer (zukünftigen) Regelung in Einzelrichtlinien entfallen. Ausgenommen von der Geltung der Richtlinie bleiben weiterhin die in Art. 2 Abs. 1 aufgezählten Abfallkategorien.

Die Mitgliedstaaten werden in Art. 3 Abs. 1 verpflichtet, das Prinzip der Abfallvermeidung und -verwertung zu fördern, dabei müssen die mitgliedstaatlichen Maßnahmen vorrangig auf die Abfallvermeidung ausgerichtet sein. In Art. 4 der Richtlinie sind die bei der Abfallbeseitigung zu beachtenden Schutzgüter und Schutzziele $^{93}$ aufgelistet. Die Mitgliedstaaten werden in Art. 5 der Richtlinie dazu verpflichtet, die zuständigen Behörden zu benennen, die Planung ${ }^{94}$ und Organisation ${ }^{95}$ der Beseitigung von Abfällen zu regeln. Sie haben die Genehmigung und Überwachung 96 bei Bau und Betrieb von Abfallbeseitigungsanlagen und der Beseitigungsunternehmen durchzuführen. Art. 11 der Richtlinie schreibt das Verursacherprinzip für die Übernahme von Beseitigungskosten fest ${ }^{97}$.

Gegenüber der bislang gültigen Fassung der Richtlinie ergaben sich insbesondere folgende Änderungen ${ }^{98}$ : Die in Art. 1 der Richtlinie bislang vorhandene Bezugnahme beim objektiven Abfallbegriff auf einzelstaatliche Vorschriften, die eine Entledigungspflicht begründen, ist entfallen; sie wird durch in einem Anhang spezifizierte Gründe für eine Entledigungverpflichtung ersetzt. Maßnahmen zur Vermeidung und Verwertung erhalten Vorrang vor der Beseitigung. Die Mitgliedstaaten werden zum Aufbau einer ausreichenden Entsorgungsinfrastruktur verpflichtet ${ }^{99}$,

92 Vgl. Pernice NVwZ 1990, S. 414, 415-416. Pernice spricht von „strukturellen Unterschieden“ zwischen deutschem Abfallrecht und Gemeinschaftsrecht. Nicht so Hösel/ v. Lersner, § 1 III AbfG, Rdnr. 31. Auf die Bedeutung des Abfallbegriffs für die grenzüberschreitende Abfallentsorgung wird unten in Kapitel B. weiter eingegangen.

93 Vgl. Art. 4 der Richtlinie 75/442/EWG (a.F.).

94 V gl. Art. 6 der Richtlinie 75/442/EWG (a.F.). und unten zum „Planeinwand“ Kapitel A.II.2.d).

95 Vgl. Art. 7 der Richtlinie 75/442/EWG (a.F.).

96 Vgl. Art. 8-10 der Richtlinie 75/442/EWG (a.F.).

97 Vgl. auch 8. Begründungserwägung der Richtlinie 75/442/EWG (a.F.).

98 Vgl. Informationen des BMU Nr. 7/1990/S. 322 und EG-Generalsekretariat, Mitteilungen an die Presse 6715/90 (Presse 81).

99 Voraussichtlicher Art. 5 Abs. 1 der Neufassung der Richtlinie 75/442/EWG. 
mit dem Ziel einer nationalen Entsorgungsautarkie - allerdings unter Beachtung regionaler Besonderheiten. Detaillierte Abfallwirtschaftspläne zur Verwirklichung der gemeinschaftlichen Ziele bei der Abfallentsorgung müssen aufgestellt werden, um eine umweltverträgliche Entsorgung zu gewährleisten. Es werden umfassende Genehmigungs- und Überwachungssysteme insbesondere für das Sammeln, Befördern und Entsorgen von Abfällen gefordert. Soweit ergaben sich keine Änderungen gegenüber dem Vorschlag der Kommission.

Äußerst bedeutsame Abweichungen und Ergänzungen gegenüber dem Vorschlag der Kommission ${ }^{100}$ ergaben sich in folgenden Punkten: Abgestützt wurde die Richtlinie nicht wie vorgesehen auf Art. 100a EWGV, sondern auf Art. 130s EWGV. Die Mitgliedstaaten haben daher die Möglichkeit zur Beibehaltung höherer nationaler Schutzniveaus oder zu deren Verschärfung. Bei einer Abstützung auf Art. 100a EWGV sind die Belange des Umweltschutzes dagegen nur auf Gemeinschaftsebene durchsetzbar.

Bezüglich der Verbringung von Abfällen, für die keine europarechtliche Spezialregelung vorhanden ist ${ }^{101}$, ergibt sich eine Beschränkung der Freizügigkeit bei der Verbringung dergestalt, da $\mathrm{A}$ Abfälle innergemeinschaftlich in der nächstgelegenen angemessenen Entsorgungseinrichtung entsorgt werden müssen ${ }^{102}$. Dies ist für die grenzüberschreitende Abfallentsorgung von erheblicher Bedeutung, da einerseits dadurch die weiträumige Verbringung der nicht von einer speziellen Regelung erfaßten Abfallkategorien eingeschränkt wird, andererseits erscheint die grenzüberschreitende Abfallentsorgung sogar als Pflicht, wenn die nächste geeignete Anlage im europäischen Ausland liegt. Die Mitgliedstaaten werden in der Neufassung der Richtlinie ermächtigt eine Abfallverbringung zu unterbinden, wenn diese der Verwirklichung nationaler Entsorgungspläne zuwiderläuft ${ }^{103}$.

\section{b) Richtlinie des Rates über giftige und gefährliche Abfälle, 78/319/EWG ${ }^{104}$}

In der Richtlinie über giftige und gefährliche Abfälle wurde in Art. 1 lit. a und c auf die entsprechenden Begriffsbestimmungen für Abfälle und Beseitigung der Richt-

100 Vgl. ABl. Nr. C 326/6 vom 30. 12. 1989.

101 Das sind giftige und gefährliche Abfälle, Abfälle aus der Titanoxidproduktion und nach Art. 2 Abs. 1 der Richtlinie 75/442/EWG ausgeschlossene Abfälle.

102 Voraussichtlicher Art. 5 Abs. 2 der Neufassung Richtlinie 75/442/EWG.

103 Voraussichtlicher Art. 5 Abs. 3 der Neufassung Richtlinie 75/442/EWG.

104 Richtlinie des Rates über giftige und gefährliche Abfälle, vom 20.3. 1978, ABl. Nr. L 84 vom 31. 3. 1978, S. 43. 
linie über Abfälle ${ }^{105}$ zurückgegriffen und diese wörtlich übernommen. Die von den Bestimmungen der Richtlinie erfaßten Stoffe werden gemäß Art. 1 lit. b der Richtlinie in einer Liste zusammengestellt. Abfälle, die Stoffe enthalten, welche in dieser Liste verzeichnet sind, unterliegen nach Art. 1 lit. b der Richtlinie diesen Bestimmungen nur dann, wenn die Abfälle diese Stoffe in einer solchen „Beschaffenheit“, „Menge“ oder „Konzentration“ enthalten, daß sie auch eine reale Gefahr für die menschliche Gesundheit darstellen. Den Mitgliedstaaten bleibt wegen dieser nicht weiter präzisierten Formulierung ein relativ großer Regelungsspielraum bezüglich der festzulegenden Grenzwerte.

Durch das Abheben auf solche Begriffe ergibt sich allerdings die illegale aber schwer nachweisbare Möglichkeit, durch Vermischen mit anderen Substanzen oder vergleichbare Maßnahmen - wie beispielsweise Absenkung der Konzentration - die Abfälle diesem Regelungsbereich zu entziehen. Dies ist für grenzüberschreitende Abfallverbringung von grundlegender Bedeutung, da solche „ungefährlichen“ Abfälle aus dem Überwachungs- und Kontrollverfahren der Richtlinie über die grenzüberschreitende Verbringung gefährlicher Abfälle herausfallen ${ }^{106}$.

Strengere Vorschriften der Mitgliedstaaten für giftige und gefährliche Abfälle sind nach Art. 8 der Richtlinie ausdrücklich zulässig, dies schließt auch die Einbeziehung weiterer Stoffe über die im Anhang der Richtlinien aufgezählten hinaus ein.

\section{c) Richtlinie des Rates über die Beseitigung polychlorierter Biphenyle und Terphenyle, 76/403/EWG ${ }^{107}$}

Hinter der Richtlinie über die Beseitigung von $\mathrm{PCB}^{108}$ steht die Absicht, den nach dem Stand der Wissenschaft von PCB zu befürchtenden Gefahren für die menschliche Gesundheit ${ }^{109}$ und die Umwelt vorbeugend zu begegnen. Mittel dazu ist eine Kontrolle aller Stufen der Verwendung ${ }^{110}$ und Beseitigung ${ }^{111}$. Die Mitgliedstaaten

105 Vgl. Art. 1 lit. a und b der Richtlinie 75/442/EWG vom 15. 7. 1975, ABl. Nr. L 194 vom 25. 7. 1975.

106 Vgl. Art. 3 Abs. 3, 4. Gedankenstrich der Richtlinie über die grenzüberschreitende Verbringung gefährlicher Abfälle. Unten Kapitel A.II.2.d).

107 Richtlinie des Rates vom 6.4. 1976 über die Beseitigung polychlorierter Biphenyle und Terphenyle, ABI. Nr. L 108, S. 41.

108 Gleiches gilt auch für PCT.

109 PCB wird vor allem in Transformatoren und Kondensatoren verwendet. Beim Menschen lagert es sich im Fettgewebe, im Nervensystem und in den Keimdrüsen ab. Hierzu ausführlicher Spill in Spill/Wingert (Hrsg.), S. 35-39 m. w. N..

$110 \mathrm{Vgl}$. 3. Begründungserwägung der Richtlinie.

111 Vgl. zum Begriff Beseitigung in diesem Zusammenhang Art. 1 lit. b der Richtlinie. 
haben entsprechend Art. 3 der Richtlinie eine Beseitigungspflicht für PCB und PCB enthaltende Geräte einzuführen. Es soll gemäß Art. 5 der Richtlinie eine unkontrollierte Beseitigung verhindert und eine weitestgehende Wiederverwertung gefördert werden. Dabei liegt es in der Zuständigkeit der Mitgliedstaaten, die institutionellen Grundlagen der Beseitigung zu regeln ${ }^{112}$. Die Besitzer von PCB-haltigen Abfällen müssen, sofern sie nicht selbst eine ausdrückliche Zulassung zur Beseitigung besitzen, die Abfälle zur Verfügung der zugelassenen Entsorger halten. Die Kosten tragen gemä $B$ dem Verursacherprinzip die Besitzer und/oder früheren Besitzer oder auch die Hersteller der PCB enthaltenden Stoffe ${ }^{113}$.

Bei einer grenzüberschreitenden Verbringung von PCB-Abfällen und PCB-haltigen Abfällen finden die Vorschriften gemäß der Richtlinie über die grenzüberschreitende Verbringung gefährlicher Abfälle Anwendung.

\section{d) Richtlinie des Rates über die grenzüberschreitende Verbringung gefährlicher Abfälle, 84/631/:EWG ${ }^{14}$}

Die Richtlinie 84/631/EWG regelt einen besonders sensiblen Bereich der grenzüberschreitenden Abfallentsorgung. Durch diese Richtlinie werden gemäß Art. 1 der Import, der Export sowie der Transit gefährlicher Abfälle ${ }^{115}$ gemäß den Bestimmungen der Richtlinie über giftige und gefährliche Abfälle, (78/319/EWG) und der Richtlinie über die Beseitigung polychlorierter Biphenyle und Terphenyle (76/ 403/EWG) innerhalb der Gemeinschaft und der Export in Drittländer.

\section{aa) Abschließende Wirkung}

Bei der Richtlinie über die grenzüberschreitende Verbringung gefährlicher Abfälle kann davon ausgegangen werden, da $B$ dieser Regelung eine absolute Sperrwirkung zukommt ${ }^{116}$. In diesem Fall ist nicht nur ein Mindeststandard für mitgliedstaatliche

112 Vgl. dazu Art. 6 der Richtlinie.

113 Vgl. Art. 8 der Richtlinie.

114 Richtlinie des Rates vom 6. 12.1984 über die grenzüberschreitende Verbringung gefährlicher Abfälle, ABl. Nr. L 326 vom 13. 12. 1984, S. 31 geändert durch Richtlinie des Rates 86/279/EWG vom 12.6. 1986, ABl Nr. L 181 vom 4. 7. 1986, S. 13 und angepaßt durch Richtlinien der Kommission 85/469/EWG vom 22. 7. 1985, ABl. Nr. L 272 vom 12. 10 1985, S. 1 und 87/112/EWG vom 23. 12. 1986, ABl. Nr. L 48 vom 17. 2. 1987, S. 31.

115 Vgl. zur Festlegung der erfaßten Stoffe durch Richtlinie 78/319/EWG (siehe oben Kapitel A.II.2.b) und Richtlinie 76/403/EWG (siehe oben Kapitel A.II.2.c).

116 Bejahend v. Wilmowsky, S. 14-15; a.A. Holtmeier, vgl. S. 122-134. 
Regelungen gesetzt, sondern es sind damit auch strengere nationale Regelungen ausgeschlossen. Absolute Sperrwirkung kommt nach der Rechtsprechung des EuGH ${ }^{117}$ einer Vollharmonisierung ${ }^{118}$ zu, die vor Inkraftsetzung der Einheitlichen Europäischen Akte 1987 auf der Grundlage des Art. 100 EWGV erfolgt ist ${ }^{119}$. Die Sperrwirkung ist aber an bestimmte Voraussetzungen gebunden ${ }^{120}$. So wird gefordert, daß die betreffende Materie durch die Richtlinie erschöpfend geregelt ist. Das bedeutet insbesondere, daß Vorschriften vorhanden sein müssen, die den angestrebten Schutz der Schutzgüter ${ }^{121}$ gewährleisten und daß gemeinschaftliche Verfahren zur Überwachung vorgesehen sind.

Für die Auffassung, daß im Fall der grenzüberschreitenden Verbringung gefährlicher Abfälle der Richtlinie eine abschließende Wirkung zukommt, sprechen folgende Sachverhalte und Hintergründe: Die Aktivitäten der Rechtsetzung auf Gemeinschaftsebene müssen vor dem Hintergrund des vorangegangenen zeitweisen Verschwinden von 41 Fässern mit dioxinverseuchten Abfällen der Umweltkatastrophe im italienischen Seveso gesehen werden ${ }^{122}$. Aus diesem Grund erscheint es plausibel, da $B$ hier eine umfassende Gemeinschaftsregelung geschaffen werden sollte, welche die potentiellen Risiken, die sich aus einer grenzüberschreitenden Verbringung gefährlicher Abfälle ergeben können, möglichst vollständig erfaßt. Diesem Regelungsbedarf durch individuelle mitgliedstaatliche Aktivitäten gerecht zu werden, erscheint hier auch unwahrscheinlich, da nationale Regelungen und Überwachungsmaßnahmen naturgemäß auf das jeweilige Territorium beschränkt sind. Die Überwachungsdefizite, die durch das Verschwinden der Seveso-Fässer deutlich wurden, können so nicht beseitigt werden. Die in diesem Zusammenhang notwendige durchgängige Überwachung und zwischenstaatliche Zusammenarbeit ist in der Regel äußerst schwierig. Ein weiterer Hinweis auf den beabsichtigten abschließenden Charakter der Richtlinie ist das völlige Fehlen einer Ermächtigung an die Mitgliedstaaten für weitere Schutzmaßnahmen.

117 Grundlegend hierzu Rs. 5/77 - Tedeschi, Slg. 1977/1555, Unberührt von dieser Sperrwirkung bleibt selbstverständlich eine in der Richtlinie selbst festgelegte Ermächtigung der Mitgliedstaaten zu strengeren einzelstaatlichen Regelungen.

118 Vgl. zu den Intensitätsstufen von Harmonisierungsmaßnahmen, Pernice, NVwZ 1990, S. 201, 201-207.

119 Die Richtlinie ist auf Art. 100 und Art. 235 EWGV gestützt.

120 Vgl. ausführlich zu den Voraussetzung Rs. 5/77 - Tedeschi, Slg. 1977/1555.

121 Vgl. zu den Schutzgütern die 2. Begründungserwägung der Richtlinie und Art. 1 der Richtlinie.

$122 \mathrm{Vgl}$. zu der damaligen Diskussion um die rechtspolitischen Konsequenzen aus diesen Vorgängen, Schneider, UPR 1983, S. 253, 253-256. 


\section{bb) Notifizierungsverfahren}

Wesentlicher Bestandteil der Richtlinie ist das Notifizierungsverfahren, es sieht in seinen Grundzügen so aus: Beabsichtigt der Besitzer ${ }^{123}$ von gefährlichen Abfällen, diese in einen anderen Mitgliedstaat der Gemeinschaft zu verbringen, so sind die zuständigen Behörden ${ }^{124}$ des Versand- und des Empfängerstaates und gleichermaBen die des oder der Transitstaaten zu benachrichtigen. Die Notifizierung, d.h. die Unterrichtung erfolgt mit Hilfe eines einheitlichen Begleitscheins; auf diesem werden alle für das Verfahren notwendigen Angaben festgehalten. Auf dem Begleitschein wird auch die Empfangsbestätigung eingetragen.

Der Adressat des Begleitscheins und damit gleichzeitig der alleinig zur Bestätigung berechtigte Staat bestimmt sich nach Art. 4 Abs. 2 der Richtlinie. Bei der Verbringung innerhalb des Gebiets oder in das Gebiet der Gemeinschaft sind die zuständigen Behörden des Bestimmungsmitgliedstaates Aussteller der Empfangsbestätigung. Für den reinen Transit durch das Gemeinschaftsgebiet liegt die Bestätigungskompetenz bei den zuständigen Behörden des letzten von der Verbringung berührten Mitgliedsstaates. Eine Verbringung aus der Gemeinschaft wird durch die Bestätigung der Behörden des Versandmitgliedstaates ermöglicht; sofern jedoch die Abfälle in einem an den letzten Transitmitgliedstaat angrenzenden Drittstaat beseitigt werden sollen, kann dieser Mitgliedstaat nach Art. 4 Abs. 2 der Richtlinie die Bestätigungskompetenz an sich ziehen.

Dem bestätigenden Mitgliedstaat steht als einzigem das Recht zu, Einwände gegen die Verbringung geltend zu machen. Diese Einwände müssen aber entsprechend der in Art. 4 Abs. 3 der Richtlinie festgelegten Weise begründet sein. Nach Art. 6 der Richtlinie besteht seitens des Versandmitgliedstaates und der Transitmitgliedstaaten die Möglichkeit, durch die zuständigen Behörden Auflagen für die Beförderung auf dem jeweiligen Hoheitsgebiet festzulegen. Diese Auflagen dürfen keinesfalls über das $\mathrm{Ma} B$ hinausgehen, das bei vergleichbaren Inlandstransporten gefordert wird (Art. 4 Abs. 6 der Richtlinie). Außerdem legen die zuständigen Behörden der Mitgliedstaaten die Grenzübergangsstellen fest, über die Transporte abgewickelt werden dürfen ${ }^{125}$. Der Versandmitgliedstaat hat darüber hinaus die Möglichkeit, den Einwand geltend zu machen, daß die Verbringung der Abfälle der Verwirklichung der nationalen Abfallentsorgungspläne entgegensteht.

123 Die Regelung knüpft beim Besitzer und nicht beim Eigentümer an, siehe Art. 3 der Richtlinie.

124 Benannt gemäß Art. 16 der Richtlinie und veröffentlicht in der Liste der zuständigen Behörden, siehe auch unten Kapitel A.III.1.b)cc).

125 Vgl. Art. 9 der Richtlinie. 
Die Umsetzung ${ }^{126}$ der Richtlinie 84/631/EWG in das nationale Recht der Bundesrepublik Deutschland erfolgte auf der Grundlage des § 13c AbfG durch die Verordnung über die grenzüberschreitende Verbringung von Abfällen ${ }^{127}$.

Da die Regelungen der grenzüberschreitenden Verbringung von gefährlichen Abfällen der Richtlinie 84/631/EWG die zentralen Bestimmungen für die grenzüberschreitende Entsorgung giftiger und gefährlicher Abfälle in der Europäischen Gemeinschaft darstellen, ist es erforderlich, die Zulässigkeit von Genehmigungsverfahren und -erfordernissen für Ausfuhr, Transit und Einfuhr einzeln zu untersuchen. Darüber hinaus ist es notwendig, die Frage der Möglichkeit der Einwandserhebung durch die betroffenen Mitgliedstaaten ausführlicher zu betrachten.

\section{aaa) Einfuhr giftiger und gefährlicher Abfälle}

Die Möglichkeit, die Einfuhr giftiger und gefährlicher Abfälle aus einem EGMitgliedstaat seitens der Mitgliedstaaten einem zusätzlichen über die Bestimmungen des Notifizierungsverfahrens hinausgehenden Genehmigungsverfahren zu unterwerfen, besteht nicht. Die Richtlinie sieht als abschließende Regelung der innergemeinschaftlichen Verbringung giftiger und gefährlicher Abfälle das Notifizierungsverfahren vor. Jede inhaltliche Abweichung von diesem Verfahren ist nicht mit der Richtlinie vereinbar ${ }^{128}$ und damit auch jedes darüber hinausgehende Genehmigungsverfahren bzw. -erfordernis.

Der Bestimmungsmitgliedstaat kann aber nach Art. 4 Abs. $2^{129}$ Einwände gegen die Verbringung giftiger und gefährlicher Abfälle zur Beseitigung auf seinem Staatsgebiet erheben. Diese Einwände sind gemäß Art. 4 Abs. 3 der Richtlinie, mit ,,.. Rechts- und Verwaltungsvorschriften zum Schutz der Umwelt, zur Wahrung der Sicherheit und der öffentlichen Ordnung oder zum Schutz der Gesundheit zu begründen ...“. Sie müssen „... mit anderen gemeinschaftlichen ... Rechtsakten in Einklang stehen“. Damit sind zwar die Begründungsmöglichkeiten eines Einwandes

126 Es wird allerdings bei v. Wilmowsky, S. 20 und Pernice, NVwZ 1990, S. 414, 417, Fn. 3 die Frage aufgeworfen, ob bei der Umsetzung der Richtlinie in das Recht der Bundesrepublik Deutschland in $\S 7$ AbfVerbrV vorgenommene Gleichsetzung des Notifizierungsverfahrens mit einem Genehmigungsverfahren eine korrekte Umsetzung darstellt. Dies wird von v. Wilmowsky verneint. Vgl. ebenda S. 24-25.

127 Vgl. unten A.III.1.b)cc).

128 So auch v. Wilmowsky, S. 24 m. w. N..

$129 \mathrm{Vgl}$. dazu die Formulierung in der 9. Begründungserwägung der Richtlinie. 
genannt, doch eine ausreichende Präzisierung des möglichen Inhalts eines Einwandes stellt dies noch nicht dar ${ }^{130}$.

Einen Anhaltspunkt für den Inhalt zulässiger Einwände bietet Art. 3 Abs. 3 der Richtlinie. Dort sind die Mindestanforderungen an die Informationen aufgeführt, die im Rahmen der Notifizierung vom Abfallbesitzer an die zuständigen Behörden des Bestimmungsmitgliedstaates übermittelt werden müssen. Eine Verweigerung der Notifizierung und damit der Einfuhr kann durch den Bestimmungsmitgliedstaat erfolgen, wenn der Empfänger, der die Abfälle beseitigen soll, über keine „angemessene technische Kapazität" verfügt, diese Abfälle ohne Gefährdung der menschlichen Gesundheit und der Umwelt zu beseitigen, oder die Anlage keine Zulassung besitzt (Art. 3 Abs. 3, 4. Gedankenstrich der Richtlinie). Neben diesen gesicherten Einwänden erlaubt Art. 4 Abs. 3 dem Bestimmungsmitgliedstaat weitere Einwände, die anhand von Rechtsvorschriften des Gesundheits- und Umweltschutzes zu begründen und inhaltlich auszugestalten sind.

Der Wortlaut des Art. 4 Abs. 3 läßt verschiedene Auslegungen zu. Sie reichen von einer Zulässigkeit nur solcher Einwände, die unterschiedslos für giftige und gefährliche Abfälle aus dem Inland und aus anderen Mitgliedstaaten gelten, bis zu einem Einfuhrverbot mit Erlaubnisvorbehalt ${ }^{131}$. Bei der Interpretation der Richtlinie sind je nach Bestimmungsort der Abfälle (und den dortigen Entsorgungsstandards) unter Umständen unterschiedlich enge oder weite Auslegungen sinnvoll, die jede für sich gesehen plausibel erscheinen. Eine weite Auslegung könnte zur Folge haben, daß ein generelles Einfuhrverbot durch jeden Mitgliedstaat ausgesprochen werden könnte, begründbar damit, daß die Beseitigung von giftigen und gefährlichen Abfällen nahezu immer Umweltbelastungen zur Folge hat. Ein generelles Einfuhrverbot lag aber wohl nicht in der Absicht des Richtliniengebers. In der 6. Begründungserwägung formuliert er, daß es um die Schaffung eines „effizienten und kohärenten Überwachungs- und Kontrollsystems" geht. Es wird in der 3. Begründungserwägung ausdrücklich anerkannt, daß eine grenzüberschreitende Verbringung notwendig sein kann, um die bestmögliche Entsorgungsmöglichkeit zu nutzen. Dieser Weg wäre aber bei faktischen Einfuhrverboten abgeschnitten. Andererseits läßt sich daraus nicht die Absicht oder gar eine Verpflichtung zur Schaffung eines gemeinsamen Entsorgungsmarktes für giftige und gefährliche Abfälle in der EWG ableiten ${ }^{132}$. Auch der Versuch aus den Zielen, die mit der Richtlinie verfolgt wurden, eine Auslegung bezüglich des Art. 4 Abs. 3 herzuleiten, führt zu keinem befriedigenden

130 So auch v. Wilmowsky, S. 26.

131 Vgl. v. Wilmowsky, S. 27.

132 Vgl. v. Wilmowsky, S. 31-34. 
Ergebnis. Damit ist für die Konkretisierung des Inhalts zulässiger Einwände gegen eine Einfuhr von gefährlichen Abfällen der EWG-Vertrag heranzuziehen, dies erfolgt im Rahmen der Beurteilung von Maßnahmen zur Beschränkung der innergemeinschaftlichen Abfallverbringung im Kapitel B..

\section{bbb) Transit giftiger und gefährlicher Abfälle}

Einem Transitmitgliedstaat steht bei der innergemeinschaftlichen Verbringung von giftigen und gefährlichen Abfällen nicht das Recht zu, Einwände zu erheben ${ }^{133}$. Selbst wenn ein Mitgliedstaat Einwände erheben würde, könnte er die Bestätigung der Notifizierung nicht verweigern, da die Bestätigung durch den Bestimmungsmitgliedstaat erfolgt. Damit kann ein Transitmitgliedstaat die Durchfuhr durch sein Territorium in einen anderen Mitgliedstaat nur dann versagen, wenn keine Notifizierungsbestätigung des Bestimmungsmitgliedstaates vorliegt.

Den Transportvorgang als solchen kann der Transitmitgliedstaat auf seinem Staatsgebiet nach Art. 4 Abs. 6 UAbs. 1 Satz 1 der Richtlinie mit Auflagen belegen. Diese Auflagen dürfen allerdings nicht strenger sein, als für vergleichbare Transporte innerhalb seines Staatsgebietes. Die Beschränkung der Möglichkeiten des Transitmitgliedstaates auf die Aufstellung von Transportauflagen schließt auch eine Genehmigungspflicht der Beförderung ein ${ }^{134}$. Die Berechtigung der Mitgliedstaaten, die Auflagen gemäß Art. 6 der Richtlinie 84/631/EWG als Genehmigungserfordernis auszugestalten, ergibt sich aus Art. 8 der Richtlinie 78/319/EWG. In der Richtlinie 78/319/EWG über giftige und gefährliche Abfälle wird den Mitgliedstaaten ausdrücklich das Recht eingeräumt, für diese Abfälle strengere als die in dieser Richtlinie enthaltenen Vorschriften zu erlassen. Beziehen kann sich dies nur auf solche Vorschriften, die nicht von der Richtlinie 84/631/EWG als Spezialvorschrift erfaßt sind. Damit kann der Inhalt von Transportauflagen und Genehmigungspflichten nur technische Aspekte des Transportes und Fragen der Transportwege regeln.

Die Überwachung der Einhaltung von Transportauflagen der Transitmitgliedstaaten wie auch des Versandstaates obliegt nach Art. 3 Abs. 3, 2. und 3. Spiegelstrich den für die Notifizierungsbestätigung zuständigen Behörden des Bestimmungsmitgliedstaates. Bei einer Nichterfüllung der Auflagen der Richtlinie 84/631/EWG müssen demnach diese Behörden die Bestätigung der Notifizierung verweigem.

133 Vgl. Präambel der Richtlinie 84/631/EWG, 9. und 11. Begründungserwägung.

134 Hoschützky/Kreft § 12 AbfG, Anm. 0.2.. 


\section{ccc) Ausfuhr giftiger und gefährlicher Abfälle}

Die Ausfuhr giftiger und gefährlicher Abfälle aus einen EG-Mitgliedstaat in einen anderen Mitgliedstaat von einem Genehmigungsverfahren abhängig zu machen, ist gemeinschaftsrechtlich unzulässig. Die abschließende Regelungen der Richtlinie 84/631/EWG über die Verbringung gefährlicher Abfälle erlaubt keine inhaltlichen Abweichungen (inbesondere Genehmigungsverfahren bzw. -erfordernisse).

Mitgliedstaaten der EWG, aus denen Abfall exportiert werden soll, wird nach Maßgabe der Richtlinie 84/631/EWG ebenfalls das Recht zugebilligt, Transportauflagen zu erheben. Die Bestimmungen der Richtlinie hierzu entsprechen denen zu Transitauflagen eines Mitgliedstaates, so da $B$ diesbezüglich auf die Ausführungen des vorherigen Kapitels verwiesen werden kann.

Welche Einwände dem Versandmitgliedstaat bei der Verbringung giftiger und gefährlicher Abfälle in einem anderen Mitgliedstaat zustehen, bestimmt sich aus Art. 4 Abs. 6 UAbs. 2 der Richtlinie. Dieser Artikel sieht vor, daß der Versandmitgliedstaat den Einwand erheben kann, wenn die Verbringung die Verwirklichung eines nach Art. 12 der Richtlinie über giftige und gefährliche Abfälle erstellten Beseitigungsplans beeinträchtigt. Allerdings ist der Wortlaut der Richtlinie im Hinblick auf andere Einwände interpretationsfähig. Der Versandmitgliedstaat kann - so der Wortlaut $-\ldots$... auch als Einwand geltend machen ...“, die Verbringung liefe einem Beseitigungsplan zuwider ${ }^{135}$ (Planeinwand). Der Rückgriff auf die 11. Begründungserwägung trägt nicht zu mehr Klarheit bei. Dort heißt es: „Desweiteren muß in bestimmten Situationen und unter bestimmten Voraussetzungen der Versandmitgliedstaat gegen die Verbringung Einwände erheben können“. Welche Voraussetzungen dies sind und zu welchen Einwänden sie den Versandmitgliedstaat berechtigen, ist aber weder in der Präambel der Richtlinie 84/631/EWG zu erkennen, noch in den Richtlinienartikeln selbst eindeutig konkretisiert - abgesehen vom Planeinwand. Das gewichtigste Argument gegen die Einräumung einer Einwendungsmöglichkeit ist, daß der Einwand mit der Begründung, es sei bei der Beseitigung in einem angrenzenden Bestimmungsmitgliedstaat eine grenzüberschreitende Umweltbelastung zu befürchten ${ }^{136}$, Transitmitgliedstaaten eben gerade verwehrt ist ${ }^{137}$. Diese im zweiten Vorschlag der Kommission zur Richtlinie

135 Art. 4 Abs. 6 UAbs. 2 Satz 2 der Richtlinie, Hervorhebung vom Verf..

$136 \mathrm{Vgl}$. 13 Abs. 1 Satz 2 Nr. 4 Buchstabe $c$ und Nr. 5 AbfG und $\S 11$ Abs. 1 AbfVerbrV, die eine solche Genehmigungsvorausetzung vorsieht.

137 So auch v. Wilmowsky S. 48 der zusätzlich noch eine Begründung am Wortlaut der Richtlinie 84/631/EWG versucht. 
84/631/EWG ${ }^{138}$ noch vorgesehene Einspruchsmöglichkeit ist in der gültigen Fassung der Richtlinie nicht enthalten. Solche Widerspruchsrechte hielt der Richtliniengeber beim Transit giftiger und gefährlicher Abfälle für nicht erforderlich ${ }^{139}$.

Die Begründung erscheint allerdings dann fragwürdig, wenn es zutrifft, da $ß$ der Gemeinschaftsgesetzgeber davon ausgegangen wäre, der Transitmitgliedstaat sei von den mit der Beseitigung verbundenen Umweltbelastungen nicht betroffen ${ }^{140}$. Das kann sehr wohl der Fall sein und dürfte als einer der Hauptgründe anzusehen sein, warum der letzte Transitmitgliedstaat bei einer Beseitigung giftiger und gefährlicher Abfälle in einem an sein Territorium angrenzenden Drittstaat die Bestätigungskompetenz an sich ziehen kann ${ }^{141}$. Unter diesem Gesichtspunkt ist dann allerdings schwer nachvollziehbar, warum das gleiche Recht innergemeinschaftlich dem letzten Transitmitgliedstaat nicht zugebilligt werden soll und damit selbstverständlich auch einem direkt angrenzenden Versandmitgliedstaat. Die Verweigerung des Rechts, den Einwand der grenzüberschreitenden Umweltbelastung zu erheben, wäre allenfalls aus zwei Gründen möglich: Erstens der Gemeinschaftsgesetzgeber steht auf dem Standpunkt, die gemeinschaftsrechtlichen Mindeststandards des Umweltschutzes würden diesen Einwand abschneiden. Die zweite, sehr viel wahrscheinlichere Möglichkeit ist, daß das im EWG-Vertrag verankerte Diskriminierungsverbot den Mitgliedstaaten bei grenzüberschreitenden Umweltbeeinträchtigungen materielle Abwehrrechte gewährt. Eine solche Möglichkeit besteht im Gegensatz dazu bei der Beseitigung in angrenzenden Drittstaaten nicht .

Da all diese Überlegungen nur spekulativ bleiben können, sind aus dem primären Gemeinschaftsrecht Kriterien zu entwickeln, nach denen die Bestimmungen der Richtlinie auszulegen wären. Dazu ist als Vorbedingung zu klären, ob giftige und gefährliche Abfälle bzw. deren Entsorgung dem Gebot des EWG-Vertrags zur wirtschaftlichen Integration unterliegen. Diese Frage ist aber bislang nicht abschließend geklärt. Daher erscheint es hier sinnvoll, mitgliedstaatliche Maßnahmen der Ausfuhrbeschränkung, die nicht sicher durch die Richtlinie 84/631/EWG begründbar sind, in diesem Zusammenhang in Kapitel B. zu prüfen.

Der in Art. 4 Abs. 6 UAbs. 2 der Richtlinie ausdrücklich erwähnte Planeinwand gibt dem Versandmitgliedstaat das Recht, den Einwand zu erheben, die Verbringung beeinträchtige die Verwirklichung eines nach Art. 12 der Richtlinie über giftige und

138 Zweiter Vorschlag der Kommission für eine Richtlinie über giftige und gefährliche Abfälle, ABl. Nr. C 176 vom 4. 7. 1983, S. 4, Bemerkungen zu Art. 5.

139 v. Wilmowsky, S. 48.

140 So bei v. Wilmowsky, S. 48.

141 Vgl. Art. 4 Abs. 2 UAbs. 2 der Richtlinie. 
gefährliche Abfälle erstellten Beseitigungsplans. Was aber der Inhalt eines solchen Planes sein darf, ist EG-rechtlich bislang noch nicht konkretisiert. Die Mindesterfordernisse lassen sich aus Art. 12 der Richtlinie über giftige und gefährliche Abfälle ableiten. Art. 8 der genannten Richtlinie ermächtigt die Mitgliedstaaten ausdrücklich zu strengeren Maßnahmen und damit auch zu weiteren Planbestandteilen. Die Frage, ob dies eine Verlagerung von generellen Ausfuhrverboten in Abfallentsorgungspläne für giftige und gefährliche Abfälle zuläßt, kann nicht aus den Richtlinienbestimmungen geklärt werden und ist daher an der Beurteilung von Ausfuhrbeschränkungen am primären Gemeinschaftsrecht zu entscheiden ${ }^{142}$.

Zusammenfassend läßt sich die Richtlinie 84/631/EWG so beurteilen: Die Bestimmung zur direkten Überwachung und Kontrolle grenzüberschreitender Beseitigung giftiger und gefährlicher Abfälle sind für diesen Bereich als abschließend anzusehen, weil, wie vom EuGH als Voraussetzung dafür gefordert, eine erschöpfende Regelung der Materie unterstellt werden kann. Gleiches gilt für die Transportauflagen hinsichtlich der Sicherheit und Streckenführung. Bei den Regelungen zu Einwänden sind dagegen aufgrund der oben geschilderten Zuordnungsprobleme bleiben zumindest $Z$ weifel ${ }^{143}$. Die Unklarheiten ergeben sich in erster Linie im Zusammenhang mit der Frage der Rechtfertigung von Aus- und Durchfuhrverboten aufgrund zu befürchtender rückwirkender Umweltbelastungen. Diese Rechtfertigung dürfte bei der Entsorgung in einem EG-Staat aufgrund des im EWG-Vertrag verankerten Diskriminierungsverbot nicht gegeben sein. EG- Mitgliedstaaten werden bei innergemeinschaftlichen grenzüberschreitenden Umweltverschmutzungen materielle Abwehrrechte eingeräumt, die sie im Interfraktionsverfahren vor dem Europäischen Gerichtshof durchsetzen können. Auslegungsmaßstab für die interpretationsbedürftigen Richtlinienbestimmungen ist das primäre Gemeinschaftsrecht.

\section{e) Richtlinie des Rates über Abfälle aus der Titanoxid-Produktion, 78/176/EWG ${ }^{144}$}

Diese gemeinschaftsrechtliche Regelung wurde geschaffen, um die Verschmutzungen der Umwelt durch im Zusammenhang mit der Titanoxidproduktion anfallende

142 Vgl. dazu unten Kapitel B..

143 v. Wilmowsky geht auch diesbezüglich von einer abschließenden Regelung aus (vgl. dort S. 24); a.A. ist Holtmeier, der offenbar zumindest für die Einwände des Versandmitgliedstaates keine abschließende Regelung annimmt (vgl. dort S. 134).

144 Richtlinie des Rates über Abfälle aus der Titanoxid-Produktion vom 20. 2. 1978, ABl. Nr. L 54 vom 25. 2. 1978, S. 19. 
Abfälle schrittweise bis zur völligen Beseitigung zu verringern ${ }^{145}$. Bis dieses Ziel erreicht ist, regelt die Richtlinie die Entsorgung der Abfälle.

Nach Art. 4 Abs. 1 Satz 1 der Richtlinie 78/176/EWG sind das Einleiten, das Versenken, das Lagern, die Ablagerung und das Einbringen von Abfällen aus der Titanoxidproduktion genehmigungsbedürftig. Die Genehmigung ergeht durch die zuständigen Behörden des Mitgliedstaates, auf dessen Gebiet der Abfall anfällt und gegebenenfalls zusätzlich durch die Behörden des Mitgliedstaates, auf oder von dessen Gebiet aus die endgültige Beseitigung geschehen soll. Damit unterliegt die grenzüberschreitende Verbringung und Entsorgung von Abfällen aus der Titanoxidproduktion nicht dem Notifizierungsverfahren entsprechend der Richtlinie über die grenzüberschreitende Verbringung gefährlicher Abfälle (84/631/EWG). Eine grenzüberschreitende Beseitigung erfordert die Erteilung zweier Genehmigungen. Diese Genehmigungen können von den zuständigen Behörden der betroffenen Mitgliedstaaten unter den in Art. 6 und Art. 7 der Richtlinie 78/176/EWG aufgezählten Vorausetzungen erteilt werden. Ein Anspruch auf Erteilung einer Genehmigung besteht dabei generell nicht.

In Art. 12 der Richtlinie über Abfälle aus der Titanoxid-Produktion wird den Mitgliedstaaten grundsätzlich freigestellt, strengere Vorschriften als die in der genannten Richtlinie zu erlassen. Die Regelungen der Richtlinie 78/319/EWG stellen also lediglich den Mindeststandard fest und mitgliedstaatliche Ein- und Ausfuhrverbote widersprechen nicht dieser Richtlinie.

\section{f) Zusammenfassender Überblick über das Abfallrecht der EG}

Das vierte Aktionsprogramm der Europäischen Gemeinschaft ${ }^{146}$ formuliert drei Ziele der Abfallwirtschaftspolitik, die ihren Niederschlag in Art. 3 Abs. 1 der (Rahmen-)Richtlinie über Abfälle gefunden haben. Die Entstehung von Abfällen soll vermieden werden. Abfälle sollen verwertet werden, nicht vermeidbare und verwertbare Abfälle sollen sicher und umweltverträglich beseitigt werden ${ }^{147}$. Dadurch sollen die Risiken für Mensch und Umwelt, die von Abfällen selbst ausgehen bzw. im Zusammenhang mit ihrer Entsorgung entstehen, auf ein Minimum

145 Art. 1 Abs. 1 der Richtlinie 78/176/EWG; vgl. auch erste Begründungserwägung dieser Richtlinie.

146 4. Aktionsprogramm der Europäischen Gemeinschaften, ABl. 1987 Nr. C 328, S. 32.

147 Vgl. 2. Aktionsprogramm der Europäischen Gemeinschaften, ABl. 1977 Nr. C 139, S. 33-34 und 4. Aktionsprogramm der Europäischen Gemeinschaften, ABl. 1987 Nr. C 328, S. 32. 
begrenzt werden. Insbesondere stehen dabei die Transportrisiken sowie die Überwachungs- und Kontrollprobleme bei der grenzüberschreitenden Verbringung im Blickpunkt des Gemeinschaftsgesetzgebers. Die angestrebte Rückgewinnung von Rohstoffen bedingt darüber hinaus zusätzlich eine Ressourcenschonung. Die Reihenfolge von Vermeidung, Verwertung und Beseitigung ist dabei als Prioritätenfolge anzusehen ${ }^{148}$. Diese Ziele sollen durch die Anwendung verschiedener Mittel erreicht werden. Neben den in den vorangegangenen Kapiteln dargestellten Richtlinien, die kontinuierlich fortentwickelt werden sollen ${ }^{149}$, sind dies insbesondere Aufklärungsaktionen sowie Forschungs- und Förderungsprogramme ${ }^{150}$.

Die Untersuchung der Abfallrichtlinien auf ihren systematischen Zusammenhang und den Regelungsumfang hin ergibt, daß seitens der Gemeinschaft der Anspruch besteht, ein umfassendes Regelungsgebäude zu schaffen. Die Richtlinien 75/442/ EWG über Abfälle und 79/319/EWG über giftige und gefährliche Abfälle bilden den Rahmen zur Erfassung nahezu aller Abfälle ${ }^{151}$. Dieser Rahmen kann später durch Einzelrichtlinien ausgefüllt werden. Für die grenzüberschreitende Verbringung giftiger und gefährlicher Abfälle ist bereits von einer abschließenden Gemeinschaftsregelung auszugehen ${ }^{152}$.

Das in den Richtlinien der Europäischen Gemeinschaft vorgesehene Instrumentarium läßt sich verkürzt so beschreiben: Es umfaßt die „... A ufstellung detaillierter Abfallwirtschaftspläne ${ }^{153}$ zur Verwirklichung der Ziele der Abfallvermeidung sowie der Abfallverwertung und -entsorgung, ohne daß die menschliche Gesundheit gefährdet und die Umwelt geschädigt wird“ und den „... Aufbau umfassender Ge-

148 Siehe Entschließung des Rates vom 7. Mai - Uber die Abfallpolitik, ABL. Nr. C 122, vom 18. 5. 1990, S. 2 Nr. 1 und S. 3 Nr. 4 und 5; Geänderter Vorschlag für eine Richtlinie des Rates zur Änderung der Richtlinie 75/442/EWG, ABl. Nr. C 326/6, vom 30. 12. 1989 und Schröder, WiVerw, S. 118, 121.

149 Vorschlag zur Änderung der Richtlinie 78/319/EWG über giftige und gefährliche Abfälle, ABl. Nr. C 295 vom 19. 11. 1988, S. 8; Vorschlag für eine Richtlinie über die zivilrechtliche Haftung für durch Abfälle verursachte Schäden, ABl. Nr. C 251 vom 4. 10. 1989, S. 3; Vorschlag für eine Richtlinie zur Beseitigung der polychlorierten Biphenyle und polychlorierten Terphenyle, ABl. Nr. C 319 vom 12. 12. 1988, S. 57; Vorschlag für eine Richtlinie betreffend gefährliche Stoffe enthaltende Batterien und Akkumulatoren, ABl. Nr. C 11 vom 17. 1. 1990, S. 6.

150 Vgl. Entschließung des Rates vom 7. Mai - Über die Abfallpolitik, ABl. Nr. C 122, vom 18. 5. 1990, S. 2-4 und Schröder, WiVerw 1990, S. 118, 121.

151 Ausnahmen in Art. 2 lit. a-g der Richtlinie 74/442/EWG und Art. 3 der Richtlinie 78/319/EWG.

152 Vgl. oben Kapitel A.II.2.d)aa).

153 Vgl. oben Kapitel A.II.2.a) und b). 
nehmigungs- und Überwachungssysteme insbesondere für Sammlung, Beförderung und Entsorgung von Abfällen"154.

\section{Recht der Abfallentsorgung in der Bundesrepublik Deutschland}

Das bundesdeutsche Abfallrecht ist öffentliches Recht. Es dient dabei im gleichen Maße der öffentlichen Daseinsvorsorge wie auch der Gefahrenabwehr. Die verfassungsrechtliche Grundlage des Abfallrechts wird durch Art. 74 Nr. 24 GG gelegt. Danach wird dem Bund die spezifische Zuständigkeit zur konkurrierenden Gesetzgebung auf dem Gebiet der Abfallbeseitigung übertragen. Dies bedeutet, daß solange und soweit der Bund von seiner Gesetzgebungskompetenz keinen Gebrauch macht, die Länder das Recht zur Gesetzgebung haben.

Das Abfallrecht ist bundeseinheitlich im „Gesetz über die Vermeidung und Entsorgung von Abfällen“155 und soweit der Bundesgesetzgeber von seinem Gesetzgebungsrecht keinen Gebrauch gemacht hat, in den jeweiligen Landesgesetzen zur Ausführung des Abfallgesetzes gesetzlich geregelt. Für die Entsorgung von industriellen Abfällen ist teilweise auch das Bundes-Immissionsschutzgesetz maßgeblich. Darüber hinaus bestehen abfallrechtliche Rechtsverordnungen und Verwaltungsvorschriften, die auf Grundlage dieser gesetzlichen Regelungen sowie des EGRechts erlassen worden sind.

\section{Bundesrecht}

Das bundesdeutsche Abfallrecht setzt sich zusammen aus Gesetzen, Rechtsverordnungen sowie Verwaltungsverfahrensvorschriften und Technischen Anleitungen. Im Abfallrecht des Bundes ist zudem die zur Erlangung der unmittelbaren innerstaatlichen Geltung erforderliche Umsetzung von Richtlinien der EWG erfolgt ${ }^{156}$.

154 Töpfer (Hrsg.), S. 332-333, Hervorhebungen durch d. Verf..

155 Gesetz über die Vermeidung und Entsorgung von Abfällen (Abfallgesetz - AbfG) vom 27. 8. 1986, BGB1. I S. 1410 zuletzt geändert durch Gesetz vom 12. 2. 1990, BGB1. I S. 205.

156 Vgl. unten Kapitel A.III.1.a)aa). 


\section{a) Gesetze}

Als wichtigstes Gesetz auf dem Gebiet des Abfallrechts ist das Abfallgesetz zu nennen. Es ist das Rahmengesetz für die Regelungen zur Abfallentsorgung und Abfallwirtschaft. Neben dem Abfallgesetz wird das Bundes-Immissionsschutzgesetz im Rahmen der Untersuchung in zweierlei Hinsicht in die Betrachtung einbezogen. Zum einen ist die Abgrenzung zwischen Abfällen und Reststoffen im Zusammenhang mit den Betrachtungen zur möglicherweise vorliegenden Relevanz der Bestimmungen des EWG-Vertrages zum freien Warenverkehr ${ }^{157}$ von Bedeutung. Zum anderen wurde durch das Dritte Änderungsgesetz zum Bundes-Immissionsschutzgesetz $^{158}$ eine Regelung in das Gesetz neu aufgenommen, welche die Verwertung oder Behandlung von Abfällen in genehmigungsbedürftigen Anlagen ermöglicht, die überwiegend einem anderem Zweck als der Abfallentsorgung dienen. Diese Umgestaltung des Bundes-Immissionsschutzgesetzes ist in die Prüfung von Bereichsausnahmen $^{159}$ von der Dienstleistungsfreiheit des EWG-Vertrages mit einzubeziehen.

\section{aa) Abfallgesetz (AbfG)}

Das neue Abfallgesetz des Bundes ist seit dem 1. 11. 1986 in Kraft. Es löste das „Gesetz über die Beseitigung von Abfällen“ ab, dessen Grundstruktur aber erhalten blieb. Bereits der Name des Gesetzes ist programmatisch. Durch den Titel „Gesetz über die Vermeidung und Entsorgung von Abfällen" macht der Gesetzgeber deutlich, daß er beabsichtigt, der Abfallvermeidung sowie der Verwertung nicht vermeidbarer Abfälle Vorrang vor der Abfallbeseitigung zu geben. Der Begriff der Abfallentsorgung umfaßt nun neben der Abfallbeseitigung auch die Verwertung von Abfällen sowie die Abfallvermeidung. Die Abfallentsorgung umfaßt das Einsammeln, Befördern, Lagern und Ablagern von Abfällen.

\section{aaa) Abfallbegriff}

Das Abfallgesetz gilt grundsätzlich für alle Abfälle, soweit diese nicht ausdrücklich gemäß $§ 1$ Abs. 3 Nr. 1-8 AbfG vom Anwendungsbereich des Abfallgesetzes ausgeschlossen sind. Ausgeschlossen sind Stoffe, deren Entsorgung in anderen Rechts-

157 Vgl. unten Kapitel B.II.2..

158 BGBl. I 1990, S. 870.

159 Vgl. unten Kapitel B.II.1.. 
vorschriften geregelt sind wie etwa Abfälle im Sinne des Atomgesetzes ${ }^{160}$, des Tierkörperbeseitigungsgesetzes ${ }^{161}$ oder Stoffe, die in Gewässer eingebracht werden ${ }^{162}$. Der Begriff „Abfall“ wird durch $\S 1$ AbfG abschließend definiert. Das Abfallgesetz unterscheidet dabei zwischen subjektivem, objektivem und fiktivem $A b$ fall.

Unter subjektiven Abfällen sind nach dem Gesetz bewegliche Sachen zu verstehen, deren sich der Besitzer entledigen will ( $\$ 1$ Abs. 1 Satz 1, 1. Fall AbfG). Dabei sind allein die Beweggründe des Besitzers der Sachen maßgeblich, d.h. sein Entledigungswille ist entscheidend ${ }^{163}$ - der objektive Wert der Sachen spielt dabei keine Rolle $^{164}$. Auf diese Weise können auch neuwertige und funktionstüchtige Sachen zu Abfall werden. Verfolgt der Besitzer mit der Entledigung jedoch einen wirtschaftlichen Zweck, so scheidet zumindest der subjektive Abfallbegriff aus ${ }^{165}$.

Zu den objektiven Abfällen gehören alle beweglichen Sachen, deren geordnete Entsorgung zur Wahrung des Wohles der Allgemeinheit geboten ist (§1 Abs. 1 Satz 1, 2. Fall $A b f G)$. Eine Beeinträchtigung des Allgemeinwohls liegt dann vor, wenn die Sachen die in $\S 2 \mathrm{AbfG}$ genannten geschützten Rechtsgüter verletzen ${ }^{166}$. $\mathrm{Zu}$ den geschützten Rechtsgütern zählen unter anderen das Leben und die Gesundheit von Menschen und Tieren, die Gewässer, der Boden, die Atmosphäre und die Pflanzenwelt. Im Gegensatz zum subjektiven Abfallbegriff ist nicht der Wille des Abfallbesitzers entscheidend, sondern das von den Gegenständen oder Stoffen ausgehende Gefährdungspotential für Mensch und Umwelt ist maßgeblich. Dies betrifft insbesondere gefährliche industrielle Sonderabfälle, die auch dann als Abfall behandelt werden müssen, wenn ihr Besitzer für sie eine Verwendungsmöglichkeit sieht ${ }^{167}$. Grundsätzlich gilt: die wirtschaftliche Nutzung und Verwertung von Stoffen verhindert nicht ihre eventuelle Einordnung als objektiver Abfall (Zwangsabfall) ${ }^{168}$.

160 Gesetz über die friedliche Verwendung der Kernenergie und den Schutz gegen ihre Gefahren (Atomgesetz) vom 15. 7. 1985, BGBI. I S. 1565, geändert durch Gesetz vom 18. 2. 1986 BGBl. I S. 265.

161 Gesetz über die Beseitigung von Tierkörpern, Tierkörperteilen und tierischen Erzeugnissen (Tierkörperbeseitigungsgesetz) vom 2. 9. 1975, BGB1. I S. 2313, ber. S. 2610.

162 Gesetz zur Ordnung des Wasserhaushaltes vom 23. 9. 1986, BGBl. I S. 1529, ber. S. 1654.

163 Kloepfer, S. 684.

164 OLG Köln, NuR 1983, S. 247, 247.

165 So Kreßel/Herkommer/Wollenschläger, UPR 1989, S. 257, 257.

$166 \mathrm{Kreßel/Herkommer/Wollenschläger,} \mathrm{UPR} \mathrm{1989,} \mathrm{S.} \mathrm{257,} 257$.

167 OLG Düsseldorf, NuR 1983, S. 241, 247.

168 VGH Kassel, NuR 1987, S. 35, 35. 
Das Abfallgesetz findet in bestimmten Fällen auch auf beweglichen Sachen Anwendung, die weder unter den subjektiven noch objektiven Abfallbegriff fallen. Der sogenannte "fiktive Abfallbegriff" bezieht sich dabei auf Abfallstoffe wie etwa Altöle im Sinne von § 5a Abs. 1 AbfG oder Reststoffe im Sinne von § 1 Abs. 1 Satz 2 AbfG. Hierbei handelt es sich um Stoffe, die dem Recycling zugeführt werden sollen und solange als Abfall gelten, bis der aus ihnen gewonnene Stoff oder die erzeugte Energie wieder in den Wirtschaftskreislauf zurückgeführt wird ${ }^{169}$.

\section{bbb) Abfallarten}

Je nach der Herkunft, Beschaffenheit und Menge sowie dem Grad ihrer schädlichen Belastung und des Gefahrenspotentials für Mensch, Natur und Umwelt sind grundsätzlich zwei Arten von Abfällen zu unterscheiden: Allgemeiner Abfall und der Sonderabfall. Zum allgemeinen Abfall zählen vornehmlich der Hausmüll sowie die hausmüllähnlichen Abfälle, der Bauschutt, der Erdaushub und Straßenaufbruch. Zu den Sonderabfällen gehören die Stoffe, die nach „Art, Beschaffenheit oder Menge in besonderem Maße gesundheits-, luft-, wassergefährdend, explosibel oder brennbar sind bzw. Erreger übertragbarer Krankheiten enthalten oder hervorbringen können“ 170 .

An die Entsorgung von Sonderabfälle werden besondere Anforderungen gestellt. So verhängt der Gesetzgeber unter anderem bei Anfall von Sonderabfällen eine Anzeigepflicht und verlangt die Führung von Nachweisbüchern über die Entsorgung dieser Abfälle ( $\$ 11$ Abs. 3 AbfG), die Bestellung eines Betriebsbeauftragten für Abfall für Betreiber von Anlagen, in denen Sonderabfälle regelmäßig anfallen (§ 11a Abs. 1 Satz 2 AbfG) sowie eine besondere Sorgfaltspflicht des Abfallbesitzers bei der Übergabe an den Entsorger ( $\$ 4$ Abs. 3 AbfG) ${ }^{171}$.

\section{ccc) Rangfolge der Entsorgungsarten}

Die Rangfolge Abfallvermeidung, Abfallverwertung, Abfallbeseitigung wird durch § 3 Abs. 2 Satz 3 AbfG vorgegeben. Die Vermeidung von Abfällen steht dabei an erster Stelle. Sie hat Vorrang vor allen anderen Entsorgungsarten, soweit sie tech-

169 Weitere: Vgl. $\$ 5$ Abs. 2 AbfG.

170 Welche Stoffe dies im einzelnen sind, regelt die Verordnung zur Bestimmung von Abfällen nach § 2 Abs. 2 AbfG vom 3. 4. 1990, BGBl. I S. 1410, sowie die einzelnen Sonderabfallverordnungen der Länder. Vgl. dazu unten Kapitel A.III.1.b)aa).

171 Jakobi/Schenkel, S. 30. 
nisch möglich und wirtschaftlich zumutbar ist. Eine unmittelbar geltende Verpflichtung zur Abfallvermeidung sieht das Abfallgesetz jedoch noch nicht vor ${ }^{172}$. Die Vermeidungspflicht in § 1a AbfG gilt nur nach Maßgabe von Rechtsverordnungen gemäß $\S 14 \mathrm{AbfG}^{173}$. Unvermeidbare Abfälle sind soweit wie möglich zu verwerten oder wieder zu verwenden. Neben den technischen und wirtschaftlichen Voraussetzungen muß schließlich auch die ökonomische Nutzung ${ }^{174}$, der durch die Abfallverwertung gewonnenen Stoffe oder Energie gewährleistet sein. Eine explizite Rangfolge zwischen energetischer Verwertung, durch Verbrennung der Abfälle und stofflicher Verwertung, durch Recycling wird durch das Abfallgesetz nicht vorgegeben. Beide Verwertungsarten werden vom Gesetz als gleichwertig angesehen ${ }^{175}$. Scheidet die Möglichkeit der Verwertung aus, so sind die Abfälle so zu beseitigen, daß keine Beeinträchtigung von Natur und Umwelt sowie des Wohles der Allgemeinheit $\mathrm{zu}$ befürchten ist.

\section{ddd) Grundsatz der öffentlichen Abfallentsorgung}

Das Abfallgesetz geht vom Grundsatz der öffentlichen Abfallentsorgung aus (vgl. § 3 Abs. 2 Satz 1 AbfG). Welche Körperschaften im einzelnen zuständig sind, wird durch Landesrecht ${ }^{176}$ bestimmt. Die zuständigen Gebietskörperschaften sind verpflichtet, grundsätzlich alle in ihrem Gebiet anfallenden Abfälle ordnungsgemäß zu entsorgen. Sie können dabei in Eigenregie tätig werden oder sich zur Erfüllung der Entsorgungsverpflichtung Dritter bedienen (§ 3 Abs. 2 Satz 2 AbfG). Ausnahmen von der Entsorgungspflicht der Gebietskörperschaften sieht das Gesetz für solche Abfälle vor, die sich nicht nach Art und Umfang zusammen mit den in Haushaltungen anfallenden Abfällen entsorgen lassen ( $\$ 3$ Abs. 3 AbfG). Hiervon betroffen sind unter anderem die in der Regel schwierig zu entsorgenden industriellen $\mathrm{Ab}$ -

172 Ein umfassendes Vermeidungsgebot besteht für Betreiber genehmigungsbedürftiger Anlagen gemäß § 5 Abs. 1 Nr. 3 BImSchG, daß nach $\S 1$ a Abs. 1 Satz 2 AbfG unberührt bleibt. Zum BImSchG vgl. unten Kapitel A.III.1.a)bb).

173 Die Bundesregierung hat nach Maßgabe des $\S 14$ Abs. 2 Satz 3 Nr. 2 und 3 AbfG die Verordnung über die Rücknahme und Pfanderhebung von Getränkeverpackungen aus Kunststoffen vom 20. 12. 1988 erlassen, BGB1. I S. 2455. Darin wird insbesondere vorgeschrieben, daß Verpackungen und Behältnisse nach Gebrauch zu umweltschonender Wiederverwendung, Verwertung oder sonstiger Entsorgung durch Hersteller, Vertreiber oder Dritte zurückgenommen werden müssen und daß die Rückgabe durch geeignete Rücknahme und Pfandsysteme sichergestellt werden muß. Vgl. Doose, S. 44.

174 Die Herstellung nicht marktgerechter Recyclingprodukte ist volkswirtschaftlich nicht sinnvoll. So Kloepfer, S. 701.

175 Kloepfer, S. 683.

176 Die meisten Länder haben als Träger der Abfallentsorgung, die Landkreise und kreisfreien Städte vorgesehen (vgl. z.B. § 1 Abs. 1 Satz 1 HAbfAG). 
fälle ${ }^{177}$. In diesen Fällen ist der Abfallbesitzer für die umweltgerechte Entsorgung verantwortlich (§ $3 \mathrm{Abs.} 4 \mathrm{AbfG})^{178}$. Zur Erfüllung ihrer Entsorgungspflicht können sich die privaten Abfallbesitzer, entsprechend den entsorgungspflichtigen $\mathrm{Ge}$ bietskörperschaften sonstiger Dritter bedienen ${ }^{179}$. Die faktische Entsorgungsgarantie der öffentlichen Hand nach § 3 Abs. 2 Satz 1 AbfG wird durch die Ausschlußpraxis der entsorgungspflichtigen Körperschaften gemäß § 3 Abs. 3 AbfG insofern relativiert, daß die Beseitigung von industriellen Abfällen nicht Aufgabe der öffentlichen Daseinsvorsorge sein soll ${ }^{180}$. Damit macht der Gesetzgeber deutlich, daß er gewillt ist, die Abfallbeseitigung dort von der öffentlichen Daseinsvorsorge auszunehmen, wo es zum Schutz der Umwelt geboten erscheint. Inwiefern eine so verstandene Verteilung der Entsorgungsverantwortung mit EWG-vertraglichen Regelungen vereinbar ist, wird Inhalt der Prüfung in Kapitel B.III.2.a) sein.

Nach Maßgabe des § 6 AbfG sind die Länder verpflichtet, unter überörtlichen Gesichtspunkten Abfallentsorgungspläne für ihren Bereich aufzustellen. Aufgabe der Landesabfallentsorgungspläne ist es, sowohl geeignete Standorte für Abfallbeseitigungsanlagen festzulegen als auch die Beseitigung der angefallenen Abfälle und Sonderabfälle systematisch zu ordnen.

\section{eee) Grundsatz der Inlandsentsorgung}

Ein wesentliches Prinzip des Abfallgesetzes ist der Grundsatz der Inlandsentsorgung. Nach § 2 Abs. 1 Satz 1 AbfG. sind Abfälle, die im Staatsgebiet der Bundesrepublik Deutschland anfallen, prinzipiell im Bundesgebiet zu entsorgen ${ }^{181}$. Für den Vorrang der Inlandsentsorgung sprechen unter anderem wirtschaftliche Gründe, so zum Beispiel der Schutz der Tätigkeit bundesdeutscher Entsorgungsunternehmen, die Erleichterung von Standortentscheidungen für neue Beseitigungsanlagen und die Vermeidung unzureichender Auslastung innerstaatlicher Entsorgungsanlagen ${ }^{182}$. Fraglich ist jedoch, ob durch den Grundsatz der Inlandsentsorgung die grenzüber-

177 Wobei es sich nicht unbedingt um gefährliche Abfälle im Sinne von § 2 Abs. 2 AbfG handeln muß. Vgl. Kloepfer, S. 705.

178 Vgl. zur Ausschlußpraxis Hösel/v. Lersner § 3 AbfG Rdn. 30, 32 und 34. Der Ausschluß führt dazu, daß die Beseitigungspflicht des Abfallbesitzers wieder auflebt, § 3 Abs. 4 AbfG.

179 So z.B. in Hessen die „Hessische Industriemüll GmbH“.

180 So Wilmowsky, S. 278.

181 Keine nähere Betrachtung findet hier die Geltung des Abfallrechts auf Hoher See sowie die Geltung des Abfallrechts bei Schiffsabfällen.

182 So K.-D. Spranger am 8. 12. 1982 auf Frage vom Abgeordneten Boroffka in BT.-Protokolle 9. Wahlperiode, S. 8364. 
schreitende Abfallverbringung gänzlich ausgeschlossen wird. Dies ist zu verneinen, da das Gesetz durchaus auch den grenzüberschreitenden Verkehr zuläßt. Dies geschieht, um einerseits den ungeregelten Import, Export und Transit von Abfällen einzuschränken und andererseits sowohl abfallwirtschaftliche ${ }^{183}$ als auch politische Gesichtspunkte zu berücksichtigen. Gründe, die für eine grenzüberschreitende Verbringung von Abfällen sprechen, sind unter anderen die Kooperation bei der Abfallbeseitigung zwischen Staaten, die insbesondere im grenznahen Regionen sinnvoll sein kann ${ }^{184}$, Unternehmensverflechtung multinationaler Konzerne, sowie die Unmöglichkeit der ordnungsgemäßen Beseitigung im Inland ${ }^{185}$.

\section{fff) Grenzüberschreitende Abfallverbringung}

Nach § 13 Abs. 1 AbfG sind alle Vorgänge der grenzüberschreitenden Abfallverbringung genehmigungspflichtig ${ }^{186}$. Zuständig für die Erteilung der Genehmigung ist nach Maßgabe des $\S 13$ Abs. 3 AbfG für den Fall des Imports von Abfällen die Behörde des Landes, in dem die Abfälle erstmals behandelt, gelagert oder abgelagert werden sollen. Für den Fall des Exports und Transits von Abfällen nimmt die Behörde des Landes, in dem die Beförderung beginnt, diese Aufgabe wahr. Die zuständige Behörde darf die Genehmigung nur dann erteilen, wenn die Voraussetzungen des $\S 13 \mathrm{Abs} .1 \mathrm{AbfG}$ erfüllt sind ${ }^{187}$. Allgemeine Anforderung für die Erteilung einer Genehmigung sind die Wahrung des Wohles der Allgemeinheit ( $\$ 2$ Abs. 1 AbfG und $\S 13$ Abs. 1 Satz 2 Nr. 1 AbfG) sowie Gründe, die in der Person des Antragstellers liegen. So muß beispielsweise der für den Transport verantwortliche Unternehmer die dafür erforderliche Zuverlässigkeit besitzen bzw. nachweisen ${ }^{188}$. Darüber hinaus werden für die unterschiedlichen Arten der grenzüberschreitenden Abfallverbringung (Export, Import, Transit) gemäß § 13 Abs. 1 Nr. 3-5 AbfG besondere Anforderungen gestellt.

Die Genehmigung für den Import von Abfällen ist nur dann zu erteilen, wenn einer Einfuhr erstens keine Abfallentsorgungspläne entgegenstehen und zweitens die ord-

$183 \mathrm{Zu}$ den abfallwirtschaftlichen Vorteilen vgl. unten Kapitel B.III..

184 Für eine staatliche Zusammenarbeit bei der Abfallentsorgung in Grenzgebieten sprechen unter anderen folgende Erwägungen, kurze Wege, Vermeidung von Doppelnvestitionen bei der Standortwahl, technisch erforderliche Abfallmengen für bestimmte Verfahren.

185 So Szelinski, UPR 1984, S. 364, 365. Zum selben Thema: Friedrich, UPR 1988, S. 4, 4.

186 Die Regelungen des $\S 13$ AbfG gilt als Reaktion des Gesetzgebers auf das Verschwinden von 41 Fässern mit Dioxin verseuchter Erde aus Seveso. Kloepfer S. 735.

187 v. Köller, Entsorga-Magazin 10/88, S. 12, 12.

$188 \mathrm{Vgl}$. dazu und zu weiteren Gründen. $§ 13$ Abs. 1 Satz 2 Nr. 2 AbfG. 
nungsgemäße Entsorgung der Abfälle im Herkunftsstaat ${ }^{189}$ nicht gewährleistet ist. Der Export von Abfällen ist nur zulässig, wenn eine ordnungsgemäße Entsorgung im Inland ${ }^{190}$ nicht möglich ist, oder diese für den Entsorgungspflichtigen eine unbillige Härte darstellen würde. Bei der Auslegung des Begriffes unbillige Härte sind neben technischen Gesichtspunkten und der Auslastung vorhandener Entsorgungsanlagen wirtschaftliche Erwägungen zu berücksichtigen. Dies darf jedoch nicht dazu führen, daß nur aufgrund eines niedrigeren Kostenniveaus Abfälle in Staaten mit geringeren Entsorgungsstandard geleitet werden. Entsprechend den Regelungen bei der Abfalleinfuhr gilt auch hier der Vorrang von Abfallentsorgungsplänen. An die Ausfuhrgenehmigung geknüpft ist ferner das Einverständnis der vom Transport berührten Staaten sowie die amtliche Erklärung des Empfängerstaates, daß eine ordnungsgemäße Entsorgung der jeweiligen Abfälle gewährleistet ist, wobei durch die Entsorgung im Ausland keine Beeinträchtigung des Wohles der Allgemeinheit in der Bundesrepublik Deutschland erfolgen darf.

Die Genehmigung für den Transit von Abfällen ist zu versagen, wenn die Abfälle im Empfängerstaat nicht ordnungsgemäß beseitigt werden können, oder wenn durch die Entsorgung im Ausland eine Beeinträchtigung des Wohles der Allgemeinheit in der Bundesrepublik Deutschland zu besorgen ist.

Um EG-Rechtsakte in bundesdeutsches Recht umzusetzen, enthält § $13 \mathrm{c}$ AbfG eine spezielle Verordnungsermächtigung ${ }^{191}$. Die Bundesregierung hat davon beim Erlaß der Abfallverbringungsverordnung Gebrauch gemacht ${ }^{192}$.

\section{bb) Bundes-Immissionsschutzgesetz (BImSchG) ${ }^{193}$}

Für die Errichtung und Änderung ortsfester Anlagen, deren Betrieb in besonderer Weise zu Umweltbeeinträchtigungen führen kann, schreibt das Bundes-Immissionsschutzgesetz nach § 4 BImSchG ein Genehmigungsverfahren vor ${ }^{194}$. § 4 BImSchG

189 Der Antragsteller muß eine dem entsprechende amtliche Erklärung des Herkunftsstaates vorlegen.

190 Also auch in anderen Bundesländern, Szelinski, S. 677, 679.

191 Kloepfer, S. 736.

192 Zur Abfallverbringungs-Verordnung vgl. die Ausführungen unten Kapitel A.III.1.b)cc).

193 Gesetz zum Schutz vor schädlichen Umwelteinwirkungen durch Luftverunreinigung, Geräusche, Erschütterungen und ähnliche Vorgänge (Bundes-Immissionsschutzgesetz BImSchG) vom 15. 4. 1974 BGBl. I S. 721, ber. S. 1193, zuletzt geändert 6. 4. 1990, BGBl. I S. 870.

194 Verordnung über genehmigungsbedürftige Anlagen - 4. BImSchV vom 24. 7. 1985, BGBl. I S. 1586 geändert durch VO vom 15. 7. 1988, BGBl. I S. 1059. 
wird ergänzt und ausgeführt durch die „Vierte Verordnung zur Durchführung des Bundes-Immissionsschutzgesetzes“. Dort werden exemplarisch 146 Anlagentypen aufgeführt, die einer besonderen Genehmigung nach dem Bundes-Immissionsschutzgesetz bedürfen ${ }^{195}$. Kernstück des Genehmigungsverfahrens bildet die Regelung des § $5 \mathrm{BImSchG.} \mathrm{Sie} \mathrm{legt} \mathrm{die} \mathrm{sachlichen} \mathrm{Pflichten} \mathrm{fest,} \mathrm{die} \mathrm{ein} \mathrm{Betreiber} \mathrm{einer}$ solchen Anlage zu beachten hat. Abfallrechtliche Bedeutung hat dabei die Regelung des $\S 5$ Abs. 1 Nr. 3 BImSchG. Sie verpflichtet die Betreiber von Anlagen, die nach $\S 4$ BImSchG genehmigungsbedürftig sind, zur Vermeidung der bei der Produktion anfallenden Reststoffe. Anders als das Abfallgesetz, knüpft das Immissionsschutzgesetz nicht an den Abfallbegriff an, sondern es wird der Begriff des Reststoffs verwendet. Reststoffe im Sinne des Gesetzes „... sind alle Stoffe, die bei der Energieumwandlung oder bei der Herstellung, Bearbeitung oder Verarbeitung von Stoffen entstehen, ohne daß der Zweck des Anlagenbetriebes darauf abzielt" ${ }^{196}$. Damit erfaßt der Begriff Reststoff auch solche Stoffe, die nicht Abfälle im Sinne von § 1 AbfG sind, wie etwa Abwässer und Tierkörperreste.

Das Immissionsschutzgesetz regelt nicht die Art und Weise, wie Abfälle zu entsorgen sind, sondern es will den Abfallanfall steuern und bereits im immissionsschutzrechtlichen Genehmigungsverfahren sicherstellen, daß eine ordnungsgemäße Abfallbeseitigung gewährleistet ist ${ }^{197}$. Die Bestimmungen des $\S 5 \mathrm{Abs} .1 \mathrm{Nr} .3$ BImSchG sind dabei dem Abfallgesetz vorgelagert ${ }^{198}$.

Das Immissionsschutzgesetz verpflichtet die Betreiber von Anlagen, die nach $\S 4$ BImSchG genehmigungsbedürttig sind, zur Vermeidung der bei der Produktion anfallenden Reststoffe, es sei denn, sie werden ordnungsgemäß und schadlos verwertet ( $\$ 5$ Abs. 1 Nr. 3 BImSchG). Die Beseitigung der Reststoffe als Abfälle ist dann zulässig, wenn sowohl Vermeidung als auch Verwertung technisch nicht möglich oder unzumutbar sind und eine Beeinträchtigung des Wohles der Allgemeinheit durch die Beseitigung nicht zu befürchten ist ${ }^{199}$. Reststoffverwertung und Abfallbeseitigung werden nur als Ausnahmen zugelassen ${ }^{200}$. Soweit die Beseitigung von

195 Müller/Schmitt-Gleser, S. 6.

$196 \mathrm{Vgl}$. Musterentwurf des Länderausschusses für Immissionsschutz für eine Verwaltungsvorschrift zu § 5 Abs. 1 Nr. 3 BImSchG, NVwZ, 2/1989, S. 130, 130.

197 Dies gilt nicht nur für Anlagen, die einer Genehmigung nach dem BImSchG bedürfen, sondern auch für nicht-genehmigungsbedürftige Anlagen, $\S 22$ Abs. 1 Satz 1 Nr. 3 BImSchG.

198 Hansmann, NVwZ 1990, S. 409, 410.

199 Hansmann, NVwZ 1990, S. 409, 412. Zum selben Sachverhalt: Rehbinder, DVB1. 1989, S. 496, 498.

200 Rehbinder, DVBI. 1989, S. 496, 499. 
Reststoffen aus der Produktion als Abfälle zulässig ist, findet auf diese in vollem Umfang das Abfallgesetz Anwendung 201.

Durch das 3. Änderungsgesetz zum Bundes-Immissionsschutzgesetz ${ }^{202}$ wurde eine Regelung in das Gesetz neu aufgenommen, welche die Verwertung oder Behandlung von Abfällen in genehmigungsbedürftigen Anlagen im Sinne des BundesImmissionsschutzgesetz ermöglicht, die überwiegend einem anderem Zweck als der Abfallentsorgung dienen. Bedeutung erlangt diese Regelung vor allem im Hinblick auf die thermische Verwertung von Abfällen, also die Abfallverbrennung ${ }^{203}$.

\section{b) Rechtsverordnungen}

Eine große Anzahl von gesetzlichen Regelungen des Abfallgesetzes sowie der Landesabfallgesetze ermächtigen beispielsweise die Bundesregierung, die Landesregierungen oder die zuständigen Ministerien zum Erlaß von ergänzenden abfallrechtlichen Rechtsverordnungen ${ }^{204}$. In den Rechtsverordnungen werden spezifische Einzelfragen und Problemstellungen des Abfallrechts näher geregelt.

Die Rechtsverordnungen im Abfallrecht der Bundesrepublik Deutschland sind unter EG-rechtlichen Gesichtspunkten in mancherlei Hinsicht von Belang. So setzt die Abfallverbringungs-Verordnung, die Richtlinie 84/631/EWG über die grenzüberschreitende Verbringung giftiger und gefährlicher Abfälle in deutsches Recht um. In Hinblick auf den Untersuchungsgegenstand der vorliegenden Arbeit sind die Abfallbestimmungs- und die Reststoffbestimmungs-Verordnung von grundlegender Bedeutung, da im Zusammenhang mit den Vorschriften des EWG-Vertrages über die Sicherung des freien Warenverkehrs für die grenzüberschreitende Verbringung von Abfällen oder Reststoffen gänzlich andere Rechtsvorschriften zur Anwendung kommen.

201 Rehbinder, DVBl. 1989, S. 496, 496.

202 BGB1. 1990, S. 870.

203 Schlabach, UPR 1990, S. 250, 255.

204 Vgl. z.B. §§ 2 Abs. Satz 2 und Abs. 3 Satz 1; 4 Abs. 4; 5a Abs. 2 Satz 2; 11 Abs. 2 Satz 3 und Abs. 3 Satz 4; 13 Abs. 5 Satz 1; 14 Abs. 1 und 2; 15 Abs. 2 und 3 AbfG. 


\section{aa) Abfallbestimmungs-Verordnung (AbfBestV) 205}

Durch $\S 2$ Abs. 2 AbfG wird die Bundesregierung ermächtigt, mittels Rechtsverordnung, die auf dem Gebiet der Bundesrepublik Deutschland anfallenden besonders überwachungsbedürftigen Abfälle (Sonderabfälle) zu bestimmen. Sie hat mit der Abfallbestimmungs-Verordnung von dieser Ermächtigung Gebrauch gemacht. Die Abfallbestimmungsverordnung ist die zentrale Vorschrift für Sonderabfälle.

Von der Verordnung erfaßt werden nach Maßgabe von $\S 1 \mathrm{AbfBestV}$ alle in der Anlage zur Verordnung aufgeführten Abfallarten, soweit sie aus gewerblichen oder sonstigen wirtschaftlichen Unternehmen oder öffentlichen Einrichtungen stammen ${ }^{206}$.

\section{bb) Reststoffbestimmungs-Verordnung (RestBestV) ${ }^{207}$}

$\S 2$ Abs. 3 AbfG enthält die Ermächtigung an die Bundesregierung zum Erlaß einer Rechtsverordnung zur Bestimmung von Stoffen, die keine Abfälle im Sinne des Abfallgesetzes sind, sondern als Reststoffe ${ }^{208}$ verwertet werden sollen. Der Gesetzgeber hat mit der Reststoffbestimmungsverordnung von dieser Ermächtigung Gebrauch gemacht.

Nach dem Wortlaut des § 1 Abs. 1 RestBestV sind die in der Anlage zu dieser Verordnung genannten Stoffe Reststoffe im Sinne von $\S 2$ Abs. 3 AbfG, soweit sie aus gewerblichen oder sonstigen wirtschaftlichen Unternehmen oder öffentlichen Einrichtungen stammen ${ }^{209}$.

205 Verordnung zur Bestimmung von Abfällen nach § 2 Abs. 2 des Abfallgesetzes vom 3. 4. 1990, BGB1. I S. 614.

206 Für Kleinmengen bis zu einem jährlichen Aufkommen von $500 \mathrm{~kg}$ sieht $\S 1$ Abs. 2 AbfBestV eine Ausnahmeregelung vor.

207 Verordnung zur Bestimmung von Reststoffen nach $\S 2$ Abs. 3 des Abfallgesetzes (Reststoffbestimmungs-Verordnung - RestBestV) vom 3. 4. 1990, BGB1. I, S. 631.

208 Der sowohl im BImSchG als auch im Abfallgesetz verwendete Begriff des Reststoffes ist vom Gesetz- geber nicht definiert worden ( $\S 1$ a Abs. 1 Satz 2 und 2 Abs. 3 Satz 1 AbfG, §5 Abs. 1 Nr. 3 BImSchG). So das OVG Saarland Beschluß vom 5. 10. 1989, 1 W $125 / 89$.

209 Für Kleinmengen bis zu einem jährlichen Aufkommen von $500 \mathrm{~kg}$ sieht $\S 1$ Abs. 2 RestBestV eine Ausnahmeregelung vor. 


\section{cc) Abfallverbringungs-Verordnung (AbfVerbrV) 210}

Für den Import, Export und Transit von Abfällen wird durch § $13 \mathrm{AbfG}$ der gesetzliche Rahmen vorgegeben. Die Abfallverbringungs-Verordnung ist eine Durchführungsverordnung zu $\S 13 \mathrm{AbfG}^{211}$ und setzt gleichzeitig nach § $13 \mathrm{c}$ AbfG die EGRichtlinie 84/631/EWG in deutsches Recht um ${ }^{212}$. Die Abfallverbringungs-Verordnung regelt Einzelheiten des Überwachungs- und Kontrollsystems. Sie übernimmt dabei das von der EG-Richtlinie vorgegebene Notifizierungsverfahren ${ }^{213}$ und füllt somit den von den $\S \S 13$ und $13 \mathrm{c}$ AbfG vorgegebenen Rahmen aus.

Anwendung finden die Vorschriften der Abfallverbringungs-Verordnung bei der Verbringung von Abfällen jeglicher Art in den, aus dem oder durch den Geltungsbereich des Abfallgesetzes. Die Abfallverbringungs-Verordnung gilt mithin auch für Verbringungen, die nicht den Bestimmungen der EG-Richtlinie 84/631/EWG unterliegen, wie z.B. Hausmüll214.

In der Abfallverbringungs-Verordnung sind je nach Abfallart unterschiedliche Genehmigungsverfahren vorgesehen. In der Verordnung wird dabei zwischen Hausmüll215, gefährlichen Abfällen und nichteisenmetallhaltigen Abfällen $^{216}$ unterschieden.

Der Begriff gefährlicher Abfall wird durch § 5 AbfVerbrV mittels einer doppelten Bezugnahme definiert ${ }^{217}$. Gefährliche Abfalle im Sinne der Verordnung sind danach zum einen alle in der Abfallartenliste zur Abfallbestimmungsverordnung aufgeführten Abfälle, ohne Rücksicht auf ihre Herkunft. Darüber hinaus gelten alle Abfälle, die in einem bei der Verbringung berührten EG-Mitgliedstaat als gefährliche Abfälle angesehen werden, auch in der Bundesrepublik Deutschland als solche.

210 Verordnung über die grenzüberschreitende Verbringung von Abfällen (Abfallverbringungs-Verordnung - AbfVerbrV) vom 18. 11. 1988, BGBl. I S. 2126, ber. S. 2418.

211 Als Durchführungsverordnung zu $\S 13$ AbfG, kann sie jedoch nicht über den vom Gesetz vorgegebenen Rahmen hinausgehen und beispielsweise den Export bestimmter Abfälle gänzlich untersagen. So v. Köller, Entsorga-Magazin 10/88 S. 12.

212 Die Rechtsgrundlage für die Umsetzung von Rechtsakten der Europäischen Gemeinschaften in deutsches Recht wird durch § 13c AbfG gegeben. Dazu vgl. oben Kapitel A.III.1.a)aa).

213 Ausführlich dazu vgl. oben Kapitel A.II.2.d).

214 Vgl. Musterverwaltungsvorschrift zur Durchführung des § 13 AbfG und der Abfallverbringungs-Verordnung in Bim/Jung Teil 7, Kapitel 5, Seite 3.

215 Definition Hausmüll vgl. oben Kapitel A.III.1.a)aa).

216 Zum Beispiel Aluminiumspäne.

217 v. Köller, Entsorga-Magazin 10/88, S. 12, 15. 
Diese Regelung gilt jedoch nur für den Verbringungsvorgang und nicht für die Entsorgung in der Bundesrepublik Deutschland.

Nach Maßgabe des $\S 13$ Abs. 1 AbfG sind alle Vorgänge der grenzüberschreitenden Abfallverbringung genehmigungspflichtig. Aufgabe der zuständigen Behörde ist es zu prüfen, welches Genehmigungsverfahren durchzuführen ist. Erst nachdem eine Genehmigung erteilt wurde, darf Abfall grenzüberschreitend verbracht werden ( 22 Abs. 1 AbfVerbrV). Das bundesdeutsche Recht geht damit über den Regelungsgehalt des EG-Rechts hinaus und unterwirft die grenzüberschreitende Verbringung von Abfälle jeglicher Art einem Genehmigungsverfahren. Um eine wirksame Überwachung und Kontrolle zu erleichtern, muß die amtliche Genehmigung während des gesamten Transports mitgeführt werden ( $\$ 2$ Abs. 2 AbfVerbrV). Die Form der in der Verordnung vorgesehenen Begleitscheine richtet sich nach den Vorgaben der Richtlinie 84/631/EWG zum EG-einheitlichen Begleitschein.

Werden Abfälle der Kategorie Hausmüll ${ }^{218}$ grenzüberschreitend entsorgt, so ist eine Genehmigung nach $\S 6 \mathrm{AbfVerbrV}$ bei der nach § $13 \mathrm{Abs}$. 3 Satz 1 AbfG zuständigen Behörde zu beantragen. Die Behörde kann zur Wahrung des Wohls der Allgemeinheit Auflagen bezüglich Beförderungsweg, Beförderungsmittel und Art der Beförderung stellen ( $\$ 6$ Abs. 2 AbfVerbrV).

Für gefährliche Abfälle ist die nach § $13 \mathrm{AbfG}$ erforderliche Genehmigung gemä $B$ des in den $\S \S 7$ bis 13 AbfVerbrV geregelten Verfahrens zu beantragen. In $\S 7$ AbfVerbrV werden die von der EG-Richtlinie und aufgrund dieser von den Vollzugsbehörden der anderen EG-Mitgliedstaaten verwandten Begriffe ${ }^{219}$ dem deutschen Verwaltungsrecht angepaßt.

Die Prüfung des Verbringungsvorgangs erfolgt entweder durch das unbeschränkte Genehmigungsverfahren gemäß $\S 8,9 \mathrm{AbfVerbrV}$ oder durch das beschränkte Genehmigungsverfahren gemäß $\S \S 10,11 \mathrm{AbfVerbrV}$. Von einem unbeschränkten Genehmigungsverfahren spricht man dann, wenn die zuständigen bundesdeutschen Behörden den gesamten Verbringungsvorgang regeln. Unter der Voraussetzung, da $\beta$ ein anderer EG-Mitgliedstaat bereits eine Empfangsbestätigung oder Genehmigung

218 Im Wortlaut der Verordnung heißt es: „Abfällen, die nicht gefährliche Abfälle im Sinne des $§ 5$ AbfVerbrV sind".

219 Ein Antrag auf Erteilung einer Genehmigung wird im deutschen Recht mit einer „Notifizierung“ im Sinne des Artikels 3 der Richtlinie 84/631/EWG und eine Genehmigung für die Verbringung der Abfälle einer „Empfangsbestätigung“ im Sinne des Artikels 4 Abs. 1 der Richtlinie 84/631/EWG gleichgesetzt. 
erteilt hat, braucht die bundesdeutsche Behörde diesen Teilaspekt des Verbringungsvorgangs nicht mehr zu prüfen. Die Prüfung des Verbringungsvorgangs kann auf die in $\S 11$ Abs. 1 AbfVerbrV genannten drei Prüfungsgegenstände beschränkt werden. Geprüft werden erstens die Ordnungsmäßigkeit der Beförderung sowie die Zuverlässigkeit der hierzu beauftragten Personen, zweitens Auswirkungen auf das Wohl der Allgemeinheit und drittens die Vereinbarkeit mit bestehenden Abfallentsorgungsplänen.

Das unbeschränkte Genehmigungsverfahren findet Anwendung beim Import von gefährlichen Abfällen in die Bundesrepublik Deutschland, beim Export von gefährlichen Abfällen in ein Drittland sowie für gefährliche Abfälle, die durch die Bundesrepublik Deutschland im Transit in ein Drittland verbracht werden. Stammt der Abfall, der importiert werden soll, aus einem EG-Mitgliedstaat, so kann gemäß $\S 8$ Fall a, 2. Halbsatz AbfVerbrV auf eine amtliche Erklärung, daß die ordnungsgemäße Entsorgung im Herkunftsland nicht gewährleistet ist, verzichtet werden. Werden gefährliche Abfälle in ein EG-Mitgliedstaat exportiert oder wird gefährlicher Abfall durch die Bundesrepublik Deutschland in einen EG-Mitgliedstaat verbracht, so findet das beschränkte Genehmigungsverfahren Anwendung.

Ein Anzeigeverfahren gemäß $\S 14$ AbfVerbrV genügt für nichteisenmetallhaltige Abfälle die einer Verwertung zugeführt werden; eine Verbringungsgenehmigung ist nicht notwendig. Absender und Empfänger sind verpflichtet der zuständigen Behörde die Verbringung anzuzeigen. Die Anzeige soll es der Behörde ermöglichen, den Transport zu überwachen.

Sollen Abfälle mit gleichen physikalischen und chemischen Eigenschaften mehrfach über dieselbe bzw. dieselben Zollstellen zu demselben Empfänger verbracht werden, so besteht die Möglichkeit, eine Sammelgenehmigung nach §4 AbfVerbrV zu beantragen.

\section{dd) Abfall- und Reststoffüberwachungs-Verordnung (AbfRestÜberwV) 220}

Die gesetzliche Grundlage für die behördliche Überwachung der Abfallentsorgung enthält § 11 des Abfallgesetzes, die Beförderung von Abfällen wird in § $12 \mathrm{AbfG}$ gesetzlich geregelt. Zum Vollzug der $\S 11$ und 12 AbfG ist die Abfall- und Rest-

220 Verordnung über das Einsammeln und Befördern sowie über die Überwachung von Abfällen und Reststoffen (Abfall- und Reststoffüberwachungs-Verordnung AbfRestUberwV) vom 3.4. 1990 BGBl. I S. 648. 
stoffüberwachungs-Verordnung ergangen, sie löst die Abfallnachweis-Verordnung und die Abfallbeförderungs-Verordnung ab. Die Verordnung regelt Einzelheiten bezüglich des Antrages und der Genehmigung zum Einsammeln und Befördern von Abfällen - auch im Rahmen der grenzüberschreitenden Abfallentsorgung soweit diese Vorgänge das Inland betreffen -, den Nachweis über die Zuverlässigkeit der vorgesehenen Entsorgung sowie über die Einrichtung, Führung und Vorlage der Nachweisbücher ${ }^{221}$ über entsorgte Abfälle. Nach Maßgabe der $\S \S 25$ und 26 der Abfall- und Reststoffüberwachungs-Verordnung gilt diese auch für Besitzer von Reststoffen im Sinne von § 1 RestBestV. Anwendung findet die Verordnung erstens auf Betreiber einer Anlage, in der Abfälle anfallen (Abfallerzeuger), zweitens auf jeden der Abfälle dieser Art einsammelt oder befördert (Abfallbeförderer) und drittens auf die Betreiber von Abfallentsorgungsanlagen (Abfallentsorger).

\section{c) TA-Abfall 222}

Durch Artikel 84 Abs. 2 des Grundgesetzes in Verbindung mit $\S 4$ Abs. 5 des Abfallgesetzes wird die Bundesregierung, nach Anhörung der beteiligten Kreise, zum Erlaß einer allgemeinen Verwaltungsvorschrift über Anforderungen an die Entsorgung von Abfällen nach dem Stand der Technik ${ }^{223}$ ermächtigt. Diese Verwaltungsvorschrift wird als „Technische Anleitung Abfall“ (kurz „TA-Abfall“) bezeichnet.

Die TA-Abfall legt die technischen Mindestanforderungen an die Abfallentsorgung fest. Derzeit werden vorrangig solche Abfälle erfaßt, die nach § 2 Abs. 2 AbfG als besonders überwachungsbedürftig gelten. Welche Abfälle dies im einzelnen sind, regeln die Abfallbestimmungverordnung ${ }^{224} \mathrm{bzw}$. die Reststoffbestimmungsverordnung 225 . Längerfristig ist geplant, durch die TA-Abfall sämtliche Abfallarten zu erfassen.

221 Eine gesetzliche Nachweispflicht ergibt sich aus $\S 11$ Abs. 3 Satz 1 AbfG für Abfälle im Sinne von § 2 Abs. 2 AbfG.

222 Zweite allgemeine Verwaltungsvorschrift zum Abfallgesetz (TA-Abfall). Teil 1: Technische Anleitung zur Lagerung, chemisch/physikalischer und biologischer Behandlung und Verbrennung von besonders überwachungsbedürftigen Abfällen vom 10. 4. 1990, GmB1., S. 170.

223 Stand der Technik im Sinne der TA-Abfall ist ,... der Entwicklungsstand fortschrittlicher Verfahren, Einrichtungen oder Betriebsweisen, der die praktische Eignung einer Maßnahme für eine umweltverträgliche Abfallentsorgung gesichert erscheinen läßt“. Vgl. Wortlaut der Verwaltungsvorschrift.

224 Vgl. oben Kapitel A.III.1.b)aa).

225 Vgl. oben Kapitel A.III.1.b)bb). 
Zielsetzung der TA-Abfall ist es, umfassend und bundeseinheitlich technische und organisatorische Anforderungen an die Errichtung und den Betrieb von Abfallentsorgungsanlagen auf einem so hohen Niveau vorzugeben, wodurch eine Beeinträchtigung des Allgemeinwohls soweit wie möglich ausgeschlossen wird ${ }^{226}$. Dazu stellt die TA-Abfall Anforderungen an die Zuordnung von Abfällen zu bestimmten Entsorgungswegen, die Steuerung und Überwachung von Abfallströmen sowie die Überwachung und betriebliche Organisation der Abfallentsorgungsanla$\operatorname{gen}^{227}$.

Abfälle, die nachweislich nicht verwertet werden können, sind bestimmten Entsorgungswegen nach ihrer Herkunft und Zusammensetzung zuzuordnen. Eine Entscheidungshilfe bei der Zuordnung gibt der Abfallartenkatalog, der zugleich Empfehlungen für bestimmte Entsorgungswege gibt. Im einzelnen erfolgt die Zuordnung mit Hilfe des Entsorgungsnachweises. Er setzt sich zusammen aus der Abfalldeklaration und der nach $\S 4 \mathrm{Abs}$. $3 \mathrm{AbfG}$ erforderlichen Annahmebescheinigung des Betreibers der Entsorgungsanlage ${ }^{228}$.

\section{d) Verwaltungs-, Verfahrens- und Raumordnungsrecht}

Die Rechtsbereiche des Verwaltungs-, Verfahrens-, und Raumordnungsrechts werden nur in Form eines kurzen Überblicks über die für die Abfallentsorgung relevanten Regelungen dargestellt. Den Einfluß des EG-Rechts einzuschätzen, ist hier nicht vorgesehen. Zur Einwirkung des sekundären Gemeinschaftsrechts in Form der Umweltverträglichkeitsprüfungs-Richtlinie existiert umfangreiche Spezialliteratur $^{229}$, so daß dieser Hinweis darauf genügen soll. $\mathrm{Ob}$ sich Auswirkungen durch das primäre Gemeinschaftsrecht auf das Verwaltungs-, Verfahrens- und Raumplanungsrecht der Bundesrepublik Deutschland ergeben können, soll hier nicht untersucht werden.

226 Müller/Schmitt-Gleser II-1, S. 4.

227 Vgl. zur Bedeutung der TA-Abfall im Rahmen der grenzüberschreitenden Abfallentsorgung unten Kapitel B.III.1.d).

228 Sondermann, S. 35.

229 Vgl. z.B. Gassner, UPR 1990, S. 361, mit Literatumachweisen. 
Überblick über die relevanten Genehmigungsverfahren:

- Bei der Zulassung von ortsfesten Entsorgungsanlagen oder ihrer Änderung in wesentlichen Teilen oder ihres Betriebs ist nach $\S 7$ Abs. 1 AbfG die Durchführung eines förmlichen Planfeststellungsverfahrens erforderlich. Dieses abfallrechtliche Planfeststellungsverfahren richten sich nach §§ 72-78 VwVfG. Nach der Planfeststellung und dem Eintritt der Unanfechtbarkeit kommt dem Planfeststellungsbeschluß Ausschlußwirkung zu, d.h. Ansprüche von Betroffenen auf Unterlassung des Vorhabens, auf Beseitigung oder Änderung der Anlagen oder auf Unterlassung der Anlagenbenutzung sind dann ausgeschlossen. Weitere behördliche Entscheidungen neben der Planfeststellung sind nicht erforderlich (z.B. nach Bau-, Immissions-, Wasserrecht usw.).

In Ausnahmefällen kann nach § 7 Abs. 2 AbfG die zuständige Behörde statt des Planfeststellungsverfahrens das vereinfachte Plangenehmigungsverfahren durchführen. Voraussetzung ist, daß es sich um die Zulassung einer unbedeutenden ortsfesten Entsorgungsanlage oder eine Änderung einer Entsorgungsanlage in wesentlichen Teilen oder ihres Betriebs handelt und dabei keine Einwände zu erwarten sind. Bei Plangenehmigungsverfahren sind nachfolgend die erforderlichen Genehmigungen nach anderen Fachgesetzen einzuholen. Falls es sich am Ende eines Plangenehmigungsverfahrens als notwendig herausstellt, kann dieses in ein Planfeststellungsverfahren übergeleitet werden.

- Nicht ortsfeste Abfallentsorgungsanlagen bedürfen keiner abfallrechtlichen Genehmigung. Bei ihnen ist regelmäßig nur eine immissionschutzrechtliche $\mathrm{Ge}-$ nehmigung nach § 4 BImSchG erforderlich. 


\section{Landesrecht am Beispiel des Hessischen Abfallgesetzes 230}

Die Länder haben zur Umsetzung und Ergänzung des Abfallgesetzes des Bundes eigene Landesabfallgesetze erlassen. Die Landesabfallgesetze regeln insbesondere vom Bundesrecht nicht erfaßte Detailfragen und schließen damit die im Abfallgesetz des Bundes bewußt offengelassenen Regelungslücken.

Das im Juli 1989 in weiten Bereichen novellierte Hessische Abfallgesetz beinhaltet Regelungen über entsorgungspflichtige Körperschaften des öffentlichen Rechts, grenzüberschreitende Abfallentsorgung, Sonderabfälle, Abfallentsorgungsplanung, Deponieschonung etc.. Der zweite Teil des Gesetzes geht schwerpunktmäßig auf die Sanierung von Altlasten und die damit verbundenen Probleme ein.

\section{a) Allgemeine Regelungen}

Das Hessische Abfallgesetz in der Fassung vom 10.7.89 verpflichtet die Kreise und kreisfreien Städte, die in ihrem Gebiet angefallenen Abfälle einzusammeln ${ }^{231}$. Dabei haben sie die nach Maßgabe des $\S 1$ la Abs. 2 in Verbindung mit $\S 3$ Abs. 2 Satz 3 AbfG gegebene Rangfolge der Abfallvermeidung vor der Abfallverwertung ${ }^{232}$ und Abfallbeseitigung bei der Durchführung abfallwirtschaftlicher Maßnahmen zu beachten. Weiterhin sind sie verpflichtet, die hierfür notwendigen Anlagen und Einrichtungen zu schaffen und zu betreiben (§1 Abs. 2 Satz 3 HAbfAG). Zur Erfüllung ihrer Aufgaben können sich die Entsorgungspflichtigen in Analogie zum Abfallgesetz geeigneter Dritter bedienen (§ 1 Abs. 6 HAbfAG). Für den Fall, daß die entsorgungspflichtigen Gebietskörperschaften ihrer Aufgabe zur Schaffung von Anlagen nicht nachkommen, sieht das HAbfAG nach § 1 Abs. 3 HAbfG die Möglichkeit vor, daß der Umweltminister nach Ablauf einer Frist von 6 Monaten, der betreffenden Gebietskörperschaft diese Aufgabe abnehmen und auf einen Dritten übertragen kann. Dieser übernimmt dann Bau und ggf. den Betrieb der Anlage 233 .

230 Gesetz über die Vermeidung, Verminderung, Verwertung und Beseitigung von Abfällen und die Sanierung von Altlasten (Hessisches Abfallwirtschafts- und Altlastengesetz-HAbfAG) in der Fassung vom 10. 7. 1989, GVBl. I S. 197, 247.

231 Für das Gebiet des Umlandverbandes Frankfurt tritt an die Stelle der Kreise und kreisfreien Städte der Umlandverband Frankfurt.

232 Nach Maßgabe des $\S 5$ Abs. 6 HAbfAG ist auch beim Betrieb von Deponien auf Verwertungs- möglichkeiten zu achten. So sind z.B. Deponiegase nach dem Stand der Technik zu erfassen, zu behandeln und zu verwerten.

233 Pflugradt in Bim/Jung, Teil 18, Kapitel 4, Seite 25. 
In § 2 HAbfAG ist im einzelnen aufgeführt, was in den Abfallsatzungen der entsorgungspflichtigen Körperschaften zu regeln ist. Dazu gehört unter anderem die Festlegung, welche Abfälle von der Entsorgungspflicht ausgeschlossen werden können und die Festsetzung der Gebühren für die Abfallentsorgung.

Neben dem Einsammeln und Befördern von Abfällen haben die Kreise und kreisfreien Städte allgemeine abfallwirtschaftliche Maßnahmen zu berücksichtigen. $\mathrm{Zu}$ diesen Maßnahmen gehören die jährliche Erstellung von Abfallmengenbilanzen ( 3 Abs. 1 HAbfAG) die Bestellung von Abfallberatern, deren Aufgabe es ist, die Abfallbesitzer über Möglichkeiten der Abfallvermeidung und Abfallverwertung zu informieren (§ 3 Abs. 2 HAbfAG). Schließlich werden die Behörden des Landes, die Gemeinden und Gemeindeverbände verpflichtet, vermehrt Recyclingprodukte zu verwenden, um der Notwendigkeit einer verstärkten Abfallverwertung Rechnung zu tragen ( 3 Abs. 3 HAbfAG).

Nach Maßgabe des § 3a HAbfAG darf unbelasteter Bauschutt und Erdaushub nicht auf Deponien verbracht werden, die für Hausmüll oder hausmüllähnliche Gewerbeabfälle zugelassen sind.

Die Landesanstalt für Umwelt erstellt unter Berücksichtigung der Voraussetzungen des $\S 8$ Abs. 1 HAbfAG den Landesabfallentsorgungsplan nach § 6 AbfG. Der Landesabfallentsorgungsplan bedarf der Zustimmung des Umweltministeriums. Inhalte des Abfallentsorgungsplans sind Vorgaben für die Abfallvermeidung, -verwertung und sonstige Entsorgung von Abfällen, sowie die Festlegung von Standorten für Abfallentsorgungsanlagen. Der Einzugsbereich des Abfallentsorgungsplans ist nach wirtschaftlichen und technischen Gesichtspunkten auszuweisen.

\section{b) Regelungen zur grenzüberschreitenden Abfallentsorgung}

Die grenzüberschreitende Abfallentsorgung ist nach Maßgabe des § 1a Abs. 1 HAbfG nur für den Fall zulässig daß die entsorgungspflichtige Gebietskörperschaft außerstande ist, Hausmüll oder hausmüllähnliche Abfälle ihres Verantwortungsbereiches in einer ihr zur Verfügung stehenden Anlage zu entsorgen. Dies schließt auch die Mitbenutzung nach $\S 3$ Abs. 5 HAbfAG und die Entsorgung in einer anderen Anlage in der Bundesrepublik Deutschland mit ein ${ }^{234}$. In diesem Fall kann die zuständige Behörde die Überlassung an einen Dritten anordnen. Die Einzelheiten bestimmt der zuständige Minister durch Rechtsverordnung (§ 1a Abs. 2 HAbfAG).

234 Vgl. Pflugradt in Bim/Jung, S. 27. 
Sollen Sonderabfälle, die außerhalb Hessens angefallen sind, nach Hessen verbracht werden ${ }^{235}$, so ist dies nur zulässig, wenn der im Abfallentsorgungsplan ausgewiesene Einzugsbereich dies ausdrücklich zuläßt. Eine Ausdehnung des Einzugsbereiches über die Grenzen Hessens hinaus auf andere Bundesländer wird aber nur für den Fall eines Verbundes gegeben sein, also dann, wenn die Gegenseitigkeit der Abfallentsorgung durch vertragliche Vereinbarung gewährleistet ist ${ }^{236}$. Folgt man dieser Einschätzung, würde dies gleichzeitig bedeuten, daß der Import von Abfällen aus dem europäischen Ausland nur noch dann möglich wäre, wenn die „Gegenseitigkeit der Abfallentsorgung" sichergestellt ist.

\section{Kommunales Satzungsrecht}

Das staatliche Abfallrecht in Form von Gesetzen und Rechtsverordnungen zum wird durch das kommunale Satzungsrecht in wesentlichen Punkten ergänzt. Die entsorgungspflichtigen Gebietskörperschaften regeln die Abfallbeseitigung durch kommunale Satzungen, sogenannte Abfallsatzungen. Der Inhalt solcher Abfallsatzungen umfaßt dabei neben Regelungen über den Ausschluß von Abfällen aus der Entsorgungspflicht, Nutzungsrechte sowie die Festlegung der Beseitigungsgebühren. Ferner werden Bestimmungen über die Abfalleinsammlung, Müllbehälter, Behältervolumen, Gebührenpflicht, Fälligkeit etc. festgelegt. Hauptgegenstand ist jedoch die Festlegung der Beseitigungsgebühren. Als öffentliche Aufgabe ist die Abfallbeseitigung kostendeckend zu betreiben ${ }^{237}$.

235 Dies betrifft die Untertagedeponie Herfa-Neurode und die Sondermüllverbrennungsanlage Biebesheim.

236 So Pflugradt in Birn/Jung, S. 29. Im Hinblick auf EWG-Vertragliche Regelungen erscheint diese Einschätzung als nicht haltbar. Eine detailierte Prüfung dieser Frage ist Gegenstand von Kapitel B.III.1..

237 Pflugradt in Birn/Jung, Teil 15, Kapitel 12, Seite 4. 
Bert Rürup and Uwe H. Schneider - 978-3-631-75109-1

Downloaded from PubFactory at 01/11/2019 08:13:45AM

via free access 


\section{B. Konflikte aus unterschiedlichen Zwecksetzungen und syste- matischen Unterschieden der Regelungssysteme}

Bevor auf mögliche Konflikte zwischen den für das Abfallrecht relevanten Rechtsgrundlagen eingegangen werden kann, ist zu prüfen, ob und im welchem Umfang die Regelungen des primären Gemeinschaftsrechts als Rechtsgrundlagen anzuwenden sind.

\section{Integrationsgebot des EWG-Vertrags}

Die Zuordnung der Vorstufen der eigentlichen Entsorgung (Sammeln, Sortieren, Befördern und $Z$ wischenlagern ${ }^{238}$ ) von Abfall ist unproblematisch, diese Tätigkeiten stellen Dienstleistungen dar.

Auch da $B$ die Abfallentsorgung insgesamt als Teil des Wirtschaftslebens im Sinne von Art. 2 EWGV gelten muß, ist leicht zu begründen. Ohne eine gesicherte Abfallentsorgung ist in weiten Bereichen des produzierenden Gewerbes eine Produktion nicht möglich, und damit hat die Abfallentsorgung ähnliche wirtschaftliche Funktion wie die Versorgung mit Rohstoffen. Zusätzlich dazu besteht durch die abfallrechtlichen Bestimmungen, die bestimmte Anforderungen an die Entsorgung stellen, ein Markt für Entsorgungsleistungen. Damit sind auch die Bestimmungen zum Gemeinsamen Markt auf die grenzüberschreitende Abfallentsorgung innerhalb der Europäischen Gemeinschaft anzuwenden.

\section{Abfall- und Verwertungsbegriff}

Notwendige Voraussetzung zur Beantwortung der Frage, ob Abfälle Waren und/ oder Abfallentsorgung Dienstleistungen sind, ist die Klärung des anzuwendenden Abfall- und Verwertungsbegriffes. Die Untersuchung, ob die grenzüberschreitende Verbringung von Abfällen Warenverkehr darstellt, kann nur auf der Grundlage eines klar abgegrenzten Abfallbegriffs durchgeführt werden. Eine Feststellung der Stoffe und Gegenstände sowie der Umstände, unter denen diesen die Abfalleigenschaft zukommt, ist dazu unerläßlich. Des weiteren ist es notwendig zwischen

238 Vgl. § 1 Abs. 1 AbfG. 
„Verwertung“ und „endgültiger Beseitigung" zu unterscheiden, da sich auch hieraus unterschiedliche Beurteilungen bezüglich der Geltung der Marktfreiheiten ergeben könnten.

Die Präzisierung der Begriffe erfolgt auf den folgenden Grundlagen: Die jüngste Rechtsprechung des BGH zum subjektiven und objektiven Abfallbegriff im bundesdeutschen Recht ${ }^{239}$, die vorangegangenen Ausführungen des EuGH zum Abfallbegriff $^{240}$ und die Klärung des Verwertungsbegriffs im Beschluß des OVG Koblenz im Zusammenhang mit der immissionsrechtlichen Teilgenehmigung einer Feuerungsanlage, in der Reststoffe verbrannt werden sollten ${ }^{241}$.

\section{a) Präzisierung des Abfallbegriffs}

Ausgehend von der weitergehenden Präzisierung des Abfallbegriffs im Recht der Bundesrepublik Deutschland ist zu prüfen, ob sich aus dem Vergleich der Begriffsbestimmung und ergänzenden Regelungsinhalten des EG-Rechts eine Abweichung oder eine definitorische Übereinstimmung erkennen läßt. Dabei wird der letzte Kommissionsvorschlag zur Änderung der Abfallrichtlinie ${ }^{242}$ herangezogen. Diese Prüfung ist notwendig, da bei Abweichungen zwischen den abfallrechtlichen Begriffsbestimmungen im bundesdeutschen Abfallrecht und diesbezüglichen EGRichtlinien (im Sinne einer Kollision) der Anwendungsvorrang des sekundären EGRechts greift, und in diesem Fall der Abfallbegriff entsprechend der Regelung im EG-Recht angewendet werden müßte. Dies hat der EuGH in der oben genannten Entscheidung ausdrücklich herausgestellt.

\section{aa) Objektiver Abfallbegriff}

Bei der Entscheidung durch den BGH zum Abfallbegriff ging es in den Vorinstanzen zunächst nur um Frachttarife für den Transport von Rohstoffen, Produktionsrückständen und Abfällen. In seinem Urteil hat der I. Zivilsenat des Bundesgerichtshofs zusätzlich dazu zum Abfallbegriff ausgeführt, daß der Sinn und Zweck

239 BGH, Urteil vom 1. 2. 1990 - I ZR 126/88 - (Kammergericht).

240 EuGHE vom 28. 3. 1990 in Rs C-206/88 und -207/88 sowie -359/88, UPR 1990, S. 109.

241 OVG Koblenz, Beschluß vom 11. 6. 1990 - 7 B 10809/90 - in diesem Beschluß hat sich das OVG Koblenz auch zur Abgrenzung der stofflichen Verwertung von der Beseitigung durch Verbrennung geäußert.

242 KOM(89) 560 endg. - SYN 145, ABl. Nr. C 326 vom 30. 12. 1989, S. 6. Auf den Wortlaut der verabschiedeten Fassung konnte noch nicht zurückgegriffen werden. 
des objektiven Abfallbegriffs darin zu sehen ist „..., daß gefährdende Sachen im öffentlichen Interesse auch - anders als der subjektive Abfallbegriff zuläßt - gegen den Willen ihres Besitzers einer zwangsweisen Beseitigung zugeführt werden müssen" 243 . Diese Auffassung findet sich bereits in der Begründung zum Entwurf des Abfallgesetzes für die Bundesrepublik Deutschland wieder ${ }^{244}$. Es heißt dort, daß es dem Besitzer überlassen werden kann, welcher Sachen er sich entledigt und sie damit zu Abfällen macht. Es besteht allerdings die Einschränkung durch das öffentliche Interesse an der Beseitigung solcher Abfallstoffe, von denen Gefahren für die in § $2 \mathrm{AbfG}$ genannten Rechtsgüter ausgehen können. Der objektive Abfallbegriff nach diesem Verständnis erlaubt es damit nicht, beispielsweise Altglas, Altpapier und alte Kleidung von vorne herein dem Abfall zuzuordnen, da dies einer Enteigung der Stoffe aus der Verfügungsgewalt des Besitzers gleichkäme ${ }^{245}$.

\section{bb) Subjektiver Abfallbegriff}

Nach der Auffassung des BGH sind der subjektive und der objektive Abfallbegriff als gleichberechtigt anzusehen und unabhängig voneinander dazu geeignet die Abfalleigenschaft einer Sache zu begründen. Bei dem beispielhaft genannten Altglas ist auch nach dem Einwurf in einen Sammelbehälter keine Abfalleigenschaft zu unterstellen, da es dabei am Entledigungswillen fehlt ${ }^{246}$. Ansonsten würde der subjektive Abfallbegriff auch auf karitative und gewerbliche Sammlungen von gebrauchten Kleidern, Alttextilien oder Haushaltsgegenständen ausgedehnt, was der ausdrücklichen anderslautenden Bestimmung des $§ 1$ Abs. 3 Nr. 6 und Nr. 7 AbfG widersprechen würde. Daraus folgt, daß neben der Besitzaufgabe zusätzlich der Wille des Besitzers treten muß, sich von der Sache ohne weitere Zweckbestimmung zu trennen. Dieser Wille fehlt nach h.M., wenn ein Besitzer mit der bewußten Besitzaufgabe einem anderen einen Vorteil einräumen will ${ }^{247}$. Der subjektive Abfallbegriff im Urteil des BGH steht nicht im Widerspruch zu dem, was der EuGH in den vorangegangenen Urteilen zum Begriff des Abfalls ${ }^{248}$ ausgeführt hat.

Der EuGH sieht „die wesentlichen, in den 3. und 4. Erwägungsgründen aufgeführten Ziele beider Richtlinien 75/442/EWG und 78/319/EWG, nämlich der Schutz der menschlichen Gesundheit und der Umwelt (...) gefährdet, wenn die Anwendung

243 UPR 1990, S. 298

244 BT-Drucksache VI/2401, S. 11.

245 Handelsblatt vom 13. 6. 1990, S. 22.

246 OVG Münster GewArch 1983, S. 247 m. w. N..

247 BGH UPR 1990, S. 299, m. w. N..

248 Vgl. EuGHE in Rs C-206/88 und -207/88 sowie -359/88, UPR 1990, S. 109. 
beider Richtlinien von der Absicht des Besitzers abhinge, die wirtschaftliche Wiederverwendung durch andere Personen ausschließen zu wollen oder nicht"249. Dadurch wird aber nur verhindert, daß die subjektive Abfalleigenschaft einzig daran zu knüpfen ist, daß der Besitzer die Wiederverwertung ausdrücklich ausgeschlossen hat. Es kann aber auch nicht im Umkehrschluß aus der Wiederverwertungsmöglichkeit von bestimmten Abfällen generell auf einen fehlenden Entledigungswillen des Besitzers geschlossen werden ${ }^{250}$. Stoffe oder Gegenstände, die wiederverwertbar sind, können nicht schon allein deshalb aus der Definition des Begriffs Abfall herausgenommen werden. Der fehlende Entledigungswille des Besitzers äußert sich aber in der Verfügungstellung für z.B. karitative oder gewerbliche Sammlungen von Altpapier oder Gebrauchttextilien. Der Besitzer hat dabei eindeutig die Absicht, die Sache(n) im Wirtschaftskreislauf zu halten, d.h. sie einer Nutzung als Wirtschaftsgut zu erhalten und nicht einer Beseitigung zuzuführen. Anders zu beurteilen ist die Überlassung an einen Entsorgungspflichtigen, hier schließt der ehemalige Besitzer die Wiederverwertung zwar nicht aus - er könnte dies überhaupt nicht; er trennt sich aber ohne weitere Zweckbestimmung von ihr. Selbst wenn einer Sache die subjektive Abfalleigenschaft zukommt, endet diese dann, wenn sich vor einer Übernahme durch den Entsorgungspflichtigen ein neuer Besitzer findet, bei dem kein Entledigungswillen mehr besteht. Die Mitnahme eines Sofas vom Sperrmüll zur Nutzung als Wohnungseinrichtung hat zur Folge, daß die Abfalleigenschaft mit dem Zeitpunkt der Aneignung durch den neuen Besitzer nicht mehr gegeben ist.

Eingriffsvoraussetzung des Abfallgesetzes bei Sachen, die nicht unter den objektiven Abfallbegriff fallen, ist damit die Überlassung an eine entsorgungspflichtige Körperschaft oder an durch diese beauftragte Dritte. Aber selbst dann ist die subjektiv begründete Abfalleigenschaft von Altpapier oder ähnlichen Wertstoffen, welche durch oder im Auftrag einer entsorgungspflichtigen Körperschaft gesammelt wurden, nicht endgültig. Sie endet unbeschadet des § 3 Abs. 2 AbfG mit der Übergabe oder Veräußerung an ein gewerbliches Recyclingunternehmen oder einen Zwischenhändler. Glas, Papier und vergleichbare Wertstoffe, die in Systemen entsorgungspflichtigen Körperschaften oder von beauftragten Dritten erfaßt werden, gelten gemäß $\S 3$ Abs. 2 AbfG bis zu ihrer Wiedereinführung in den Wirtschaftskreislauf als Abfälle. Sie werden also rechtlich zunächst anders behandelt, als gleichartige Abfälle aus karitativen oder gewerblichen Sammlungen. Die Übergabe oder Veräußerung ist aber nach Ansicht der Verfasser als Wiedereinführung in den

249 EuGHE vom 28. 3. 1990 in Rs C-206/88 und $-207 / 88$ sowie $-359 / 88$, UPR 1990, S. 109.

$250 \mathrm{Vgl}$. EuGHE in Rs C-206/88 und -207/88 sowie -359/88, UPR 1990 S. 109. 
Wirtschaftskreislauf i.S. § 3 Abs. 2 AbfG anzusehen; andernfalls wäre in diesem Beispiel bei einem Zwischenhändler befindliches Altpapier aus gewerblichen Sammlungen rechtlich anders zu behandeln, als solches aus Sammlungen entsorgungspflichtiger Körperschaften. Ein derart unübersichtlicher Zustand ist aus Gründen der Überwach- und Kontrollierbarkeit nicht wünschenswert. Er ist darüber hinaus weder vom subjektiven noch vom objektiven Abfallbegriff - entsprechend des oben formulierten Präzisierung - gedeckt. Der Hintergrund der Regelung in $\S 3$ Abs. 2 AbfG sind vermutlich Befürchtungen, daß Hausmüll bzw. seine Bestandteile, die wiederverwertbar sind, je nach dem Entledigungswillen und der Sortierung Abfall oder Wirtschaftsgut darstellen.

Das Ergebnis der Bestimmung des für die innereuropäische, grenzüberschreitende Abfallentsorgung anzuwendenden subjektiven und objektiven Abfallbegriffs läßt sich also folgendermaßen zusammenfassen:

Zwischen EG-Abfallrecht und bundesdeutschem Abfallrecht ergibt sich bezüglich subjektiven Abfallbegriffs kein Widerspruch, da der subjektive Abfallbegriff beider Regelungsbereiche inbesondere aus Gründen des Eigentumsschutzes als kompatibel angesehen werden muß ${ }^{251}$. Beim objektiven Abfallbegriff knüpfte das EG-Recht bislang an die nationalen Bestimmungen an. In der Neufassung der Abfallrichtlinie 75/442/EWG ist dieser Rückgriff nicht vorgesehen. Es werden daher in Anhang I des Richtlinien-Entwurfs Gründe aufgeführt, die den Besitzer zwingen, sich von Sachen oder Gegenständen zu entledigen. Die vorausichtliche Abstützung der Neufassung der Abfallrichtlinie auf Art. 130s EWGV erlaubt aber die Beibehaltung strengerer mitgliedstaatlicher Regelungen. Für giftige und gefährliche Abfälle, Altöle und PCB ist nach den entsprechenden Richtlinien der objektive Abfallbegriff ohnehin anzuwenden.

\section{b) Verwertungsbegriff}

In Zusammenhang mit der Untersuchung der Anwendung der Grundfreiheiten des EWG-Vertrags bedarf es einer klaren Definition und Abgrenzung des Verwertungsbegriffs, denn es ist vorstellbar, daß zwischen Verwertung und endgültiger Beseitigung von Abfällen bezüglich einer möglichen Geltung der Grundfreiheiten des EWG-Vertrags zu differenzieren ist.

251 Hösel/v. Lersner, § 1 Abs. 3 AbfG, Rdnr. 3, a.A. Pernice, NVwZ 1990, S. 414, $415-$ 416. 
Eine Verwertungspflicht für Abfälle kann nach § 1a Abs.1 Satz 2 AbfG verhängt werden. Rechtsverordnungen auf dieser Grundlage sind bisher jedoch nicht ergangen. Für Reststoffe besteht gemäß $\S 5$ Abs $1 \mathrm{Nr} 3 \mathrm{BImSchG}$ ein Verwertungsgebot. Zwar sind Reststoffe im Sinne des Abfallgesetz, sofern sie nicht vom objektiven Abfallbegriff erfaßt werden, kein Abfall, doch kann die Rechtsprechung des OVG Koblenz zur Präzisierung des Verwertungsbegriffs herangezogen werden. Gegenstand des Verfahrens war die Erteilung einer immissionsrechtlichen Teilgenehmigung für ein Erweiterungsvorhaben zur Errichtung einer zusätzlichen Feuerungsanlage in einem bestehenden Heizkraftwerkskomplex. In dieser Feuerungsanlage sollten Reststoffe aus der Kartonproduktion verbrannt werden ${ }^{252}$. In dem Beschluß des OVG Koblenz wird darauf hingewiesen, daß eine Verwertung dann nicht vorliegt „..., wenn die stoffliche oder energetische Nutzung lediglich nachgeordneter Zweck eines hauptsächlich auf Entledigung ausgerichteten Vorgangs

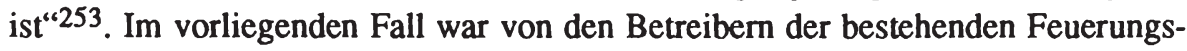
anlage nicht nachweisbar, daß die vorgesehene Verbrennung von Fangstoffen aus der Kartonagenproduktion einen bedeutenden Beitrag zur Gewinnung von Energie liefern kann, daher sei nicht von Verwertung auszugehen.

Damit ergibt sich folgender Verwertungsbegriff: Verwertung liegt nur vor, wenn die stoffliche oder energetische Nutzung zur Rückgewinnung stofflicher Ressourcen bzw. meßbaren Gewinnung von Energiebeiträgen führt, andernfalls ist von (endgültiger) Beseitigung auszugehen.

Auf dieser Grundlage ist nachfolgend der Warencharakter von Abfällen und die Dienstleistungseigenschaft von Abfallentsorgung zu klären.

\section{Anwendbarkeit der Bestimmungen zum Warenverkehr oder zur Dienstleistungsfreiheit}

Der EuGH hatte bislang noch nicht über die Frage der Erfassung von Abfällen und der Abfallentsorgung durch das Integrationsgebot des EWGV zu entscheiden. In einem Vertragsverletzungsverfahren der Kommission gegen Belgien ${ }^{254}$ wirft die Kommission Belgien vor, mit einem regionalen Verbot der Ablagerung von gefährlichen Abfällen unter anderem gegen Art. 30 und 36 EWGV verstoßen zu haben. Der EuGH wird sich daher bei seiner Entscheidung mit dem Warencharakter von giftigen und gefährlichen Abfällen befassen müssen.

252 OVG Koblenz, Beschluß vom 11. 6. 1990, 7 B 10809/980.

253 UPR 1990, S. 306.

254 Rs. C-2/90-Kommission/Belgien, vgl. EuZW 1990, S. 45-46. 


\section{a) Warencharakter von Abfällen}

In seiner bisherigen Rechtsprechung hat sich der EuGH bereits in anderem $\mathrm{Zu}$ sammenhang mit dem Warenbegriff bzw. Warencharakter von Gegenständen auseinandergesetzt - es ging in diesem Fall um Ausfuhrabgaben ${ }^{255}$ auf Kunstgegenstände. In zwei anderen Fällen hat der EuGH die Wareneigenschaft bestimmter Abfallarten geprüft. In der Entscheidung zu Ausfuhrabgaben auf Kunstgegenstände hat der EuGH eine Definition des Begriffs Ware gegeben. Waren im Sinne von Art. 9 EWGV sind „Erzeugnisse, die einen Geldwert haben und deshalb Gegenstand von Handelsgeschäften sein können“. Der in der Literatur ${ }^{256}$ vertretenen Auffassung, daß es dem EuGH in dieser Begriffsbestimmung primär auf die Eigenschaft „Gegenstand von Handelsgeschäften“ sein zu können ankam, kann hier nicht zugestimmt werden. Es erscheint vielmehr gleichermaßen notwendig, auf den Geldwert einer Sache oder eines Stoffes abzuheben. Die Besitzer von Abfällen müssen in fast allen Fällen für deren Entsorgung bezahlen, d.h. Abfall hat dann einen „negativen“ Geldwert $^{257}$. Hierzu ist Frage zu stellen, ob Waren in allen Fällen einen positiven Geldwert besitzen müssen. Diese Frage ist bislang weder in der Fachliteratur noch durch die Rechtsprechung des EuGH ausreichend geklärt.

Die Abfälle, denen der EuGH Warencharakter zugebilligt hat, sind solche mit positivem Geldwert ${ }^{258}$. Es handelt sich bei den Abfällen, zu denen diese Entscheidungen ergangen sind, um Schlachtabfälle und Altöl. Ob diese Entscheidungen den Warencharakter von Abfällen grundsätzlich und allgemein begründen können, ist aus mehreren Gründen zu bezweifeln:

Altöle besitzen nur in größeren Gebinden einen positiven Geldwert. Eine grenzüberschreitende Verbringung kleiner Gebinde wurde daher sicherlich nicht in die richterliche Würdigung des Sachverhalts einbezogen. Es kann somit aus diesem Urteil des EuGH nicht gefolgert werden, daß der Warencharakter auch solchen Abfällen mit negativem Geldwert zukommt. Zusätzlich dazu haben Altöle nur dann einen positiven Geldwert, wenn sie nicht mit Schadstoffen verunreinigt sind (z.B. mit $\mathrm{PCB}$, in diesem Fall unterliegen sie den Bestimmungen der PCB-Richtlinie ${ }^{259}$ ).

255 EuGH, Urteil vom 10. 12. 1968, Rs 7/68, Slg. 1968/634, S. 642.

256 So Friedrich, UPR 1988, S. 4, 9; zustimmend Studie der europäische Stiftung zur Verbesserung der Lebens- und Arbeitsbedingungen über den Transport gefährlicher Abfälle, S. 11-12.

257 v. Kempis, UPR 1985, S. 354, 354.

258 EuGH, 10. 3. 1983, Rs. 172/82 Slg. 1983/555 und EuGH, 6. Oktober 1987, Rs. 118/86, Rdnr. 11.

259 Vgl. oben Kapitel A.II.2.c). 
Schlachtabfälle von Geflügel werden in der Regel restlos weiterverarbeitet, so z.B. zu Tierfutter, zu Klebstoffen und Gelatineprodukten oder zu Düngemittel. Die Schlachtabfälle von Geflügel sind Reststoffe entsprechend dem Begriffsverständnis im bundesdeutschen Recht. Sie fallen bei der Verarbeitung an, ohne daß dies vom Hersteller angestrebt wird ${ }^{260}$. Ihre Abfalleigenschaft ergibt sich gemäß dem Tierkörperbeseitigungsgesetz und damit nach dem objektiven Abfallbegriff, d.h. auch dann, wenn der subjektive Entledigungswille des Besitzers fehlt.

Die Ableitung eines generellen Warencharakters aller Abfälle, insbesondere solcher mit negativem Geldwert, erscheint daher aus den genannten Entscheidungen nicht gerechtfertigt.

Um den Warencharakter näher zu bestimmen, könnten das primäre oder sekundäre Gemeinschaftsrecht sowie das bundesdeutsche Recht Anhaltspunkte bieten.

Im primären Gemeinschaftsrecht ist auf den Wortlaut des Art. 9 EWGV abzustellen, da von einer Klärung durch die Rechtsprechung bisher nicht ausgegangen werden kann. Aber auch die Auslegung am Wortlaut selbst kann unter Einbeziehung etymologischer Überlegungen ${ }^{261}$ nicht mit der notwendigen Sicherheit begründen, da $\beta$ Gegenstände mit negativem Geldwert nicht als Waren anzusehen sind. Bei Abfällen mit positivem Geldwert spricht das allgemeine Sprachempfinden eher für eine Wareneigenschaft. „Abfälle“ mit positivem Geldwert, d.h. für die der Abnehmer einen Kaufpreis zu zahlen bereit ist, sind allerdings wegen des fehlenden Entledigungswillens eben gerade nicht vom subjektiven Abfallbegriff erfaßt. Abfälle dagegen, die dem objektiven Abfallbegriff unterliegen, sind dem Warenverkehr durch hoheitliche Entscheidung entzogen und daher aus rechtlichen Gründen von einer wirksamen Nachfrage abgeschnitten ${ }^{262}$.

Im sekundären Gemeinschaftsrecht finden sich ebenfalls keine Bestimmungen, die als Auslegungshilfe dienen könnten ${ }^{263}$.

Das bundesdeutsche Recht bietet Ansatzpunkte im BGB und HGB; $\S 433$ Abs. 2 BGB verpflichtet den Käufer dazu, den vereinbarten Kaufpreis zu zahlen und die gekaufte Sache abzunehmen. Diese Regelung spricht dafür, daß Waren einen

260 Hoschützki/Kreft § 2 AbfG Anm. 3.2. m. w. N..

261 Vgl. dazu v. Kempis, UPR 1985, S. 354, 355.

262 v. Wilmowsky, S. 100, es bestehen aber die Ausnahmen bei Altölen und Schlachtabfällen.

263 So auch v. Wilmowsky, S. 101. 
positiven Geldwert aufweisen. Da aber die etymologische Herkunft des Begriffs „Ware“ - wie erwähnt - in der deutschen Sprache unklar ${ }^{264}$ ist, kann auf diesem Weg keine befriedigende Klärung erfolgen.

Zusammenfassend läßt sich feststellen, daß der Versuch, den Begriff der Ware ausreichend zu präzisieren, durch Auslegung von Gemeinschaftsrecht und bundesdeutschem Recht zu keinem zufriedenstellenden Ergebnis führt.

Eine andere Möglichkeit ist der Versuch, eine Klärung unter Zugrundelegung der systematischen Gestaltung des EWG-Vertrag herbeizuführen. Grundsätzlich ist die gleichzeitige Anwendung der Bestimmungen zum freien Warenverkehr und zur Dienstleistungsfreiheit ausgeschlossen ${ }^{265}$. Das verdeutlicht der Wortlaut des Art. 60 EWGV, der als Dienstleistungen nur solche entgeltlichen Leistungen einschließt, die nicht den Vorschriften über den freien Waren- und Kapitalverkehr sowie über die Freizügigkeit der Personen unterliegen. Somit kann die grenzüberschreitende Abfallentsorgung (die Transportvorgänge nicht eingeschlossen) den Bestimmungen zum freien Warenverkehr nicht gleichermaßen unterliegen. Diese systematische Trennung ergibt sich auch aus Gründen der unterschiedlichen Beschränkungsformen bezüglich des Waren- und Dienstleistungsverkehrs. Warenverkehr wird durch Zölle und Kontingentierungen beschränkt, während die Einschränkung des Dienstleistungsverkehrs durch direkte Bevorzugung inländischer Dienstleistungserbringer oder über höhere rechtliche Anforderungen an ausländische Dienstleistungserbringer erfolgt.

Da bei grenzüberschreitender Abfallentsorgung Stoffe oder Gegenstände die Grenze körperlich passieren, sind die Beschränkungsformen des Warenverkehrs besser geeignet, diese Form der Abfallentsorgung zu reglementieren. So halten die Vertreter der EG-Kommission es auch für ausschlaggebend, daß beim Abfallexport „... körperliche Gegenstände über die Grenze gebracht werden und daher das Vertragskapitel über den Warenverkehr ${ }^{266}$ die passenderen Regelungen enthalte“. Aus dieser ausschließlich an der Form des Grenzübertritts orientierten Sicht eine Anwendung der Bestimmung zum freien Warenverkehr auf die grenzüberschreitende Abfallentsorgung abzuleiten, erscheint allerdings nicht gerechtfertigt. Von grundlegender Bedeutung ist bei dieser Betrachtungsweise offensichtlich die grenzüberschreitende Verbringung von Stoffen bzw. Gegenständen. Die Argumentation baut rein auf der Betrachtung des Grenzübertritts auf. Daraus im

264 Vgl. v. Kempis S. 354, 355 und dort insbes. Fn. 15.

265 Vgl. zum Postulat der Widerspruchsfreiheit im EWG-Vertrag v. Kempis, UPR 1985, S. 354, 355.

266 Vgl. oben Kapitel A.II.1.c)aa). 
Zusammenhang mit dem unbestrittenen Postulat der Widerspruchsfreiheit ${ }^{267}$ in der Systematik des EWG-Vertrags eine Erfassung des Abfalls vom Grundsatz des freien Warenverkehrs herzustellen, erscheint nicht schlüssig ${ }^{268}$. Diese Herleitung beruht im Wesentlichen auf der Umkehrung der negativen Definition des Begriffs Dienstleistung in Art. 60 Satz 1 EWGV. Dort heißt es: Dienstleistungen sind, „... entgeltliche Leistungen ... soweit sie nicht den Vorschriften über den freien Warenund Kapitalverkehr und über die Freizügigkeit der Personen unterliegen". Diese Formulierung wird in eine positive Beschreibung umgekehrt. „... Dienstleistung (ist ${ }^{269}$ ) nur der Handel mit Erzeugnissen, der nicht mit beweglichen Sachen, sondern mit allen sonstigen Produkten unternehmerischer Tätigkeit erfolgt“270. Daraus wird nun geschlossen, daß Abfallentsorgung keine Dienstleistung sei. Unter Umgehung der Schwierigkeit bei der Definition des Begriffs Ware ${ }^{271}$ wird gefolgert, daß die Bestimmungen zur Warenverkehrsfreiheit anwendbar seien. Dem kann hier nicht gefolgt werden. Abfälle werden damit zumindest indirekt als Produkte unternehmerischer Tätigkeit bezeichnet. Diese Charakterisierung ist sehr fragwürdig. Die Betrachtung des Wortes „Produkt" hinsichtlich seiner Herkunft führt zum lateinischen Wort „productum“. Dieser Begriff wird übersetzt mit „auf den Markt Gebrachtes" bzw. zum „Verkauf Vorgeführtes"272. Ein wesentliches Charakteristikum von Abfällen ist, daß bis auf wenige Ausnahmen gerade kein Markt ${ }^{273}$ vorhanden ist (Markt verstanden als Ort, an dem Angebot und Nachfrage aufeinandertreffen); für Entsorgungsleistungen gibt es dagegen sehr wohl einen Markt. Außerdem fallen Abfälle ungewollt an, sie werden nicht gezielt hergestellt. Damit werden die Schwierigkeiten, die bei der Bestimmung des Begriffs Ware entstehen, bestenfalls auf das Wort Produkt verlagert, aber nicht gelöst. Schließlich ist es nicht hilfreich, die unklare Definition des Begriffs Ware aus gerade eben dem Begriff ableiten zu wollen, der nur mittels einer negativen Definition des Warenverkehrs (und der anderen Freiheiten im EWG-Vertrag) bestimmt ist.

Es muß außerdem in Betracht gezogen werden, daß nicht immer wenn Stoffe oder Gegenstände grenzüberschreitend verbracht werden, dies Warenverkehr im Sinne des EWG-Vertrags darstellt. So ist beispielsweise anerkannt, daß die Lohnveredelung von Waren im Ausland für einen inländischen Auftraggeber zu den Dienstleistungen zu zählen ist; ebenso trifft dies für Leasing von Maschinen bei einem aus-

267 Vgl. v. Kempis zur Systematik des EWG-Vertrag, UPR 1985, S. 354, 355.

268 Vgl. Friedrich UPR 1988, S. 4, 9.

269 Textumstellung vom Verf..

270 Friedrich, UPR 1988, S. 4, 9.

271 Vgl. v. Kempis UPR, S. 354, 354-355.

272 Knauer, zum Wort „Produkt“.

273 Vgl. oben in diesem Kapitel die Ausnahmen in der Rechtsprechung des EuGH. 
ländischen Leasinggeber zu, wie für das Mitführen von Werkzeugen beim Grenzübertritt, die zur Leistungserbringung in einem anderen Mitgliedstaat eingesetzt werden $^{274}$. Eine Analogie zur Abfallverbringung erscheint dennoch nicht gegeben, da die bezeichneten Gegenstände nach Erbringen der Leistung in der Regel wieder in das Herkunftsland zurückgeführt werden. Der mögliche Ankauf von Maschinen nach Ablauf der Leasingdauer ist davon getrennt zu beurteilen. Er stellt wiederum Warenverkehr dar, mit einer dazwischenliegenden Zeitspanne der Nutzung zwischen Einfuhr und Erwerb. Bei Abfällen stellt sich die Situation anders dar, nach der Deponierung verbleiben die Abfälle im Ausland, nach der Verbrennung zur Beseitigung oder thermischen Verwertung sind die Abfälle nicht mehr in ihrer ursprünglichen Form existent und können somit nicht mehr rückgeführt werden. Bei der Verwertung ist dies denkbar, allerdings muß der Abnehmer nicht mit dem Auftraggeber der Entsorgung übereinstimmen. Die Herleitung einer Analogie zwischen den oben genannten Beispielen und der Abfallentsorgung ist also nicht angebracht.

\section{b) Abfallentsorgung als Dienstleistung}

Ein anderer Ansatzpunkt bei der Klärung der Frage der Zuordnung könnte die Absicht sein, die vom Abfallerzeuger und vom Beseitiger bei der grenzüberschreitenden Abfallverbringung verfolgt wird. Es ist dabei auf die Zwecke der (unternehmerischen) Tätigkeiten abzustellen. Der Abfallbesitzer wählt die Entsorgung im Ausland deshalb, weil sie im Inland nicht oder nur zu höheren Kosten durchführbar ist. Der Besitzer von Abfällen kommt mit der Übergabe des Abfalls an ein autorisiertes Entsorgungsunternehmen einer gesetzlichen Verpflichtung nach. Das Entsorgungsunternehmen bezahlt nicht für den Erwerb der Abfälle, im Gegenteil es erhält ein Entgelt für seine Leistungen. Aus der Perspektive der Beteiligten, d.h. des Abfallerzeugers und desjenigen, der die Entsorgung der Abfälle durchführen soll, ist die Entsorgung und nicht der zu beseitigende Stoff oder Gegenstand von primärem Interesse, sondern die daran zu erbringende (Dienst-)Leistungen. Auch die staatliche Reglementierung der Abfallentsorgung setzt nicht mit Anforderungen an die Abfallbeschaffenheit an, so wie dies etwa bei Beschaffenheitsanforderungen an Produkte der Fall ist; dies wäre auch wenig sinnvoll, da Abfälle ja nicht gezielt und gewollt

274 v. d. Groeben u.a. Vorbemerkungen zu Art. 59 bis 66, Rdnr. 3 und Art. 60, Rdnr. 2 und Empfehlung der Kommission an die Mitgliedstaaten über das Zollverfahren, in dem Werkzeuge, Instrumente und Geräte abgefertigt werden, die vorübergehend aus einem Mitgliedstaat eingeführt werden, um dort zur Ausführung von Arbeiten aller Art verwendet werden, ABI. 1962, S. 2767 sowie Allgemeines Programm zur Aufhebung der Beschränkung des freien Dienstleistungsverkehrs, ABI. 1962, S. 32. 
produziert werden. Sie knüpft vielmehr an den Aspekt der Gefahren an, die bei unsachgemäßer Entsorgung drohen und ordnet daher beispielsweise bestimmte $\mathrm{Ab}$ fälle spezifischen Entsorgungsverfahren und -orten zu (TA-Abfall) und schreibt für diese Verfahren Standards vor (z.B. geplante Abfallverbrennungsverordnung). Somit sind die Entsorgungsleistungen das Gut, welches grenzüberschreitend angeboten und nachgefragt wird. Ein zusätzliches Argument für diese Einschätzung bildet die Völkerrechtspraxis, die grenzüberschreitende Abfallverbringung in Dienstleistungsabkommen zu regeln 275 .

\section{c) Sonderfall Verwertung}

Ein Sonderfall der Abfallentsorgung bildet die Verwertung ${ }^{276}$. Die Verwertung von Abfällen wird in der Regel nur aus zwei Gründen vorgenommen: Entweder es besteht eine gesetzliche Verwertungspflicht oder die Verwertung ist gegenüber anderen Entsorgungsformen mit geringeren Kosten verbunden. Abfälle müssen, um eine Verwertung zu ermöglichen, in bestimmten Mindestmengen vorliegen. Bei solchen größeren Mengen wird es sich in der Regel um Reststoffe ${ }^{277}$ handeln. Besteht darüber hinaus ein Absatzmarkt für einen Reststoff, so wird der Besitzer sich dieser Stoffe nicht entledigen wollen, sondern er wird beabsichtigen, sie zu veräußern. Damit fehlt einem solchen Reststoffen zumindest die subjektive Abfalleigenschaft. Trifft dies auch auf die objektive Abfalleigenschaft zu, so hat dieser Stoff die Wareneigenschaft und seine grenzüberschreitende Verbringung unterliegt der Liberalisierung.

In den zwei zuvor erwähnten Fällen, bei denen auf solche Reststoffe mit positivem Geldwert der objektive Abfallbegriff anwendbar ist, hat der EuGH diese Stoffe als Waren angesehen und damit den Reststoffen, die nicht vom objektiven Abfallbegriff erfaßt sind gleichgestellt. Auf Altöl und Geflügel-Schlachtabfälle (in größeren Mengen) finden somit die Vertragsregelungen zum freien Warenverkehr Anwendung.

\section{d) Schlußfolgerung}

Abfallentsorgung ist Dienstleistung, es werden entgeltliche Entsorgungsleistungen für Abfallerzeuger oder -besitzer erbracht. Auf die Verbringung von Abfällen von

275 Vgl. Dienstleistungsabkommen zwischen der Bundesrepubik Deutschland und der DDR vom 10. Juni 1986.

276 Vgl. oben Kapitel B.I.1.b).

277 Vgl. oben Kapitel A.III.1.b)bb). 
einem Mitgliedstaat in einen anderen zum Zwecke der Deponierung, Verbrennung, Neutralisierung und vergleichbarer Entsorgungsformen finden damit die Bestimmungen des EWG-Vertrags zur Dienstleistungsfreiheit Anwendung.

Bei der Entsorgungsform der Verwertung sind zwei Fälle zu unterscheiden. Die Verwertung, die nur aufgrund eines gesetzlichen Verwertungsgebots oder wegen Kostenvorteilen gegenüber anderen Entsorgungsformen vorgezogen wird, ist ebenfalls auf eine Entledigung ausgerichtet und daher gleichermaßen als Dienstleistung zu verstehen. Die Verwertung von Reststoffen unterliegt den Bestimmungen zum freien Warenverkehr. Abfalleigenschaft kommt Reststoffen nur dann zu, wenn sich der Besitzer ihrer entledigen will, z.B. weil keine Absatzmöglichkeit besteht (so z.B. Schlacke, die bei der Stahlerzeugung anfällt oder den Gips aus der Rauchgaswäsche, von beidem wird nur eine begrenzte Menge nachgefragt). Die Entsorgung ist dann eine Dienstleistung. In Fällen, in denen Reststoffe vom objektiven Abfallbegriff erfaßt werden, obwohl eine Absatzmöglichkeit besteht, ist die von EuGH bei Altöl und Schlachtabfällen eingeschlagene Linie beizubehalten und solchen Stoffen (Abfällen) die Wareneigenschaft zuzubilligen. Auf diese Stoffe sind damit gleichfalls die Bestimmungen zum freien Warenverkehr anzuwenden.

Zum gleichen Ergebnis hinsichtlich der Zuordnung von Abfall und Abfallentsorgung zum Waren- bzw. Dienstleistungsverkehr kamen auch Fachleute des Statistischen Bundesamtes in Rahmen einer volkswirtschaftlichen Würdigung des Sachverhalts. Nachdem das Angebot von gemischtem Altpapier in der Bundesrepublik die Nachfrage überstieg, setzten sie den Großhandelspreisindex für die Ware „Sortiertes gemischtes Altpapier", bislang Rechengrundlage für Verträge zwischen Lieferanten und Abnehmern, mit der Begründung aus: „Hier werde keine Ware mehr gehandelt, sondern eine Dienstleistung angeboten, nämlich die Beseitigung des Abfalls, ...“278.

\section{EWG-Vertragliche Legitimation von Beschränkungen der Grundfreiheiten}

Die im EWG-Vertrag vorgesehenen Legitimationen von Beschränkungen der Grundfreiheiten sind dazu geeignet, die aus den verschiedenen $Z$ wecksetzungen der relevanten Rechtsgrundlagen resultierenden Konflikte zu vermeiden. Sie sind daher auf ihre Anwendbarkeit zu untersuchen.

278 FR vom 21.2. 1991, S. 9. 


\section{Ausnahme von Dienstleistungsbereichen}

Für den Bereich der Dienstleistungen sind mehrere Ausnahmemöglichkeiten im EWG-Vertrag vorgesehen, die auf die Abfallentsorgung Anwendung finden könnten.

\section{a) Öffentliche Unternehmen}

Nach dieser Vorschrift können „Unternehmen, die mit Dienstleistungen von allgemeinem Interesse betraut sind", von der Anwendung der Bestimmungen des EWGVertrag ausgenommen werden. Diese Ausnahme darf aber nur soweit erfolgen, wie es zur Sicherung der Funktionsfähigkeit der Unternehmen erforderlich ist. Weiterhin bezieht sich die Vorschrift nur auf öffentliche und monopolartige Unternehmen. Durch den Art. 90 Abs. 2 EWGV sind aber nicht nur die genannten Unternehmen teilweise von der Anwendung des EWG-Vertrag ausgenommen, sondern die Mitgliedstaaten können sich bei Maßnahmen gegenüber solchen Unternehmen auf der Grundlage von Art. 90 Abs. 1 EWGV auf Art. 90 Abs. 2 EWGV berufen ${ }^{279}$. Zur Frage, in welchem Umfang Art. 90 Abs. 2 EWGV Eingriffe in die Waren- und Dienstleistungsfreiheit rechtfertigt, bestehen in der Fachliteratur sehr unterschiedliche Ansichten 280 .

\section{aa) Unternehmensbegriff}

Bevor diese Frage weiterverfolgt wird, soll der Begriff des „Unternehmens“ präzisiert werden. Ob der Staat als Unternehmen i.S. des Art. 90 Abs. 2 EWGV anzusehen ist, wenn er Entsorgungsleistungen erbringt, bestimmt sich rein funktional281. Damit dürfte der Staat, in Bereichen in denen er Leistungen gegen Bezahlung erbringt, als Unternehmen i.S. des Art. 90 Abs. 2 anzusehen sein. Gleiches gilt für öffentlichrechtliche Unternehmen und für privatrechtliche Unternehmen, auf die der Staat aufgrund von Beteiligungen, personeller Verflechtungen oder satzungsmäßiger bzw. sonstiger Bestimmungen unmittelbar oder mittelbar einen beherrschenden Einfluß ausüben $k^{2}{ }^{282}$. Private Unternehmen, auf die dies nicht zutrifft, sind von den Bestimmungen des Art. 90 EWGV nur dann erfaßt, wenn die Gewährung ausschließlicher oder besonderer Rechte, die betreffenden Unternehmen in eine ähnli-

279 Pernice in Grabitz, Art. 90, Rdnr. 51.

280 Vgl. die Fundstellen bei v. Wilmowsky, S. 156.

281 Allgemein herrschende Ansicht Gleis/Hirsch, Art. 90, Rdnr. 2 und Art. 85, Rdnr. 6.

282 Pernice in Grabitz, Art. 90, Rdnr. 16. 
che Abhängigkeitsstellung bringt, wie die öffentlichen Unternehmen ${ }^{283}$ (Denkbar ist z.B. der Betrieb einer Sonderabfallverbrennungsanlage durch ein privates Unternehmen, dem durch einen Benutzungs- und Anschlußzwang das ausschließliche Recht zur Abfallverbrennung in einem bestimmten Gebiet eingeräumt wird). $\mathrm{Zu}$ den Unternehmen, die nach Art. 90 Abs. 2 EWGV von der Anwendung der Bestimmungen des EWG-Vertrags ausgenommen werden können, zählen nicht die Unternehmen, die entsprechend der Möglichkeiten, die nach Inkrafttreten des 3. Änderungsgesetzes zum Bundes-Immissionsschutzgesetz bestehen, neben ihrem eigentlichen Produktionszweck z.B. auch Abfallverbrennung durchführen (So z.B. bei der Zementproduktion). Hier fehlt es an der Notwendigkeit, diese Unternehmen zur Erfüllung ihrer Aufgabe zu priviligieren, da der primäre Zweck der Unternehmen nicht in der Abfallentsorgung liegt.

\section{bb) Allgemeines wirtschaftliches Interesse}

Dienstleistungen von allgemeinem wirtschaftlichen Interesse sind anerkanntermaßen Versorgungsleistungen im weiten Sinne und wirtschaftliche Aktivitäten zur Sicherung der Infrastruktur und der Daseinsvorsorge ${ }^{284}$. Voraussetzung für die Ausnahme der Unternehmen vom EWG-Vertrag ist ein tatsächlicher Konflikt ${ }^{285}$ zwischen den notwendigen Maßnahmen zur Sicherung der Wahrnehmung der Aufgaben und den Bestimmungen des EWG-Vertrags. Das Interesse der Gemeinschaft gilt dabei als Grenze der Ausnahmemöglichkeit. Es spricht vieles dagegen, $\mathrm{da} B$ eine Priviligierung durch Auslastung von Entsorgungskapazitäten beispielsweise mittels eines Anschluß- und Benutzungszwangs für inländische Abfallverursacher im Interesse der Gemeinschaft liegt. Dies würde verhindern, daß die EWG ihr mit Änderung der Richtlinie über Abfälle 75/442/EWG verfolgtes Ziel erreichen kann. Beabsichtigt ist vielmehr, „... ein integriertes und angemessenes Netz von Entsorgungsanlagen zu errichten, das es der Gemeinschaft insgesamt erlauben müßte, die Entsorgungsautarkie zu erreichen... (und) daß die Beseitigung der Abfälle in einer der dem Entstehungsort am nächsten gelegenen angemessenen Entsorgungsanlagen unterstützt wird“286. Dem läuft eine Priviligierung von Unternehmen durch nationale Entsorgungsgarantien und ein Anschluß- und Benutzungszwang entgegen, der auf Inländer begrenzt ist. Zum einen wäre in diesem Fall die Inanspruchnahme der nächsten angemessenen Entsorgungsanlage durch Ausländer

283 Pernice in Grabitz, Art. 90, Rdnr. 19.

284 Pernice in Grabitz, Art. 90. Rdnr. 35.

285 Pernice in Grabitz, Art. 90, Rdnr. 53.

286 Rat der Europäischen Gemeinschaften Generalsekretariat, Mitteilungen an die Presse 6715/90 (Presse 81). 
unmöglich, wenn diese in einem anderen Mitgliedstaat liegt. Zum anderen ist die Forderung nach einer nationalen Entsorgungsautarkie jedes einzelnen Mitgliedstaates nur aus der Sicht eines großen Mitgliedstaates vertretbar. Sie berücksichtigt nicht die Situation kleinerer Mitgliedstaaten wie z.B. Luxemburg. Es wäre aus dem Gemeinschaftsgedanken heraus völlig überzogen, von diesen kleinen Mitgliedstaaten die Herstellung einer Entsorgungsautarkie für alle Abfallarten zu fordern.

Die Priviligierung von Entsorgungsunternehmen muß sich deshalb an der gemeinschaftlichen Strategie zur Abfallwirtschaft ausrichten. Aus diesem Grund ist auch eine generelle Ausnahme des Entsorgungssektors eines Mitgliedstaates durch die Bestimmungen des EWG-Vertrags nicht gerechtfertigt. Eine Ausnahme von Entsorgungsunternehmen ist daher nicht auf mitgliedstaatlicher Ebene begründbar und durchführbar, sie ist vielmehr der Aktivität der Gemeinschaft vorbehalten, wenn sie zur Verwirklichung der formulierten Ziele dient.

\section{b) Ausübung öffentlicher Gewalt}

Art. 66 EWGV stellt den Zusammenhang der Bestimmungen zur Dienstleistungsfreiheit zu den Art. 55-58 EWGV im Vertragsteil zur Niederlassungsfreiheit her. Art. 55 EWGV nimmt Tätigkeiten, die in einem Mitgliedstaat dauernd mit der Ausübung öffentlicher Gewalt verbunden sind, in diesem Mitgliedstaat von der Anwendung der Bestimmungen des Vertragskapitels über Dienstleistungsfreiheit aus. Bei der Begriffsbestimmung der öffentlichen Gewalt hat sich der EuGH bislang nicht auf eine einheitliche Definition festgelegt, sondern prüft jeden Einzelfall nach den individuellen Gegebenheiten ${ }^{287}$.

Das weitestgehende staatliche Engagement, daß bei der Abfallentsorgung denkbar ist, stellt die Übernahme der Entsorgungsverpflichtung für sämtliche auf dem Staatsgebiet anfallenden Abfälle dar. In der Europäischen Gemeinschaft hat nur Dänemark eine Entsorgungspflicht sowohl für Haushaltsabfälle als auch für industrielle Sonderabfälle übernommen ${ }^{288}$. In den anderen Mitgliedstaaten besteht diese nur für Haushaltsabfälle.

Die Situation in der Bundesrepublik Deutschland stellt sich folgendermaßen dar: Zwar hat der Staat die Entsorgungsverpflichtung grundsätzlich für alle Abfälle übernommen, in der Praxis allerdings haben sich alle entsorgungspflichtigen

287 Randelzhofer in Grabitz, Art. 55, Rdnr. 4.

288 v. Wilmowsky, S. 140. 
Körperschaften gemäß $\S 3$ Abs. 3 AbfG von der Entsorgungspflicht für Sonderabfälle ausgeschlossen. Die Abfallentsorgung könnte, soweit sich die öffentlichen Körperschaften nach \& 3 Abs. 3 AbfG nicht von ihrer Entsorgungspflicht ausgeschlossen haben ${ }^{289}$, von den Bestimmungen des EWG-Vertrags zur Dienstleistungsfreiheit ausgenommen sein.

Der Zweck der Vorschrift des Art. 55 EWGV besteht allerdings darin zu verhindern, daß sich Inländer der Ausübung öffentlicher Gewalt durch Ausländer gegenüber sehen. Dies ist im Zusammenhang mit der Abfallentsorgung nicht gegeben, da hier die öffentliche Tätigkeit in der Verwaltung, Gebührenerhebung und -einziehung zu sehen ist sowie in der Beauftragung Dritter mit Entsorgungsleistungen. Die Tätigkeiten der Entsorgung selbst sind aber nicht als Ausübung öffentlicher Gewalt anzusehen. Sie sind daher auch nicht gemäß Art. 55 EWGV von den Bestimmungen zur Dienstleistungsfreiheit ausgenommen.

\section{Beschränkungen der Warenverkehrsfreiheit}

Nach Art. 30 EWGV sind den Mitgliedstaaten, „mengenmäßige Einfuhrbeschränkungen sowie alle Maßnahmen gleicher Wirkung" im innergemeinschaftlichen Warenverkehr untersagt ${ }^{290}$. Für Ausfuhrbeschränkungen wird in Art. 34 EWGV ein gleichlautendes Verbot formuliert ${ }^{291}$. Ausnahmen von diesen Verboten zum Schutz des freien Warenverkehrs auf dem Gebiet der Gemeinschaft sind unter bestimmten Voraussetzungen zulässig. Beschränkungen des Warenverkehrs durch einseitige mitgliedstaatliche Maßnahmen sind auf der Grundlage von Art. 36 EWGV möglich. Der in Art. 36 EWGV enthaltene Katalog ist abschließend. Ist eines der in Art. 36 EWGV genannten Rechtsgüter durch Gemeinschaftsrecht abschließend geregelt, so ist eine Heranziehung von Art. 36 EWGV ausgeschlossen ${ }^{292}$.

Für den Fall, daß oder soweit keine Gemeinschaftsregelung besteht, hat der EuGH in seiner Rechtsprechung beim Vorliegen „Zwingender Erfordernisse“ (= rule of reason) festgestellt, daß unterschiedslos anwendbare Einfuhrregelungen dann nicht

289 Die Heranziehung Dritter zu Tätigkeiten zur Erfüllung der Entsorgungsverpflichtungen ist nicht von Belang.

290 Die Abgrenzung der Begriffe „mengenmäßige Einfuhrbeschränkungen“ sowie „Maßnahmen gleicher Wirkung" war nur bis zum Ablauf der Ubergangszeit am 1. Januar 1970 gemäß Art. 33 Abs. 7 EWGV in Bezug auf die Sanktionsfolgen von praktischer Bedeutung, Matthies in Grabitz Art. 31 Rdnr. 3. Gleiches gilt für die Art. 31-33, Matthies in Grabitz Art. 31-33 Rdnr. 1.

291 Für Art. 35 gilt hinsichtlich der Begriffsabgrenzung das für die Art. 31 -33 gesagte.

292 Matthies in Grabitz, Art. 36, Rdnr. 9. 
unter die Maßnahmen gleicher Wirkung fallen ${ }^{293}$. Im Fall der Ausfuhr ist aus der neueren Rechtsprechung des EuGH abzuleiten, daß sich Art. 34 EWGV nur auf solche nationale Maßnahmen erstrecken soll, die durch spezifische Beschränkungen der Ausfuhr der nationalen Produktion oder dem Binnenmarkt einen Vorteil gegenüber der Produktion oder dem Handel anderer Mitgliedstaaten verschaffen.

Für den Gemeinschaftsgesetzgeber gilt das Verbot in Art. 30 und Art. 34 EWGV nicht. Er ist aber ebenfalls verpflichtet, bei seinen Rechtsetzungsaktivitäten keine Handelsbeschränkungen einzuführen, denn seine Aufgabe besteht ja gemäß Art. 3 lit. a EWGV in der Herstellung und Gewährleistung des freien Warenverkehrs.

\section{Maßnahmentypen zur Beschränkung der grenzüberschreitenden Abfall- entsorgung in der Gemeinschaft}

Ein Vergleich des bundesdeutschen Abfallrechts mit den Vorschriften des primären Gemeinschaftsrechts zeigt, daß es wegen der unterschiedlichen Zwecksetzungen zwischen diesen Regelungen zu Konflikten kommen kann. Die Divergenzen zwischen nationalen Bestimmungen zur grenzüberschreitenden Abfallentsorgung und den einschlägigen Vorschriften des Gemeinschaftsrechts entstehen vor dem Hintergrund der Frage, inwieweit Abfälle und die Abfallentsorgung von den Garantien der Grundfreiheiten des EWG-Vertrags erfaßt werden. Verlangt der EWG-Vertrag einen gemeinschaftlichen Markt auch für Abfälle und die mit der Entsorgung verbundenen (Dienst-)Leistungen, so bedeutet dies, daß es den EG-Mitgliedstaaten verwehrt wäre, Maßnahmen zu treffen, die zu einer Behinderung des grenzüberschreitenden Handels und des Dienstleistungsangebotes sowie zu einer Beeinträchtigung der Wettbewerbsbedingungen in der Gemeinschaft führen. In den folgenden Kapiteln soll daher geprüft werden, ob und inwieweit nationale Regelungen, die zu einer Beschränkung der grenzüberschreitenden Abfallentsorgung führen, durch Gemeinschaftsrecht gedeckt sein können. Dabei werden sowohl Maßnahmen geprüft, die zu Exportbeschränkungen von Abfällen führen, als auch Maßnahmen, welche die Einfuhr von Abfällen begrenzen.

\section{Export}

Exportbeschränkungen sind Maßnahmen, die einerseits den inländischen Abfallerzeugern bzw. Entsorgungspflichtigen den Zugang zu Entsorgungsanlagen in ande-

293 Matthies in Grabitz, Art. 30, Rdnr. 6. 
ren EG-Mitgliedstaaten verwehren oder zumindest die grenzüberschreitende Verbringung von Abfällen erschweren. Andererseits werden die einheimischen Entsorgungsanlagen vor Konkurrenz aus anderen Mitgliedstaaten geschützt. Die wirtschaftlichen und ökonomischen Konsequenzen von Beschränkungen der Abfallausfuhr sind demnach für den einheimischen Entsorgungssektor und für die inländischen Abfallerzeuger sowie Entsorgungsunternehmen aus anderen Mitgliedstaaten unterschiedlich. Der einheimische Entsorgungssektor profitiert eindeutig von solchen Maßnahmen, denn ihnen wird neben dem bereits angesprochenen Schutz vor Konkurrenz aus anderen Mitgliedstaaten durch das Verbot der Ausfuhr von Abfällen die wirtschaftliche Auslastung ihrer Anlagen gesichert. Mit Nachteilen müssen dagegen beispielsweise die inländischen Industrieunternehmen rechnen, bei denen unter anderem Sonderabfälle anfallen. Ihnen wird der Zugang zu eventuell kostengünstigeren Entsorgungsanlagen in anderen EG-Mitgliedstaaten verwehrt.

Zur Rechtfertigung von Exportbeschränkungen werden, neben der Sicherung der Wirtschaftlichkeit des inländischen Entsorgungssektors, vorallem der umweltpolitische Nutzen von ausfuhrbeschränkenden Maßnahmen angeführt. Dabei sind insbesondere folgende Argumente in Betracht zu ziehen ${ }^{294}$. Exportverbote verhindern das Ausweichen auf ausländische Entsorgungsanlagen mit niedrigerem Beseitigungsstandard. Dadurch können mit höheren Entsorgungskosten und geringeren Umweltbelastungen verbundene strengere inländische Entsorgungsstandards leichter durchgesetzt werden. Zudem droht durch eine möglicherweise unsachgemäße Entsorgung von Abfällen im grenznahen Ausland die Gefahr negativer Rückwirkungen auf die inländische Umwelt. Die oft langen Transportwege bergen Transportrisiken und erschweren Überwachung und Kontrolle der Verbringung. Schließlich läuft der Export von Abfällen auf Dauer den umweltpolitischen Anstrengungen entgegen, generelle Abfallvermeidungs- und Abfallverwertungsstrategien zu entwickeln und durchzusetzen.

Exportbeschränkungen, wie sie das bundesdeutsche Abfallrecht aus den oben genannten Gründen mit dem Grundsatz der Inlandsentsorgung, dem Anschluß- und Benutzungszwang an Abfallentsorgungsanlagen und Abfallvermeidungs- und Abfallverwertungsgeboten vorsieht, müssen aber dennoch auf ihre Vereinbarkeit mit dem Gemeinschaftsrecht überprüft werden. Sie könnten mit Gemeinschaftsrecht unvereinbar sein, mit der Folge ihrer Unanwendbarkeit.

Eine erste Beurteilung der Vertragskonformität von ausfuhrbeschränkenden Maßnahmen ergibt, daß autonome Maßnahmen der Mitgliedstaaten, die sich nicht auf

294 Vgl. dazu v. Wilmowsky, S. 516, 517, mit der Angabe weiterer Regelungsziele. 
einen Rechtsakt der Gemeinschaft stützen können, grundsätzlich ausgeschlossen sind. Damit wäre aus dieser Sicht unter anderem die bundesdeutsche Praxis, Abfälle generell inländischen Entsorgungsanlagen zuzuordnen, nicht mit der Begründung zu rechtfertigen, die Umwelt in anderen Mitgliedstaaten mit niedrigeren Entsorgungsstandards schützen zu wollen. Der Grundsatz der Inlandsentsorgung von Abfällen ließe sich damit nicht ohne weiteres aufrechterhalten. Vielmehr müßte inländischen Abfallerzeugern und Entsorgungspflichtigen der Zugang zu Entsorgungsanlagen in anderen EG-Mitgliedstaaten offengelassen werden. Zu den Maßnahmen, die zu einer Beschränkung der Abfallausfuhr führen könnten, gehört aber auch die Verpflichtung, im Ausland zumindest eine solche Entsorgungsanlage aufzusuchen, die den für die inländische Beseitigung geltenden umweltpolitischen Standards genügt. Durch eine solche Verpflichtung ließe sich zumindest verhindern, daß Abfälle aus Kostengründen in Anlagen mit niedrigerem technischen Niveau verbracht werden 295 .

\section{a) Grundsatz der Inlandsentsorgung}

Im bundesdeutschen Abfallrecht wird vom Grundsatz der Inlandsentsorgung ausgegangen. Nach Maßgabe des § 2 Abs. 1 Satz 1 AbfG sind Abfälle, die im Geltungsbereich des Abfallgesetzes anfallen, grundsätzlich auch dort zu entsorgen. Unterstützt wird der Grundsatz der Inlandsentsorgung durch die Bestimmungen des Art. 4 Abs. 6 der Richtlinie des Rates über die grenzüberschreitende Verbringung gefährlicher Abfälle 84/631/EWG. Diese ermöglicht es den Mitgliedstaaten, die Benutzung inländischer Abfallentsorgungsanlagen in den gültigen Abfallentsorgungsplänen festzuschreiben, wenn andernfalls deren Durchführung gefährdet würde.

Bei einer Erfassung der grenzüberschreitende Abfallentsorgung von den Liberalisierungsgeboten des EWG-Vertrags verstößt das Gebot der Inlandsentsorgung im deutschen Abfallgesetz gegen Gemeinschaftsrecht. Sind Abfälle Waren im Sinne von Art. 9 EWGV, so unterliegen sie dem Grundsatz des freien Warenverkehrs. Handelt es sich bei Abfallentsorgungsleistungen um Dienstleistungen im Sinne des EWG-Vertrages, so finden die Vorschriften über den freien Dienstleistungsverkehr Anwendung (Art. 59 ff. EWGV).

Inwiefern die auf den Grundsatz der Inlandsentsorgung gestützten Exportbeschränkungen von Ausnahmen der Dienstleistungsfreiheit im Rahmen der EWG-vertrag-

295 Inwiefern auch für diesen Fall zwischen bundesdeutschem Abfallrecht und EG-Recht Konflikte entstehen, ist Inhalt der Prüfung in Kapitel B.III.1.d). 
lichen Regelungen gedeckt werden, oder ob gegebenenfalls umweltpolitsche Gesichtspunkte die Beschränkung der freien Ausfuhr von Abfällen legitimieren, soll im folgenden Abschnitt geprüft werden.

\section{aa) Ausschluß der Anwendbarkeit des EWG-Vertrags}

Die Abfallentsorgung ist nach deutschem Recht als Staatsaufgabe dem Bereich der Gefahrenabwehr und der öffentliche Daseinsvorsorge zuzurechnen ${ }^{296}$. Nach Maßgabe des Art. 66 EWGV i. V. m. Art. 55 EWGV finden auf Tätigkeiten, die in einem Mitgliedstaat dauernd oder zeitweise mit der Ausübung öffentlicher Gewalt verbunden sind, die Vorschriften über den freien Dienstleistungsverkehr keine Anwendung 297 . Die Abfallentsorgung ist nach bundesdeutschem Abfallrecht jedoch nicht in jedem Fall mit der Ausübung öffentlicher Gewalt verbunden. So können nach Maßgabe des § 3 Abs. 3 AbfG öffentlichrechtliche Körperschaften als Träger der Abfallentsorgung ausnahmsweise von einer Verpflichtung zur Abfallentsorgung hefreit sein. Die Abfallbesitzer haben in diesen Fällen die ordnungsgemäße Entsorgung der Abfälle selbst zu übernehmen und zu verantworten. In einem solchen Fall kann Art. 66 EWGV i. V. m. Art. 55 EWGV nicht zur Anwendung kommen. Inwiefern aber darüber hinaus die Abfallentsorgung von den Ausnahmen des Art. 66 EWGV i. V. m. Art. 55 EWGV erfaßt ist, erscheint aus den bereits genannten Gründen 298 und der neueren Rechtsprechung des EuGH zu Art. 48 EWGV 299 mehr als fraglich $^{300}$. Die grenzüberschreitende Abfallentsorgung als Inanspruchnahme von Dienstleistungen über Landesgrenzen hinweg, ist daher durch Art. 59 EWGV geschützt. Nach Maßgabe des Art. 59 Abs. 1 EWGV unterliegen zunächst nur die ausländischen Entsorgungsunternehmen der Liberalisierung des Dienstleistungsverkehrs. Für eine analoge Anwendung auf Inländer spricht der Grundsatz des EWGVertrags, jede wirtschaftliche Tätigkeit zu erfassen und keine Regelungslücken hinsichtlich der Liberalisierung entstehen zu lassen ${ }^{301}$. Ausfuhrbeschränkende Maßnahmen, die mit dem Gebot der Inlandsentsorgung begründet werden, sind also nicht auf Art. 66 EWGV i. V. m. Art. 55 EWGV abstützbar. Der Grundsatz der Inlandsentsorgung unterliegt insofern einer Überprüfung.

296 v. Kempis, UPR 10/1985, S. 354, 357.

297 Zu Reichweite und Zielsetzung des Art. 55 EWGV im Hinblick auf die grenzüberschreitende Abfallentsorgung, vgl. oben Kapitel B.II.1.b).

298 Vgl. oben Kapitel B.II.1.b).

299 Vgl. EuGH, NJW 1988, S. 1441. EuGH, NVwZ 1987, S. 41.

300 So auch, Pemice, NVwZ 1990, Heft 5, S. 414, 416, m. w. N.

301 Vgl. v. Kempis, UPR 10/1985, S. 354, 358. 
Eine Rechtfertigung des Grundsatzes der Inlandsbeseitigung könnte sich aus Art. 66 EWGV i. V. m. Art. 56 Abs. 1 EWGV ergeben. Art. 66 EWGV i. V. m. Art. 56 Abs. 1 EWGV sieht zwar für Ausländer eine Sonderregelung vor, falls dies aus Gründen der öffentlichen Sicherheit, Ordnung oder Gesundheit gerechtfertigt ist. Eine Sonderregelung aus Gründen des Umweltschutzes ist jedoch nicht explizit vorgesehen. Gegen die Anwendung in Bezug auf die Abfallentsorgung spricht außerdem, daß die Sonderregelungen im Sinne von Art. 56 EWGV im wesentlichen personenbezogene und nicht sachbezogene Vorschriften sind ${ }^{302}$, sowie der Sachverhalt, daß auch die grenzüberschreitende Verbringung von Abfällen inländischer Unternehmen von der Liberalisierung erfaßt sein muß. Mögliche Gefahren beim Transport sind ebenfalls nicht ausreichend zur Rechtfertigung einer Beschränkung der Dienstleistungsfreiheit, andernfalls müßten neben den Transporten von gefährlichen Abfällen sämtliche vergleichbaren Gefahrguttransporte eingeschränkt werden. Ein Transport zu einer ausländischen Entsorgungsanlage kann außerdem im Einzelfall viel kürzer und sicherer sein als zur nächsten inländischen Anlage ${ }^{303}$.

Eine Beschränkung des freien Dienstleistungsverkehrs könnte durch Art. 90 EWGV legitimiert $\operatorname{sein}^{304}$. Danach steht es den Mitgliedstaaten frei, durch die Gewährung einer Monopolstellung oder durch die Verstaatlichung eines Sektors den inländischen Wettbewerb auszuschalten ${ }^{305}$, dem EWG-Vertrag widersprechende Maßnahmen sind jedoch nicht gestattet. Die Mitgliedstaaten haben deshalb dafür Sorge zu tragen, daß inländische und EG-ausländische Bewerber, bei der Vergabe des Gebietsmonopols gleich behandelt werden. Staatliche Unternehmen dürfen ebensowenig vor ausländischer Konkurrenz abgeschirmt werden wie private. Die Gewährung von inländischen Monopolen wird damit zwar durch Art. 90 EWGV gedeckt jedoch nicht deren Schutz durch ein generelles Exportverbot ${ }^{306}$.

Nach Maßgabe des Art. 90 Abs. 2 EWGV finden die Regelungen über den freien Dienstleistungsverkehr keine Anwendung, wenn die Erfüllung der den Unternehmen übertragenen Aufgaben „rechtlich“ oder „tatsächlich“ durch diese ausgeschlossen

302 Folgerichtig weist v. Kempis daraufhin, daß bei der Abfallentsorgung die Gefahr jedoch gerade von der Sache selbst, nämlich dem Abfall ausgeht. v. Kempis, UPR 1985, S. 354, 360.

303 Pernice, NVwZ 1990, S. 414, 416.

304 Zu Reichweite und Zielsetzung des Art. 90 EWGV im Hinblick auf die grenzüberschreitende Abfallentsorgung, vgl. oben Kapitel B.II.1.a).

305 v. Wilmowsky, S. 533.

306 v. Wilmowsky weist in diesem Zusammenhang zu Recht darauf hin, daß es durch den EWG-Vertrag nicht gedeckt ist, daß ein Mitgliedstaat seiner, möglicherweise mit hohem finanziellem Aufwand aufgebauten Entsorgungswirtschaft, durch Exportbeschränkungen einen hohen Auslastungsgrad sichern will. Siehe ebenda, S. 534, m. w. N. 
wird. Bezogen auf die Abfallentsorgung bedeutet dies, da $\beta$ deren Ausschluß von der Anwendung der Art. $59 \mathrm{ff}$. EWGV erst dann in Betracht kommt, wenn bei Geltung der Grundfreiheiten der Betrieb einer Entsorgungsanlage wirtschaftlich unmöglich $\mathrm{zu}$ realisieren ist ${ }^{307}$. Fraglich ist aber, inwieweit wirtschaftliche Gesichtspunkte wie die Sicherung der Auslastung von technisch aufwendigen inländischen Entsorgungsanlagen durch den Grundsatz der Inlandsentsorgung eine Rolle bei der Beurteilung rechtlicher oder tatsächlicher Verhinderungen spielen können. Das Betreiben einer Entsorgungsanlage wird auch beim Unterbleiben ausfuhrbeschränkender Maßnahmen nicht nachweisbar unmöglich, daher rechtfertigt Art. 90 Abs. 2 EWGV kein uneingeschränktes Exportverbot für Abfälle.

\section{bb) Rechtfertigung eines Verstoßes gegen die Art. 59 ff. EWGV}

Eine Rechtfertigung des Gebots der Inlandsentsorgung könnte dennoch durch Art. 36 EWGV gegeben sein. Einer Anwendung von Art. 36 EWGV auf Dienstleistungen steht entgegen, daß sich diese Regelung nur auf die Bestimmungen zum freien Warenverkehr bezieht. Die Regelungen über den freien Warenverkehr und über die Dienstleistungen schließen jedoch einander gegenseitig aus. In Artikel 60 EWGV werden die Dienstleistungen den anderen Grundfreiheiten gegenüberstellt: „.... Soweit sie nicht den Vorschriften über den freien Waren- und Kapitalverkehr und über die Freizügigkeit der Personen unterliegen“ 308.

Eine direkte Beschränkung der Ausfuhr von Abfällen durch mitgliedstaatliche Maßnahmen wie den Grundsatz der Inlandsentsorgung könnte zu einer Verbesserung der Umweltsituation führen und damit dem Schutz der Gesundheit und des Lebens von Mensch, Tieren und Pflanzen dienen. Durch Art. 36 EWGV werden aber nur solche Maßnahmen gedeckt, die ein Staat zum Schutz der eigenen Bevölkerung trifft. Bezogen auf die grenzüberschreitende Abfallverbringung bedeutet dies, da $B$ eine Beschränkung der Abfallausfuhr sich nur dann auf Art. 36 EWGV abstützen ließe, wenn durch die Entsorgung im Ausland bzw. den Transport dorthin, eine unmittelbare Gefährdung des innerstaatlichen Territoriums entstehen würde. Dies dürfte jedoch nur bei der Verbringung und Entsorgung in grenznahen Anlagen der Fall $\operatorname{sein}^{309}$.

307 v. Kempis, UPR 1985, S. 354, 358.

308 Vgl. Europäische Stiftung zur Verbesserung der Lebens- und Arbeitsbedingungen, Transport gefährlicher Abfälle, Amt für amtliche Veröffentlichungen der Europäischen Gemeinschaften, 1987, S. 11.

309 Friedrich, UPR 1/1988, S. 4, 10. Dazu und zu Abwehrrechten der Mitgliedstaaten vgl. oben Kapitel A.II.2.d). 
Zudem erscheint die Anwendung von Art. 36 EWGV aus einem anderen Grund zweifelhaft. In erster Linie verfolgen die Mitgliedstaaten mit Exportbeschränkungen das Ziel, eine effiziente Auslastung und damit eine wirtschaftliche Nutzung von einheimischen Entsorgungsanlagen sicherzustellen. Der Grundsatz der Inlandsentsorgung zielt demnach auf die wirtschaftliche Machbarkeit $a b^{310}$. Geht es darum, wirtschaftliche Interessen durchzusetzen, so kann sich ein Mitgliedstaat nach der ständigen Rechtsprechung des EuGH gerade nicht auf Art. 36 EWGV berufen ${ }^{311}$. Zudem gilt nach ständiger Rechtsprechung des $\mathrm{EuGH}$, daß nationale Maßnahmen dann nicht mehr auf Art. 36 EWGV gestützt werden können, wenn auf einem Gebiet eine abschließende Gemeinschaftsregelung in Form von Verordnungen, Richtlinien oder Entscheidungen der Gemeinschaft bereits ergangen ist ${ }^{312}$. Davon ist zumindest für den Bereich der grenzüberschreitenden Verbringung und Entsorgung gefährlicher Abfälle in Form der Richtlinie 84/631/EWG auszugehen.

\section{cc) Sekundäres Gemeinschaftsrecht}

Der Grundsatz der Inlandsbeseitigung könnte aber durch gemeinschaftliches Sekundärrecht gerechtfertigt sein. In Betracht zu ziehen sind die auf dem Gebiet der Abfallentsorgung erlassenen Richtlinien und dabei insbesondere die Richtlinie über die grenzüberschreitende Verbringung gefährlicher Abfälle 84/631/EWG und die Richtlinie über Abfälle 75/442/EWG.

Da sowohl der nationale Gesetzgeber als auch der Gemeinschaftsgesetzgeber die Grundsätze zur Waren- und Dienstleistungsfreiheit zu beachten hat, sind sich auf Sekundärrecht stützende Ausfuhrbeschränkungen ebenso auf ihre Vereinbarkeit mit dem EWG-Vertrag zu prüfen wie einzelstaatliche Maßnahmen. Eine Einschränkung des Primärrechts durch Sekundärrecht erscheint in Bezug auf die grenzüberschreitende Abfallverbringung nur dann möglich, wenn dies umweltpolitisch auf Gemeinschaftsebene gerechtfertigt werden kann. Bei auslegungsbedürttigen Bestimmungen des Sekundärrechts ist ohnehin das Primärrecht als Maßstab heranzuziehen.

Die Richtlinie über die grenzüberschreitende Verbringung gefährlicher Abfälle 84/631/EWG ermöglicht es den Mitgliedstaaten nach Maßgabe des Art. 4 Abs. 6 Satz 4 sowie voraussichtlich Art. 7 Abs. 3 der Neufassung der Richtlinie des Rates

310 So v. Kempis, UPR 1985, S. 354, 361.

311 Nachweise bei v. d. Groeben/Thiesing/Ehlermann, 205. Lfg. Februar 1984, Art. 36 Rdnr. 25, 31.

312 Friedrich, UPR 1988, S. 4, 10. 
über Abfälle 75/442/EWG von 1990313, die Benutzung inländischer Entsorgungsanlagen in Abfallbeseitigungsplänen vorzuschreiben, wenn durch den Abfallexport die Durchführung eines Abfallentsorgungsplans beeinträchtigt wird. Somit könnte argumentiert werden, da $\beta$ der Gemeinschaftsgesetzgeber insoweit den Ausschluß ausländischer Entsorgungsanlagen aus den jeweils gültigen Abfallwirtschaftsplänen legitimiert. Für eine solche Auslegung der Vorschrift würde auch die Tatsache sprechen, da $B$ im Wortlaut der Richtlinie über die grenzüberschreitende Verbringung gefährlicher Abfälle nur allgemein von „erforderlichen Maßnahmen“ die Rede ist. Unter diesen „erforderlichen Maßnahmen“ ließe sich dementsprechend die Sicherung von technisch aufwendigen inländischen Entsorgungsanlagen, deren Betrieb auf die Absicherung durch Exportverbote angewiesen ist, subsumieren ${ }^{314}$. Eine solche Auslegung der Richtlinie ist zweifelhaft ${ }^{315}$, da der Grundsatz der Inlandsentsorgung nicht ausdrücklich in der Vorschrift erwähnt wird. Im Gegenteil, es spricht sogar grundsätzlich nichts dagegen, auch ausländische Entsorgungsanlagen in den Abfallentsorgungsplänen vorzusehen.

Der freie Dienstleistungsverkehr innerhalb der Gemeinschaft stellt auch den Zugang zu ausländischen Entsorgungsanlagen unter Schutz, somit bedarf Art. 4 Abs. 6 der Richtlinie über die grenzüberschreitende Verbringung gefährlicher Abfälle 84/631/EWG einer vertragskonformen Auslegung 316 .

Eine Rechtfertigung nationaler Alleingänge durch die Richtlinie 84/631/EWG dürfte auch deshalb nicht möglich sein, da sich diese auf Art. 100 EWGV als Rechtsgrundlage stützt ${ }^{317}$ und somit abschließende Wirkung hat. Sie muß daher EG-einheitlich ausgelegt werden. Nur so kann verhindert werden, da $B$ umsetzungs- und auslegungsbedingte Unterschiede in nationalen Rechtssystemen zu ungleichen Wettbewerbsbedingungen führen.

Eine Rechtfertigung des Grundsatzes der Inlandsentsorgung könnte sich ferner nach Maßgabe der Art. 6 der Richtlinie 75/442/EWG und Art. 12 der Richtlinie 78/319/EWG ergeben. In den Artikeln werden die Mitgliedstaaten verpflichtet, Abfallbeseitigungspläne zu erstellen und fortzuschreiben. Bei der Erstellung der Abfallentsorgungspläne sind Planinhalte, wie „geeignete Flächen für Deponien“318

313 v. Wilmowsky, NVwZ 1991, S. 1,9.

314 Vgl. v. Kempis, UPR 1985, S. 354, 358.

315 Eine Verpflichtung der Mitgliedstaaten, in ihren Plänen die Benutzung inländischer Entsorgungsanlagen festzuschreiben ist daraus aber nicht herleitbar. Vgl. v. Kempis, UPR 1985, S. 354, 359.

316 v. Wilmowsky, NVwZ 1991, S. 1, 10.

317 Vgl. oben Kapitel A.II.2.d).

318 Art. 6 der Richtlinie 75/442/EWG. 
und „geeignete Orte für die Ablagerung“319, zu berücksichtigen. Inwieweit dabei eine solche Planung auch ausländisches Territorium berücksichtigen kann, könnte in Frage gestellt werden. In Bezugnahme auf $\S 6$ Abs. 1 Satz 2 AbfG könnte gefolgert werden, eine solche Verplanung ausländischen Territoriums sei völkerrechtlich ausgeschlossen. Dem widerspricht aber die generelle Möglichkeit, völkerrechtliche Probleme durch Abschluß eines völkerrechtlichen Vertrags zu lösen ${ }^{320}$. Durch die Neufassung der Richtlinie 75/442/EWG wird die Berücksichtigung von Entsorgungsmöglichkeiten in anderen Mitgliedstaaten sogar teilweise notwendig. Ferner stellt sich die Frage, inwieweit Systemunterschiede zwischen dem einschlägigen bundesdeutschen Recht und den Richtlinienbestimmungen hinsichtlich der Verbindlichkeit eines Planes für die Entsorgungspflichtigen bestehen. Von einer solchen Verbindlichkeit im Sinne von § 6 Abs. 1 Satz 6 AbfG kann bei den genannten Richtlinienbestimmungen jedoch nicht ausgegangen werden. In den gültigen nationalen Abfallbeseitigungsplänen können also auch ausländische Entsorgungsanlagen und Deponien berücksichtigt werden. Generelle Ausfuhrbeschränkungen lassen sich daher nicht auf die oben genannten Richtlinienbestimmungen abstützen ${ }^{321}$.

Der auch von der Bundesregierung vertretene Standpunkt, die Verpflichtung zur Inlandsentsorgung diene der Sicherung der Rentabilität der inländischen Entsorgungsinfrastruktur mit hohen Standards und sei auch daher umweltpolitisch gerechtfertigt ${ }^{322}$, bedarf nicht nur im Hinblick auf die Wirkung des EWG-Vertrages einer Korrektur. Bezeichnend für die umweltpolitische Fragwürdigkeit dieser Aussage ist, daß die Ausfuhr von Abfällen ohne Rücksicht auf die von den ausländischen Entsorgungsanlagen eingehaltenen Beseitigungsstandards untersagt wird. Insofern werden ebenso Exporte in Anlagen mit höherem Niveau verwehrt. Durch die Entsorgung der Abfälle in einer solchen Anlage würde die Umwelt weniger stark in Anspruch genommen und zusätzlich könnten unter Umständen die Transportwege erheblich verkürzt werden.

Wird von einer ausländische Entsorgungsanlage der Entsorgungsstandard, der für inländische Anlagen vorgeschrieben ist, erreicht oder überschritten, so sind Exportbeschränkungen umweltpolitisch nicht zu vertreten. Damit sind ernste Zweifel an dem umweltpolitischen Nutzen der Verpflichtung zur Inlandsentsorgung angebracht. Es drängt sich vielmehr der Verdacht auf, daß es sich hierbei um protektionistische

319 Art. 12 der Richtlinie 78/319/EWG.

320 v. Kempis, UPR 1985, S. 354, 359.

321 v. Kempis, UPR 1985, S. 354, 360.

322 Vgl. Bundesregierung, Entwurf eines Dritten Gesetzes zur Änderung des Abfallbeseitigungsgesetzes, BT-Dr. 10/849, S. 8. 
Eingriffe handelt, die im Hinblick auf die Grundfreiheiten des EWG-Vertrages keinen Bestand haben können ${ }^{323}$. Die in erster Linie verfolgte Absicht der Sicherung der Rentabilität einheimischer Entsorgungseinrichtungen rechtfertigt wie oben dargestellt - keinen Eingriff in den freien Dienstleistungsverkehr. Es würden einzig inländische Entsorgungsunternehmen vor ausländischer Konkurrenz geschütz ${ }^{324}$. Ziel des EWG-Vertrages ist es aber gerade, jede Art von staatlichem Protektionismus im innergemeinschaftlichen Wirtschaftsverkehr zu verhindern. Es spielt dabei auch keine Rolle, ob die öffentliche Hand unternehmerisch tätig ist ${ }^{325}$. Staatliche Entsorgungsunternehmen dürfen ebensowenig vor ausländischer Konkurrenz geschützt werden wie private Anbieter von Entsorgungsleistungen.

\section{b) Anschluß und Benutzungszwang}

Das bundesdeutsche Abfallrecht geht vom Grundsatz der öffentlichen Abfallentsorgung aus. Nach Maßgabe des $\S 3$ Abs. 2 Satz 1 AbfG hat regelmäßig nicht derjenige, bei dem die Abfälle entstehen, für die ordnungsgemäße Entsorgung Sorge zu tragen sondern die nach dem Recht des jeweiligen Bundeslandes zuständige öffentlichrechtlichen Körperschaften ${ }^{326}$. Die Abfallerzeuger haben ihre Abfälle der entsorgungspflichtigen Körperschaft zu überlassen ( $33 \mathrm{Abs}$. $1 \mathrm{AbfG}$ ), ihnen wird damit aber auch die Beseitigungsverantwortung zwangsweise entzogen. Mit der Überlassungpflicht verbunden ist ein umfassender Anschluß- und Benutzungszwang, der prinzipiell verhindert, daß die Abfallbesitzer ihre Abfälle zur Entsorgung in einen anderen EG-Mitgliedstaat verbringen ${ }^{327}$. Aus der Tatsache heraus, da $B$ dadurch Abfallbesitzer vom Angebot von Entsorgungsleistungen aus anderen Mitgliedstaaten abgeschnitten werden, folgt zwangsläufig die Frage nach der Zulässigkeit einer solchen Ausfuhrbeschränkung und ihrer Vereinbarkeit mit der Dienstleistungsfreiheit des EWG-Vertrages.

Inwiefern der mit dem Anschluß- und Benutzungszwang verbundene zwangsweise Entzug der Entsorgungsverantwortung einen Verstoß gegen die Art. 59 ff. EWGV

323 So auch v. Wilmowsky, S. 32.

324 Ebenso Pernice, NVwZ 1990, Heft 5, S. 414, 416.

325 Anderer Ansicht ist v. Köller (Bundesumweltministerium). Eine Liberalisierung der Abfallentsorgung, komme für ihn nicht in Betracht, da die Abfallentsorgung als öffentliche Pflichtaufgabe der Daseinsvorsorge, durch Art. 36 EWGV geschützt sei und daher nicht unter die Dienstleistungsfreiheit falle. Entsorga-Magazin, 10/88, S. 12, 18.

326 Vgl. oben Kapitel A.III.1.a)aa) und A.III.2.

327 v. Wilmowsky, S. 526. 
darstellt, ist ebenso Inhalt der folgenden Prüfung ${ }^{328}$. In diesem Zusammenhang sei jedoch darauf hingewiesen, daß sich die Niederlassungsfreiheit gemäß Art. 52 EWGV ausschließlich auf ein Gebot der Inländergleichbehandlung beschränkt. Damit steht es den Mitgliedstaaten frei, einem Entsorgungsunternehmen ein Niederlassungsmonopol in ihrem Territorium einzuräumen. Die Mitgliedstaaten haben dabei lediglich zu beachten, daß inländische und EG-ausländische Bewerber bei der Vergabe des Gebietsmonopols gleich behandelt werden.

Bei der Prüfung der EWG-vertraglichen Legitimation von exportbeschränkenden Maßnahmen wie die des Anschluß- und Benutzungszwangs und des damit verbundenen Entzugs der Entsorgungsverantwortung ist es notwendig, eine Differenzierung zwischen privaten Haushalten einerseits und gewerblichen Abfallerzeuger andererseits vorzunehmen.

\section{aa) Private Haushalte}

Für den Anschluß- und Benutzungszwang bei privaten Haushalten sprechen eine Reihe von Gründen:

Den privaten Haushalten fehlt typischerweise der erforderliche Überblick über die zur Verfügung stehenden Entsorgungsmöglichkeiten. Zudem dürften sie bei der Erfüllung der mit der Abfallentsorgung verbundenen Verkehrspflichten überfordert $\operatorname{sein}^{329}$. Die Gefahr der illegalen Beseitigung wird darüber hinaus durch eine Zahlungsverpflichtung, die unabhängig von der Nutzung des Entsorgungsangebotes anfällt, weitgehend ausgeschlossen. Ein Anreiz zur „wilden“ Abfallbeseitigung besteht dann nicht. Verwirklichen läßt sich ein solches System jedoch praktisch nur im Rahmen eines Anschluß- und Benutzungszwanges ${ }^{330}$. Daneben sprechen aber auch wirtschaftliche Gründe für einen Anschluß- und Benutzungszwang, soweit es um Abfälle privater Haushalte geht. Eine Monopolisierung der Abfallentsorgung verhindert, daß eine Strecke mehrmals von verschiedenen Entsorgungsunternehmen

328 Die Prüfung von Regelungen, die mit dem Anschluß- und Benutzungszwang verbunden sind und die in erster Linie Importrechte berühren, ist Inhalt des Kapitels über die $\mathrm{Zu}$ lässigkeit mitgliedstaatlicher Entsorgungsgarantien. Vgl. dazu unten Kapitel B.III.2.a).

$329 \mathrm{Zu}$ den Verkehrspflichten des Abfallbesitzers bei der Abfallentsorgung gehören bspw. die Auswahl und Uberwachung der Entsorger. Vgl. weitergehend dazu, oben Kapitel A.III.1.a)aa).

330 v. Wilmowsky, S. 527. 
parallel abgefahren wird ${ }^{331}$. Die Konzentration der Entsorgungskapazitäten ermöglicht dagegen ein effizientes Sammeln und Transportieren von Abfällen. Die Stützung ausfuhrbeschränkender Maßnahmen auf wirtschaftliche Gründe stößt dabei auf Grenzen, die durch den EuGH gesetzt wurden. So betont der EuGH in ständiger Rechtsprechung, da $B$ allein nichtwirtschaftliche Regelungsinteressen zu Eingriffen in den innergemeinschaftlichen Waren- und Dienstleistungsverkehr berechtigen. Die im Abfallgesetz, nach Maßgabe des § 3 Abs. 1 AbfG vorgesehene Überlassungspflicht ist bei Haushalten dennoch gerechtfertigt und gemeinschaftrechtlich gedeckt. Das mit dem Anschluß- und Benutzungszwang verbundene Exportverbot ist, soweit es Haushaltsabfälle oder hausmüllähnliche Abfälle betrifft, wegen der geschilderten umweltpolitischen Notwendigkeit mit dem EWG-Vertrag vereinbar und auch aus Gründen ökonomischer Effizienz geboten.

\section{bb) Gewerbliche Abfallerzeuger}

Anders stellt sich die Situation bei Industrieabfällen dar. Es kann grundsätzlich davon ausgegangen werden, daß Industrieunternehmen in der Lage sind, ihrer Entsorgungspflicht in eigener Verantwortung nachzukommen ${ }^{332}$. Ihnen muß die uneingeschränkte technische und wirtschaftliche Kompetenz zugestanden werden, für eine ordnungsgemäße Beseitigung der Abfälle in eigener Verantwortung Sorge zu tragen. Zudem sind Industrieabfälle im wesentlichen als eine variable Größen anzusehen, sie fallen in unterschiedlichen Mengen und Zusammensetzungen an. Eine Anbindung an ein Beseitigungsunternehmen würde daher im Allgemeinen nicht zu gleichen Rationalisierungswirkungen führen, wie dies bei der Entsorgung von Haushaltsabfällen der Fall ist. Entscheidend ist aber, daß staatliche Abnahmegarantien der Industrie eine Abfallerzeugung ohne Rücksicht auf die zur Verfügung stehenden Entsorgungskapazitäten ermöglichen. Die Verwendung und Entwicklung abfallarmer bzw. abfallvermeidender Produktionsverfahren wird damit nicht nur gebremst sondern sogar verhindert. Den Erzeugern von Produktionsabfällen die Entsorgungsverantwortung durch einen Anschluß- und Benutzungszwang faktisch zu entziehen, ist daher umweltpolitisch nicht zu rechtfertigen. Damit besteht auch keine Notwendigkeit, vom Liberalisierungsgebot des EWG-Vertrags abzuweichen.

Der Abgrenzung zwischen Haushalts- und Industrieabfällen kommt im bundesdeutschen Recht eine erhebliche Bedeutung zu. Die nach Maßgabe des $§ 3$ Abs. 3

331 v. Wilmowsky vergleicht die Entsorgung von Haushalten insofem mit der leitungsgebundenen Versorgungswirtschaft, bei der ebenfalls „scale efficiencies“ einen Anschluß- und Benutzungszwang rechtfertigen. Vgl. v. Wilmowsky, S. 527.

332 So auch v. Wilmowsky, S. 527. 
AbfG bestehende Ausschlußmöglichkeit der öffentlichen Körperschaften von der Entsorgungspflicht für Abfälle, die sich nicht nach Art und Umfang zusammen mit den in Haushalten anfallenden Abfällen entsorgen lassen, dokumentiert die Absicht des Gesetzgebers, die Industrie in diesem Fall gerade nicht aus ihrer Entsorgungsverantwortung zu entlassen. Aus europarechtlichen Regelungen zum freien Dienstleistungsverkehr ergibt sich aber für die nach deutschem Recht gültige Überlassungspflicht unweigerlich, da $B$ dem Besitzer von industriellen Abfällen ein Anspruch auf Ausschluß von der Überlassungspflicht zu gewähren ist ${ }^{333}$. Dieser Anspruch besteht nach bundesdeutschem Recht bislang nicht. Es wurde bisher lediglich davon ausgegangen, daß dem Abfallbesitzer nach deutschem Recht kein Anspruch zustehen könne, von der Überlassungspflicht gemäß § 3 Abs. 3 AbfG entbunden zu werden ${ }^{334}$.

\section{c) EG-weite Wirkungen von nationalen Abfallvermeidungsgeboten}

Das bundesdeutsche Abfallrecht schreibt ein umfassendes Vermeidungsgebot nur im Rahmen des Bundes-Immissionsschutzgesetz vor. Für Betreiber genehmigungspflichtiger Anlagen besteht gemäß § 5 Abs. 1 Nr. 3 BImSchG die Pflicht zur Vermeidung von bei der Produktion anfallenden Reststoffen ${ }^{335}$. Unter EWG-vertraglichen Legitimationsdruck könnten nationale Abfallvermeidungsgebote insofern geraten, als es für das Wirksamwerden der Vermeidungsverpflichtung keine Rolle spielt, ob die Abfälle im Inland oder Ausland entsorgt werden sollen. Eine Benachteiligung ausländischer Anbieter von Entsorgungsleistungen könnte hierbei darin gesehen werden, daß durch das Vermeidungsgebot Reststoffe und Abfälle, die sonst zu ausländischen Entsorgungsanlagen verbracht werden könnten, erst gar nicht anfallen. Daneben wird aber durch nationale Abfallvermeidungsgebote auch die Umwelt eines potentiellen Bestimmungslandes geschützt.

\section{aa) Vermeidungsgebote in Form von Produktionsregelungen}

Wie bereits erwähnt, läßt der EWG-Vertrag keine ausfuhrbeschränkenden Maßnahmen zum Schutz der Umwelt eines anderen Mitgliedstaates zu. Es kann keinem Mitgliedstaat ein höheres Umweltschutzniveau aufgezwungen werden, als das dort für notwendig erachtete Niveau. Maßnahmen nach $\S 5 \mathrm{Abs} .1 \mathrm{Nr} .3 \mathrm{BImSchG}$ dürften aber dennoch ohne Schwierigkeiten umweltpolitisch zu rechtfertigen sein:

333 Bejahend v. Wilmowsky, S. 528.

334 Vgl. beispielsweise Hösel/v. Lersner, § 3 AbfG Rdn. 31.

335 Vgl. oben Kapitel A.III.a)bb). 
Die Vermeidung von Abfällen reduziert nicht nur die Gefahren am Ort ihrer Entsorgung, sondern es werden bereits im Herkunftstaat durch Maßnahmen zur Abfallvermeidung die Gesundheits- und Transportrisiken sowie die Gefahr der illegalen Beseitigung verringert. Darüber hinaus ist die auf Abfallvermeidung zielende Regelung des $\S 5$ Abs. 1 Nr. 3 BImSchG eine Produktionsregelung, diese unterliegen nach der Rechtsprechung des EuGH keiner Legitimationskontrolle hinsichtlich der EWG-vertraglichen Bestimmungen zum freien Waren- und Dienstleistungsver$\mathrm{kehr}^{336}$. Abfallvermeidungsgebote wie das des $\S 5 \mathrm{Abs} .1 \mathrm{Nr} .3 \mathrm{BImSchG}$ sind also in Form von Produktionsregelungen mit dem EWG-Vertrag zu vereinbaren.

\section{bb) Produktbezogene Maßnahmen zur Abfallvermeidung}

Anders liegt dagegen der Sachverhalt bei produktbezogenen Maßnahmen zur Abfallvermeidung bei Erzeugnissen, die für den Export bestimmt sind. Hierbei handelt es sich beispielsweise um Anforderungen bezüglich der Verpackung oder Beschaffenheit von Waren. Diese gelten nach Maßgabe von Rechtsverordnungen gemäß § 14 AbfG. Sie können dazu führen, daß die Produktion bestimmter Erzeugnisse unmöglich wird. Inländische produktbezogene Maßnahmen zur Abfallvermeidung können im Normalfall nicht auf Produkte angewendet werden, die zum Export bestimmt sind. Diese werden in der Regel erst nach Ablauf ihrer Zweckbestimmung zu Abfall, deshalb entstehen die mit der Entsorgung verbundenen Gefahren nicht im Herkunftsstaat sondern erst im Bestimmungsstaat. Es fehlt dem Exportstaat daher an eigenen schutzwürdigen Interessen, um eine Beschränkung der Warenverkehrsfreiheit zu rechtfertigen. Der Schutz der Umwelt des Bestimmungsstaates scheidet als Rechtfertigungsgrund generell aus, da der Bestimmungsmitgliedstaat mit den geringeren vorgeschriebenen Produktstandards zum Ausdruck gebracht hat, daß er gewillt ist bestimmte Umweltbelastungen zuzulassen. Produktbezogene Maßnahmen zur Abfallvermeidung können also nicht auf Erzeugnisse, die zum Export bestimmt sind, ausgedehnt werden, ohne gegen die Grundfreiheit des EWG-Vertrags zu verstoßen.

d) Verpflichtung im Ausland zumindest eine gleichwertige Anlage aufzusuchen

Durch die Verpflichtung, im Ausland eine Anlage aufzusuchen, die inländischen Mindeststandards gerecht wird, ließe sich unter Umständen eine Verbesserung der gemeinschaftsweiten Umweltsituation erreichen. Abfallexporte wären nur dann zu-

336 v. Wilmowsky, S. 530. 
zulassen, wenn in einer Anlage entsorgt wird, die den im Inland geltenden Anforderungen entspricht. Diese Regelung hätte den Vorteil, daß relativ undifferenzierte Exportbeschränkungen, wie sie durch den Grundsatz der Inlandsentsorgung aufgestellt werden, durch solche Maßnahmen ersetzt würden, die eine gemeinschaftsweite Verbesserung der Umweltsituation bewirken können. Eine Bedingung, mindestens gleichwertige Anlagen aufzusuchen, sieht das bundesdeutsche Abfallgesetz aber nicht vor. Sie könnte jedoch auch auf Gemeinschaftsebene auf mehr Interesse stoBen, falls mit der Verwirklichung des Binnenmarktes der Grundsatz der Inlandsentsorgung in seiner derzeitigen Form nicht aufrecht zu halten sein sollte ${ }^{337}$.

Eine gemeinschaftsweite Ausdehnung strengerer nationaler Entsorgungsstandards würde unter anderem die in der Bundesrepublik durch die TA-Abfall aufgestellten technischen Anforderungen an Entsorgungsanlagen und Deponien und außerdem die ebenfalls vorgeschriebene Zuordnung von Abfallarten zu bestimmtem Entsorgungswegen betreffen ${ }^{338}$. Damit könnten gesetzliche Vorgaben nationaler produktbezogener Vermeidungs- und Verwertungsgebote ${ }^{339}$ nicht mehr durch Verbringung von Abfällen in andere Mitgliedstaaten umgangen werden ${ }^{340}$.

\section{aa) Umweltpolitischer Nutzen}

Die Vorteile, die mit der Anwendung strengerer inländischer Entsorgungsstandards auf Abfallexporte verbunden sind, sind offensichtlich. Wenn Abfälle in Anlagen mit hohem technischen Standard entsorgt werden müssen, wird die Umwelt weniger stark belastet. Die mit höheren Standards in der Regel verbundenen höheren Entsorgungskosten zwingen die Abfallverursacher dazu, Abfälle in stärkerem Umfang zu vermeiden oder wiederzuverwerten. Der Betrieb von Anlagen auf hohem technischen Stand wird ebenfalls sichergestellt, da die Rentabilität solcher Anlagen nur dann gewährleistet ist, wenn bei der Entsorgung nicht auf mit niedrigerem Standard betriebene und damit die Umwelt stärker beanspruchende Anlagen ausgewichen werden kann.

337 Vgl. oben Kapitel B.III.1.a).

338 Vgl. oben Kapitel A.III.1.c).

339 Ein umfassendes Vermeidunsgebot besteht unter anderem für Betreiber genehmigungsbedürftiger Anlagen gemäß $§ 5$ Abs. 1 Nr. 3 BImSchG. Dazu vgl. oben Kapitel A.III.1.a)bb).

340 Zur Wirkung inländischer Vermeidungs- und Verwertungsgebote auf Güter, die für den Export bestimmt sind vgl. oben Kapitel B.III.1.c). 
Inwiefern solche umweltpolitischen Vorteile autonome Maßnahmen der Mitgliedstaaten rechtfertigen können, ist zweifelhaft. Probleme bei der Rechtfertigung ergeben sich auch daraus, da $B$ durch die Verpflichtung, im Ausland zumindest eine gleichwertige Anlage aufzusuchen, in der Regel nicht die eigene Umwelt sondern die des Empfängerstaates geschützt wird. Der EWG-Vertrag schließt fremdnützige Beschränkungen des innergemeinschaftlichen Wirtschaftsverkehrs aber aus, wenn sie geeignet sind, über den vom geschützten Staat selbst gewollten Umfang hinauszugehen. Daher muß sich eine solche Maßnahme auf eine Ermächtigung oder Verordnung des Gemeinschaftsrechts stützen ${ }^{341}$.

\section{bb) Schutz der inländischen Umwelt}

Eine andere Frage ist, ob ein Mitgliedstaat den Export von Abfällen zu einer schlechteren ausländischen Anlage unterbinden kann, wenn sich deren Betrieb, etwa aufgrund ihrer Nähe zur Staatsgrenze negativ auf die inländische Umwelt auswirkt. Das bundesdeutsche Abfallgesetz wie auch die Abfallverbringungsverordnung sehen eine solche Einschränkung vor. Nach Maßgabe des § 13 Abs. 1 Satz 2 Ziffer $4 c$ und $5 \mathrm{AbfG}^{342}$ und der $\S \S 10,11 \mathrm{AbfVerbrV}^{343}$ sind sowohl der Export als auch der Transit von Abfällen aus dem oder durch den Geltungsbereich des Abfallgesetzes nur dann möglich, wenn durch den Transport und die Entsorgung im Ausland keine Beeinträchtigung des Wohls der Allgemeinheit in der Bundesrepublik zu befürchten ist. Dies gilt auch für den Fall der Verbringung von Abfällen in einen anderen EGMitgliedstaat. Eine solche Exportregelung ist innergemeinschaftlich unzulässig; sie verstößt gegen die Dienstleistungsfreiheit des EWG-Vertrages und bei gefährlichen Abfällen auch gegen die Bestimmungen der Richtlinie 84/631/EWG. Den Mitgliedstaaten ist es deshalb nicht möglich, den Export von Abfällen in andere Mitgliedstaaten zu untersagen, weil von der Entsorgung dort eine Beeinträchtigung der einheimischen Umwelt zu befürchten ist. Den Mitgliedstaaten stehen statt dessen materielle Abwehrrechte gegen grenzüberschreitende Umweltbelastungen zu, die im Rahmen einer Klage vor dem EuGH durchsetzbar sind.

Autonome Maßnahmen einzelner Mitgliedstaaten, die dazu führen die eigenen Entsorgungsstandards auf andere Mitgliedstaaten auszuweiten, scheiden aus den gerade genannten Gründen aus. Es muß aber darüber hinaus geprüft werden, ob das sekundäre Recht der Gemeinschaft eine Ermächtigung enthält, die eine Verpflich-

341 So v. Wilmowsky, S. 615.

342 Vgl. oben Kapitel A.III.1.a)aa).

343 Vgl. oben Kapitel A.III.1.b)cc). 
tung ermöglicht im Ausland mindestens eine gleichwertige Anlage aufsuchen zu müssen, und wenn ja, ob Ermächtigungen dieser Art mit dem EWG-Vertrag vereinbar sind.

Der Art. 4 Abs. 6 der Richtlinie über die grenzüberschreitende Verbringung gefährlicher Abfälle 84/631/EWG erlaubt es den Mitgliedstaaten, in Abfallbeseitigungsplänen einen Anschluß- und Benutzungszwang vorzuschreiben. $\mathrm{Ob}$ daraus die Ermächtigung der Mitgliedstaaten zu Exportbeschränkungen gegenüber einer schlechteren ausländischen Entsorgungsanlage hergeleitet werden kann, ist zweifelhaft. Dies hängt vor allem davon ab, ob Entsorgungsstandards überhaupt Bestandteil von nationalen Abfallbeseitigungsplänen sein dürfen und inwieweit die durch die TA-Abfall vorgeschriebenen Entsorgungsstandards von der Richtlinie 84/631/ EWG abgedeckt werden. Die zur Klärung dieser Frage notwendige Präzisierung des EWG-rechtlichen Planbegriffs ist aber seitens der Gemeinschaftsorgane und der Fachwelt bislang nicht erfolgt.

\section{Import}

Fraglich ist, ob einzelstaatliche Maßnahmen, die zu einer Beschränkung der Abfalleinfuhr führen können, durch primäres oder sekundäres Gemeinschaftsrecht gedeckt sind. Die Notwendigkeit einer Prüfung der EWG-vertragliche Legitimation von importbeschränkenden Maßnahmen wird offensichtlich, wenn man sich deren Auswirkungen auf die grenzüberschreitende Abfallentsorgung betrachtet.

Bei den nachfolgend zu prüfenden importbeschränkenden Maßnahmen handelt es sich um solche, die dazu führen, daß Abfallerzeugern aus anderen EG-Mitgliedstaaten die Nutzung inländischer Entsorgungsanlagen erschwert oder sogar völlig verwehrt wird. Abfallerzeuger aus anderen EG-Mitgliedstaaten werden damit anders behandelt als Inländer. Auf die Dienstleistungsfreiheit im Rahmen des EWG-Vertrages können sich jedoch nicht nur die Betreiber von Entsorgungsanlagen berufen, sondern auch die Abfallerzeuger kommen in Genuß dieses Schutzes. Abfallerzeuger aus anderen EG-Mitgliedstaaten können von den Mitgliedstaaten verlangen, im Hinblick auf den Zugang zu inländischen Entsorgungsanlage gleichberechtigt wie Inlănder behandelt zu werden.

$\mathrm{Zu}$ den je nach dem Aufenthaltsort des Dienstleistungsempfängers unterschiedlich anwendbaren importbeschränkenden Maßnahmen gehören Einfuhrverbote bzw. -erschwernisse für ausländische Abfälle, Einfuhrquoten und -kontingente, das Einräumen einer Vorrangstellung in der Abfallentsorgungsplanung für inländische 
Abfallerzeuger sowie Entsorgungsgarantien für inländische Abfälle. Eine Entsorgungsgarantie kann zur Folge haben, daß Entsorgungskapazitäten vollständig für inländische Abfälle reserviert werden.

\section{a) Mitgliedstaatliche Entsorgungsgarantien}

Wie bereits oben im Kapitel über die ausfuhrbeschränkenden Wirkungen einzelstaatlicher Entsorgungsgarantien angesprochen wurde ${ }^{344}$, gehören diese zu den einzelstaatlichen Maßnahmen, die zu einer Beschränkung der grenzüberschreitenden Verbringung von Abfällen führen und ausschließlich Inländer betreffen.

Mit der Übernahme der Entsorgungsverantwortung für inländische Abfälle entlassen der Staat bzw. die durch den Staat verpflichteten Entsorgungsunternehmen, die einheimischen Abfallverursacher von der Verantwortung für die ordnungsgemäße Entsorgung der Abfälle. Dabei lassen sich generell zwei Formen der Übernahme der Entsorgungsverantwortung unterscheiden:

Zum ersten die Entsorgungsgarantie, d.h. die vollständige Entlassung des Abfallerzeugers aus der Entsorgungsverantwortung. Der Abfallerzeuger kann unabhängig von den tatsächlich zur Verfügung stehenden Entsorgungskapazitäten Abfälle entstehen lassen, der Staat veranlaßt deren Entsorgung. Das Verursacherprinzip wird so nicht verwirklicht, jedenfalls dann nicht, wenn als Ausdruck des Verursacherprinzips mehr als die verursachungsgerechte Zurechnung der direkten Beseitigungskosten verstanden wird. Wird ebenfalls die materielle Verantwortung ${ }^{345}$ des Abfallerzeugers für Abfallvermeidung, Abfallverminderung und die nachträgliche $\mathrm{Be}$ seitigung der durch die Abfallentsorgung entstandenen Umweltschäden hinzugerechnet, so widerspricht diese Form der staatlichen Entsorgungsverantwortung dem Verursacherprinzip ${ }^{346}$. Die zweite Form der Übernahme einer Entsorgungsgarantie ist die mengenmäßg begrenzte Entsorgungsverantwortung. Der Staat übernimmt zwar die Entsorgung von Abfällen, er beschränkt aber die entsorgbaren Mengen auf die zur Verfügung stehenden Entsorgungskapazitäten. Die Abfallerzeuger bleiben damit dergestalt in der Entsorgungsverantwortung, daß sie Abfälle nur im Rahmen der bestehenden Entsorgungskapazitäten entstehen lassen können und darüberhinaus zur Abfallvermeidung oder zu Produktionseinschränkungen gezwungen werden.

344 Vgl. oben Kapitel B.III.1.b).

345 Vgl. Rehbinder, S. 34-37.

346 v. Wilmowsky, S. 269. 


\section{aa) Beschränkung der Abfalleinfuhr}

Die Auswirkungen staatlicher Entsorgungsgarantien sind durchaus geeignet, $\mathrm{zu}$ einer Beschränkung des Abfallimports beizutragen. Durch eine Entsorgungsgarantie werden knappe Beseitigungskapazitäten für inländische Abfälle reserviert. Die Nutzung der Entsorgungsanlagen wird so einheimischen Abfallerzeugern vorbehalten. Im Zusammenspiel mit einer Verpflichtung zur Eigenbeseitigung ${ }^{347}$, d.h. die entsorgungspflichtigen Körperschaften sind die Betreiber von Entsorgungsanlagen, kann dies einem vollständigen Einfuhrverbot für ausländische Abfälle gleichkommen. Verstärkt wird die Reservierungswirkung von staatlichen Entsorgungsgarantien auch durch die Vergabe von sogenannten „Betreibermonopolen“. Solche Betreibermonopole sieht das Abfallgesetz nach Maßgabe des $\S 6$ Abs. 1 Satz 5 AbfG vor. Die Bundesländer können in den Landesabfallplänen einen alleinigen Träger der Abfallentsorgung festlegen, mit der Wirkung, daß einzig die entsorgungspflichtige Körperschaft bzw. das verpflichtete Entsorgungsunternehmen Abfallentsorgungsanlagen errichten und betreiben darf ${ }^{348}$.

Die Abfallentsorgung ist eine Dienstleistung des Staates bzw. des beauftragten Entsorgungsunternehmens gegenüber den Abfallverursachern. Diesen wird gegen Zahlung eines Entgeltes die Entsorgung der Abfälle abgenommen. Eine Beschränkung des Dienstleistungsangebots auf inländische Abfallerzeuger mittels einer Entsorgungsgarantie zielt auf den Aufenthaltsort der Dienstleistungsempfänger und diskriminiert damit Ausländer. Darin ist ein eindeutiger Verstoß gegen Art. $59 \mathrm{ff}$. EWGV zu sehen.

Die Erweiterung der Entsorgungsgarantie auch auf ausländische Abfallerzeuger könnte jedoch schwerwiegende negative umweltpolitische Folgen mit sich bringen. Es besteht die Gefahr eines zwischenstaatlichen „freeriding“. Mitgliedstaaten könnten versucht sein die mit ökologischen, ökonomischen und innenpolitischen Belastungen verbundene Entsorgungsverantwortung auf andere Staaten abzuwälzen. Die Gefahr die „Müllkippe“ der anderen zu werden, könnte die Bereitschaft sowohl zur Aufrechterhaltung der staatlichen Entsorgungsverantwortung als auch der nationalen Planungsträger zur Ausweisung neuer Standorte für Entsorgungsanlagen

347 Nach Maßgabe des $\S 3$ Abs. 2 Satz 2 AbfG ist es den entsorgungspflichtigen Körperschaften freigestellt, ob sie selbst Entsorgungsanlagen betreiben oder Dritte mit der Entsorgung beauftragen.

348 Ein solches Betreibermonopol für Sonderabfälle besteht bspw. in Hessen, wo allein der Hessischen Industriemüll GmbH (HIM) der Betrieb von Anlagen zur Sonderabfallbeseitigung gestattet ist. Dazu vgl. oben Kapitel A.III.2. 
gegen Null sinken lassen ${ }^{349}$. Dies würde fatale Folgen für die Umwelt nach sich ziehen. Um die Gefährdung bzw. Beeinträchtigung von Schutzgütern des Gemeinschaftsrechts auszuschließen, erscheint es hier also angebracht die Dienstleistungsfreiheit der Abfallentsorger einzuschränken. Autonome Einfuhrbeschränkungen seitens der Mitgliedstaaten und damit auch die Beschränkung der Entsorgungsgarantie auf Inländer sind dann zulässig, wenn dies aus umweltpolitischen Gesichtspunkten erforderlich ist und mit dem Gemeinschaftsinteresse im Einklang steht.

\section{bb) Rechtfertigung durch zwingende Erfordernisse}

Nach der vom EuGH entwickelten „rule of reason“ können die Mitgliedstaaten beschränkend in den zwischenstaatlichen Dienstleistungsverkehr eingreifen, wenn die Maßnahme mit der Politik der Gemeinschaft in Einklang steht und auf diesem Gebiet keine Gemeinschaftsregelung besteht. Diese einzelstaatlichen Maßnahmen sind mit Art. 59 EWGV vereinbar, wenn sie durch „... zwingende Gründe des Allgemeininteresses ..."350 gedeckt sind. Eine Rechtfertigung für den Dienstleistungsverkehr beschränkende Maßnahmen durch die rule of reason kommt nach der Rechtsprechung des EuGH jedoch nur dann in Betracht, wenn unterschiedslos anwendbare Maßnahmen vorliegen, die für inländische und für ausländische Leistungserbringer bzw. -empfänger gleichermaßen gelten. Da jedoch bei der Entsorgungsgarantie die in- und ausländischen Abfallerzeuger unterschiedlichen rechtlichen Bedingungen unterworfen werden, können diese nicht generell auf Grund der rule of reason gerechtfertigt sein. Die Abstützung müßte stattdessen nach Art. 36 EWGV oder Art. 56 EWGV erfolgen. Eine enge Auslegung von Art. 36 EWGV führt dabei zu Problemen, da der Umweltschutz nicht ausdrücklich im Katalog des Art. 36 EWGV erwähnt wird. Eine Rechtfertigung unterschiedlich anwendbarer Maßnahmen zum Schutz der Gesundheit wäre zwar möglich, jedoch nicht aus Gründen des Umweltschutzes ${ }^{351}$. Wird die rule of reason jedoch als eine Erweiterung des Art. 36 EWGV verstanden, so sollten auch unterschiedlich anwendbare Maßnahmen durch EWG-Vertrag gedeckt sein, wenn diese umweltpolitisch gerechtfertigt werden können ${ }^{352}$.

349 Zum negativen Standortkonflikt vgl. v. Wilmowsky, S. 357-366.

350 So ausdrücklich der EuGH. Nachweise bei v. Wilmowsky, Fn. 52, S. 234.

351 Zu den Widersprüchen die entstehen, wenn ,Zwingende Erfordernisse des Allgemeininteresses" allein unterschiedslos anwendbare Maßnahmen zu rechtfertigen vermögen und unterschiedliche Maßnahmen lediglich über Art. 36 EWGV gerechtfertigt werden können, vgl. v. Wilmowsky, S. 231-248.

352 Vgl. v. Wilmowsky, S. 248. 


\section{cc) Umweltpolitische Rechtfertigung}

Die Prüfung der umweltpolitischen Notwendigkeit staatlicher Entsorgungsgarantien erfolgt zweckmäßiger Weise getrennt nach privaten Haushalten einerseits und Unternehmen andererseits.

Privaten Haushalten ist es in der Regel nicht möglich und zuzumuten, die ordnungsgemäße Abfallentsorgung selbst zu organisieren. Sie dürfte zudem bei der Erfüllung der mit der Abfallentsorgung verbundenen Verkehrspflichten ${ }^{353}$, wie etwa die Auswahl und Überwachung von Entsorgern, weitgehend überfordert sein. Privaten Haushalten ist es nahezu unmöglich, ihre Abfallerzeugung auf bestehende Entsorgungskapazitäten auszurichten. Ihr Einfluß zur Verringerung der in Haushalten anfallenden Abfallmengen ist relativ gering. Die bei einer "normalen“ Lebensführung anfallende Abfallmenge stellt sich als eine relativ feste Größe dar. Verantwortlich für den Anfall von Haushaltsabfällen sind hauptsächlich die Hersteller der Produkte sowie der Handel. Zusätzlich sprechen sozialpolitische Aspekte für eine vollständige Entlassung der Haushalte aus der Entsorgungsverantwortung. Sollte sich etwa aufgrund der Verknappung von Beseitigungskapazitäten die Entsorgung drastisch verteuern, könnte dies zur Folge haben, daß Haushalten mit geringen Einkommen eine normale Lebensführung unzumutbar erschwert würde ${ }^{354}$.

Die umweltpolitische Notwendigkeit einer Entsorgungsgarantie für Haushaltsabfälle erscheint unter Berücksichtigung dieser Aspekte als durchaus gegeben und damit EG-rechtlich zulässig.

Soweit es um Unternehmen als Abfallerzeuger und damit um Produktionsabfälle geht, erscheint der umweltpolitsche Nutzen der staatlichen Entsorgungsgarantie in einem anderem Licht. Die Ausgangssituation ist hier völlig anders als bei den privaten Haushalten. Unternehmen sind grundsătzlich in der Lage, die mit einer ordnungsgemäßen Entsorgung verbundenen Verkehrspflichten zu beachten und einzuhalten. Der Einfluß, die anfallende Abfallmenge etwa durch Umstellung oder Einstellung von Produktionsverfahren zu verringern, ist vorhanden. Darüber hinaus lassen sich staatliche Abnahmegarantien nicht mit dem Verursacherprinzip vereinbaren. Sie führen stattdessen dazu, daß die Unternehmen ohne Rücksicht auf bestehende Entsorgungskapazitäten Abfälle verursachen können. Ein Anreiz zur Verwendung oder Entwicklung abfallarmer Produktionsverfahren besteht so nicht.

$353 \mathrm{Zu}$ den bei der Abfallentsorgung zu beachtenden Verkehrspflichten vgl. oben Kapitel A.III.1.a)aa).

354 Vgl. v. Wilmowsky, S. 270. 
Die Reservierung inländischer Entsorgungskapazitäten durch staatliche Entsorgungsgarantien für einheimische Abfallerzeuger könnte jedoch aufgrund Art. 4 Abs. 3 der Richtlinie über die grenzüberschreitende Verbringung gefährlicher Abfälle 84/631/EWG gerechtfertigt sein. Nach Maßgabe des Art. 4 Abs. 3 84/631/EWG steht es den Mitgliedstaaten frei, Einwände gegen eine beabsichtigte Abfalleinfuhr zu erheben, wenn diese ,.... anhand der Rechts- und Verwaltungsvorschriften zum Schutz der Umwelt, zur Wahrung der Sicherheit und der offentlichen Ordnung oder zum Schutz der Gesundheit zu begründen" sind. Die umweltpolitische Notwendigkeit als Rechtfertigungsgrund von importbeschränkenden Maßnahmen steht also auch hier im Vordergrund. Von ausländischen Abfällen gehen dieselben Gefahren für die Umwelt aus wie von Abfällen gleicher Art inländischer Herkunft. Es läßt sich daher nicht begründen, weshalb durch Art. 4 Abs. 3 der Richtlinie 84/631/EWG die Mitgliedstaaten ermächtigt sein sollten, Abfallproduzenten aus anderen EG-Mitgliedstaaten den Zugang zu inländischen Anlagen zu verwehren.

Als Zwischenergebnis läßt sich daraus zusammenfassen:

Die umweltpolitische Notwendigkeit einer Entsorgungsgarantie für Produktionsabfälle ist nicht gegeben, damit ist eine Garantie EG-rechtlich unzulässig. Eine staatliche Entsorgungsgarantie für einheimische Produktionsabfälle kommt einer Subventionierung der inländischen Wirtschaft gleich. Sie liefert darüber hinaus keinen Beitrag zur Verbesserung der gemeinschaftsweiten Umweltsituation. Eine staatliche Entsorgungsgarantie für Abfälle steht im Widerspruch zum Verursacherund Vorsorgeprinzip, da mögliche Potentiale zur Abfallvermeidung und -verringerung nicht ausgeschöpft werden. Zum Schutz der Umwelt sind staatliche Entsorgungsgarantien durchaus geboten, wenn private Haushalte aus der Abfallentsorgungsverantwortung herausgenommen werden. Bei diesen können die anfallenden Abfallmengen wegen der geringen Einflußmöglichkeiten nicht oder nur sehr schwer an die tatsächlich zur Verfügung stehenden Entsorgungskapazitäten geknüpft werden. Nur staatliche Entsorgungsgarantien, die sich innerhalb des damit vorgegebenen Rahmens bewegen sind umweltpolitisch notwendig und daher auch EG-rechtlich zulässig. $\mathrm{Ob}$ sich das bundesdeutsche Abfallrecht innerhalb dieses Rahmens bewegt, ist Inhalt der folgenden Prüfung.

\section{dd) Bundesdeutsche Praxis}

Dem bundesdeutschen Abfallgesetz liegt der Grundsatz der öffentlichen Abfallentsorgung zugrunde ${ }^{355}$. Nach Maßgabe des $\S 3$ Abs. 2 Satz 1 AbfG sind die nach

355 Vgl. oben Kapitel A.III.1.a)aa). 
dem jeweiligen Landesrecht zuständigen Gebietskörperschaften verpflichtet, grundsätzlich alle in ihrem Gebiet anfallenden Abfälle ordnungsgemäß zu entsorgen. Sie können dabei in Eigenregie tätig werden oder aber Entsorgungsunternehmen mit der Entsorgung beauftragen ${ }^{356}$. Die Abgrenzung zwischen Haushaltsabfällen und Produktionsabfällen hat im bundesdeutsche Abfallrecht erhebliche Bedeutung. Nach Maßgabe des § 3 Abs. 3 AbfG haben die entsorgungspflichtigen Körperschaften die Möglichkeit Abfälle, die sich nicht nach Art und Umfang zusammen mit den in Haushalten anfallenden Abfällen entsorgen lassen, aus ihrer Entsorgungsverantwortung auszunehmen. Dahinter könnte sich die Absicht des Gesetzgebers verbergen, Unternehmen als Abfallerzeuger gerade nicht aus ihrer Entsorgungsverantwortung zu entlassen, sondern sie die materielle Entsorgungsverantwortung tragen zu lassen. Nur soweit bewegen sich die Regelung des § 3 AbfG im Rahmen der umweltpolitischen Notwendigkeiten und sind damit EG-rechtlich zulässig. Beziehen sich Entsorgungsgarantien jedoch auch auf Produktionsabfälle, so widersprechen sie eindeutig den Bestimmungen des EWG-Vertrags. Die Abfallentsorgungspläne der Bundesländer können daher, ohne gegen Gemeinschaftsrecht zu verstoßen, lediglich die Einzugsbereiche von Hausmülldeponien in dieser Weise einschränken. Dabei sind entsprechend den Bestimmungen der Neufassung der Richtlinie 75/442/EWG regionale Aspekte in Form einer grenzüberschreitenden Zusammenarbeit zu berücksichtigen.

\section{b) Stützung nationaler Abfallvermeidungsgebote durch Importbeschränkungen}

Um zu verhindern, daß nationale Abfallvermeidungs- und -verwertungsgebote durch Importe von Abfällen unwirksam werden, könnte es umweltpolitisch erforderlich sein, die nationalen Abfallerzeugungsbeschränkungen durch Importverbote für ausländische Abfälle zu stützen. Das bundesdeutsche Abfallrecht schreibt ein umfassendes Vermeidungsgebot im Rahmen des Bundes-Immissionsschutzgesetz vor. Für Betreiber genehmigungspflichtiger Anlagen besteht danach gemäß $\S 5 \mathrm{Abs} .1$ Nr. 3 BImSchG die Pflicht, bei der Produktion anfallende Reststoffe zu vermeiden $^{357}$. Solche Produktionsregelungen betreffen allein inländische Abfallerzeuger. Eine Verminderung des Abfallanfalls soll auch durch produktbezogene Maßnahmen erreicht werden, die nach Maßgabe von Rechtsverordnungen gemäß § 14 AbfG gelten. Nationale Produktregelungen erfassen jedoch nicht solche Abfälle, die durch Produktion und Verbrauch im Ausland entstehen. Die Wirkung von mitgliedstaat-

356 Vgl. § 3 Abs. 2 Satz 2 AbfG.

357 Vgl. oben Kapitel A.III.1.a)bb). 
lichen Produkt- und Produktionsregelungen zur Abfallerzeugungsbegrenzung richtet sich lediglich auf das inländische Territorium ${ }^{358}$.

Abfälle verursachen Gefahren für Mensch und Umwelt aber nicht nur am Ort der Entsorgung, sondern bereits dort wo sie entstehen. Abfallvermeidungsgebote sind daher ein geeignetes Mittel zur Reduzierung des Abfallanfalls. Sie sind deshalb nicht nur wünschenswert, sondern auch umweltpolitisch gerechtfertigt. Der umweltpolitische Stellenwert von Abfallvermeidungsregelungen ist hoch und wird gemeinschaftsweit anerkannt. Gegenüber Abfällen ausländischer Herkunft greifen inländische Vermeidungs- und Verwertungsgebote jedoch nicht, da ein Mitgliedstaat keinen Einfluß auf Produktionsbedingungen in anderen Mitgliedstaaten hat. Maßnahmen die umweltpolitisch erforderlich sind, müssen daher gemeinschaftsweit getroffen werden 359 .

Der Gemeinschaftsgesetzgeber hat mit der Abfallrichtlinie 75/442/EWG ${ }^{360}$ und der Richtlinie über giftige und gefährliche Abfälle 78/319/EWG ${ }^{361}$ sein Interesse an mitgliedstaatlichen Beschränkungen der Abfallerzeugung konkretisiert.

Nach Maßgabe des Art. 3 Abs. 1 der Richtlinie des Rates über Abfälle 75/442/EWG sowie Art. 4 der Richtlinie über giftige und gefährliche 78/319/EWG verpflichtet der Gemeinschaftsgesetzgeber die Mitgliedstaaten, geeignete Maßnahmen zur Reduzierung der Abfallerzeugung sowie zur Wiederverwendung von Abfällen zu treffen. Im am 7. Juni 1990 verabschiedeten Kommissionsvorschlag zur Neufassung der Richtlinie 75/442/EWG ist nunmehr sogar eine ausdrückliche Priorität der Vermeidung festgelegt. Nach Art. 4 Abs. 3 der Verbringungsrichtlinie 84/631/EWG könnte es den Mitgliedstaaten erlaubt sein, solche Importbeschränkungen zu treffen, die zur Sicherung des nationalen Abfallvermeidungsgebotes notwendig sind. Eine Ergänzung nationaler Abfallerzeugungsrestriktionen durch Importverbote für ausländische Abfälle ist jedoch nur dann zulässig, wenn dadurch allein solche Abfälle betroffen sind, die im Inland aufgrund des gesetzlichen Vermeidungsgebotes nicht angefallen wären ${ }^{362}$.

358 v. Wilmowsky, S. 344.

359 Ruchay, S. 16.

360 Vgl. oben Kapitel A.II.2.a).

361 Vgl. oben Kapitel A.II.2.d).

362 v. Wilmowsky, S. 509. 
Bert Rürup and Uwe H. Schneider - 978-3-631-75109-1

Downloaded from PubFactory at 01/11/2019 08:13:45AM

via free access 


\section{Entwicklungen und Ausblick}

Auf seiner Tagung am 7. Juni 1990 in Luxemburg hat der (Umwelt-)Rat der Europäischen Gemeinschaften die Neufassung der Abfallrichtlinie 75/442/EWG verabschiedet. In dieser Neufassung wurde festgeschrieben, was sich in der Umweltpolitik der Gemeinschaft bereits längere Zeit andeutete ${ }^{363}$. Herausragende Punkte sind dabei die Verpflichtung zur Abfallentsorgung in der am nächsten gelegenen angemessenen Entsorgungseinrichtung und die geänderte Abstützung der Richtlinie auf Art. 130s EWGV anstatt wie ursprünglich vorgesehen auf Art. 100a EWGV364.

Die Verpflichtung, die nächstgelegene angemessene Entsorgungseinrichtung aufzusuchen ist deshalb von so großer Bedeutung, weil das Gebot der Inlandsentsorgung im Recht der Bundesrepublik dazu in klarem Widerspruch steht und damit wegen des Anwendungsvorrangs des sekundären Gemeinschaftsrechts innergemeinschaftlich nicht mehr wirksam ist. Die Folge ist, daß bundesdeutsche Entsorgungsanlagen für ausländische Abfälle zugänglich gemacht werden müssen, wenn sie die nächstgelegene und angemessene Anlage darstellen. Umgekehrt darf, wenn diese Bedingungen erfüllt sind, die Verbringung aus der Bundesrepublik nicht verhindert werden. Die EG hat sich damit auf eine regionale Beschränkung der Abfallverbringung festgelegt ${ }^{365}$. Sie zieht damit die Konsequenz aus der seitens der Kommission und des Rates formulierten Zielvorgabe, die Risiken und Umweltbelastung aus dem Transport von Abfällen auf das unabdingbare Maß zu begrenzen.

Mit den Risiken, die potentiell von Abfällen ausgehen, befaßt sich der Gemeinschaftsgesetzgeber nicht nur intensiv im Abfallrecht sondern auch in zwei Richtlinienentwürfen zur Regelung zivilrechtlicher Haftung. Dies ist zum einen der Entwurf einer Richtlinie zur Produzentenhaftung und zum anderen der Richtlinienentwurf zur Haftung für durch Abfälle verursachte Schäden. In diesem Zusammenhang spielen neben umweltpolitischen Überlegungen auch im besonderen $\mathrm{Ma} B$ wettbewerbspolitische Aspekte eine entscheidende Rolle.

$363 \mathrm{Vgl}$. Rudischhauser in KABV, Referat 3.

364 Hier könnten sich Zusammenhang mit der Klage um die Abstützung der Richtlinie 89/428/EWG eine völlig geänderte Ausgangslage ergeben, vgl. zu dieser Klage, NVwZ 1990, S. 205-206.

$365 \mathrm{Vgl}$. auch Leinen im KABV, Referat 2. 
Sind in einem Mitgliedstaat die Entsorgungsstandards niedrig und existiert darüber hinaus kein bzw. ein nur unzureichender Rechtsschutz für durch Abfälle verursachte Schäden oder Beeinträchtigungen an Mensch und Umwelt, so kann das Zusammentreffen dieser beiden Bedingungen dazu führen, daß Abfallströme in diese Mitgliedstaaten gelenkt werden. Darüber hinaus besteht für Industrieunternehmen der zusätzliche Anreiz abfallintensive Produktionsverfahren in solche Länder zu verlagem.

In diesem Zusammenhang ist es unbestritten, daß unterschiedliche Haftungsregelungen zu unterschiedlichen Kostenbelastungen für Unternehmen führen. Die Folge wäre eine Verzerrung des Wettbewerbes im zu schaffenden Binnenmarkt, die nur durch eine EG-weite Vereinheitlichung der geforderten Entsorgungsstandards und eine gemeinschaftsweite Haftungsregelung verhindert werden kann. Folgerichtig hat die EG-Kommission mit dem Richtlinienentwurf über die zivilrechtliche Haftung für durch Abfälle verursachte Schäden vom 2. 2. 1989 (AbfallHE) ${ }^{366}$ einen ersten Schritt hin zur Vereinheitlichung der rechtlichen Rahmenbedingungen beschritten. Ziel des Entwurfs der EG-Kommission ist es aber auch, dem Verursacherprinzip durch eine strikte Haftung für alle Arten von Abfällen Rechnung zu tragen.

Die Gemeinschaft hat ihr Tätigwerden mit der Gefährdung des Wettbewerbes im Hinblick auf die Errichtung des Binnenmarktes begründet und zur Abstützung des Richtlinienentwurfs bezüglich einer EG-einheitlichen zivilrechtlichen Haftungsregelung Art. 100a EWGV herangezogen.

Die wichtigsten Einzelregelungen des Entwurfs der Richtlinie sollen im folgenden in Bezug auf ihre Relevanz für die grenzüberschreitende Abfallentsorgung kurz dargestellt werden.

Nach Maßgabe des Art. 1 AbfallHE behandelt der Entwurf die zivilrechtliche Haftung für Schäden und Umweltbeeinträchtigungen aus Abfällen, die bei einer gewerblichen Tätigkeit anfallen. Es gilt daher der subjektive und objektive Abfallbegriff ohne Einschränkung ${ }^{367}$. Von der Haftungsregelung erfaßt sind demnach nur solche Abfälle, die die Grenzen der Mitgliedstaaten tatsächlich oder potentiell überschreiten. Folgt man dem Wortlaut des Richtlinienentwurfs, so werden ausdrücklich nur die gewerblichen Abfälle erfaßt; Haushaltsabfälle und die öffentlichen Haus-

366 KOM (89) 282 endg. - SYN 217, Abl. C 251 vom 4. 10. 1989, S. 3. Nachweis bei Roller, PHI 5/1990, Fn. 22, S. 154, 157.

367 Ausnahmen vom Abfallbegriff i.S. des Entwurfs bestehen nach Art.1 Abs. 2 AbfallHE lediglich für radioaktive Abfälle sowie Verschmutzungen durch Ölschäden. Vgl. Salje, DB 41/1990, S. 2053, 2054. 
müllverbrennungsanlagen und -deponien scheinen dagegen von der Anwendung ausgenommen. Diese Ausnahme betrifft jedoch nicht die öffentliche Entsorgung hausmüllähnlicher gewerblicher Abfälle.

Als Haftungsträger sieht Art. 3 AbfallHE den Abfallerzeuger vor, der im Rahmen einer Gefährdungshaftung (verschuldensunabhängig von eigenem rechtmäßigen oder unrechtmäßigen Verhalten) für Schäden und Umweltbeeinträchtigungen haftet $^{368}$.

Als Abfallerzeuger definiert Art. 2 Abs. 1a AbfallHE ,jede natürliche oder juristische Person, durch deren gewerbliche Tätigkeit Abfälle entstehen, sowie jede Person, die eine Vorbehandlung, eine Vermischung oder sonstige Handlungen vorgenommen hat, die zu einer Veränderung der Art und Zusammensetzung dieser Abfälle bis zum Zeitpunkt der Entstehung des Schadens oder der Umweltbeeinträchtigung führen" 369 .

Ist ein Abfallerzeuger nicht feststellbar, haften an seiner Stelle ausnahmsweise der Importeur, der die Abfälle in die Gemeinschaft eingeführt hat, der Abfallbesitzer, der während eines Transitvorgangs durch die EG die tatsächliche Kontrolle hat, oder der Abfallbeseitiger, dem die Abfälle ordnungsgemäß übergeben worden sind ${ }^{370}$. Die Haftung des Erzeugers endet bei der Übergabe der Abfälle an den Betreiber, einer entsprechend Art. 8 Richtlinie 75/442/EWG, Art. 6 Richtlinie 75/439/EWG, Art. 9 Richtlinie 78/319/EWG oder Art. 2 Richtlinie 76/403/EWG zugelassenen Entsorgungsanlage, wenn dort eine ordnungsgemäße Entsorgung erwartet werden kann. Übergibt der Abfallerzeuger den Abfall jedoch nicht an eine zugelassene Entsorgungsanlage, so bleibt er in der Haftung 371 .

Eine vertragliche Haftungsbeschränkung oder der Ausschluß der Haftung ist nach Maßgabe des Art. 8 AbfallHE unzulässig.

Durch die allgemeine verschuldenslose Haftung des Erzeugers wird jedoch eine spätere Spezialhaftung des Transporteurs für Gefahren des Transports nicht ausgeschlossen. Damit zielt der Richtlinienentwurf auf eine Haftung nach Sphären und

368 Roller, PHI 5/1990, S. 154, 157.

369 Die Definition des Abfallerzeugers entspricht demnach der der Richtlinie über die grenzüberschreitende Verbringung gefährlicher Abfälle 84/631/EWG. Vgl. oben Kapitel A.II.2.d).

370 Salje, DB 1990, S. 2053, 2054-2055.

371 Roller, PHI 1990, S. 154, 158. 
Verkehrsbereichen. Der Produzent trägt das Produktrisiko und das Abfallrisiko, der Transporteur entsprechend das Transportrisiko ${ }^{372}$.

Durch den Richtlinienentwurf über die zivilrechtliche Haftung für die durch Abfälle verursachten Schäden wird die Entsorgung wertlos gewordener, weggeworfener Produkte nicht erfaßt, denn aus Art. 2 Abs. 1a) AbfallHE ergibt sich, daß diese Abfälle nicht aus gewerblicher Tätigkeit des Produzenten entstehen. Die Haftung des ehemaligen Produkterzeugers für die ordnungsgemäße Entsorgung von ihm hergestellter Produkte ist demnach vom Richtlinienentwurf nicht vorgesehen ${ }^{373}$. Dies schließt eine Haftung im Rahmen der EG-rechtlich vorgesehenen Produkthaftung jedoch nicht aus.

Auch bezüglich der Geltung der Marktfreiheiten für Abfälle bzw. Abfallentsorgung stellt sich wegen der Risken für Mensch und Umwelt bei der grenzüberschreitenden Abfallentsorgung die Frage, ob die gewünschte Einschränkung der Mobilität mit den Bestimmungen des EWG-Vertrages zu vereinbaren ist. Da der Gemeinschaftsgesetzgeber an den EWG-Vertrag gebunden ist, bedürfen Beschränkungen der vertraglich garantierten Grundfreiheiten einer Legitimation. Es bietet sich dabei mangels anderer geeigneter Ermächtigungsnormen ein Ansatz entsprechend der „rule of reason" an. Der EuGH hat aber eine andere Richtung eingeschlagen und bei seinen Entscheidungen in solchen Fällen eine Abwägung aller betroffenen Interessen vorgenommen ${ }^{374}$. Einschränkungen des freien Waren- bzw. Dienstleistungsverkehrs hat der EuGH dann zugelassen, wenn sie im allgemeinen Interesse der Gemeinschaft liegen, für alle Mitgliedstaaten gleichermaßen verbindlich sind und den Grundsatz der Verhältnismäßigkeit wahren. Bei der Neufassung der Richtlinie 75/442/EWG ist eine Abschätzung und Abwägung bei dem augenblicklichen Informationsstand nur unvollständig möglich; sie muß daher unterbleiben. Die Formulierung der Regelung birgt eine erhebliche Brisanz bei der Spezifizierung des Begriffs „angemessen“" und „nächste“. Ist darunter der jeweilige Standard der Mitgliedstaaten zu verstehen, oder ist ein gemeinschaftlicher Standard zu erwarten? Kann ein Mitgliedstaat verhindern, daß Abfälle grenzüberschreitend in einen anderen Mitgliedstaat verbracht werden, wenn bei gleicher Entfernung der inländischen Anlage die dort als angemessen angesehenen Mindeststandards unter den eigenen liegen? Verhindert die in Art. 130t EWGV geforderte „Vereinbarkeit mit dem Vertrag“ strengerer mitgliedstaatlichen Maßnahmen eine Festsetzung höherer Standards, weil sie den Zugang zu Entsorgungsleistungen anderer Mitgliedstaaten abschneidet? Was

372 Salje, DB 1990, S. 2053, 2054.

373 Salje, DB 1990, S. 2053, 2056.

374 Vgl. Matthies in Grabitz Art. 30 Rdnr. 40-42. 
ist die „nächstgelegene“ Entsorgungsanlage; ist es die auf dem kürzesten oder die auf dem sichersten Weg erreichbare Anlage? Hier zeichnen sich viele Fragen mit äußerster umweltpolitischer und rechtlicher Tragweite ab, deren Klärung noch größte Schwierigkeiten bereiten dürfte.

Ein weiterer Punkt, dem insbesondere von dänischer und bundesdeutscher Seite große Wichtigkeit zugemessen wird, ist die Abstützung auf Art. 130s EWGV. Durch diese Abstützung der Richtlinie wird es den Mitgliedstaaten ermöglicht, auf der Grundlage von Art. 130t EWGV strengere Maßnahmen beizubehalten und auch neue zu treffen. Welche Schranken solchen Maßnahmen gesetzt sind, ist bislang völlig offen. Die Regelung des Art. 130t EWGV fordert ganz allgemein die Vereinbarkeit mit den Bestimmungen des EWG-Vertrages. Es bleiben also im direkten Zusammenhang mit der Neufassung der Richtlinie zunächst viele gewichtige Fragen offen.

Für die Abfallwirtschaft sowie für die Umweltpolitik der Bundesrepublik und der Gemeinschaft dürfte der eingeschlagene Weg weitreichende Konsequenzen haben. Dazu lassen sich folgende Thesen formulieren:

- Der zunehmende gemeinschaftsrechtliche Regelungsumfang und die größer werdende Regelungsdichte lassen die Frage der Vereinbarkeit nationaler mitgliedstaatlicher Regelungen wegen enger werdender nationaler Spielräume immer mehr in den Hintergrund treten.

- Die Binnenmarktidee zwingt die Mitgliedstaaten bei autonomen Maßnahmen auf Wettbewerbsverträglichkeit zu achten. Beschränkungen der Grundfreiheiten lassen sich nur auf Gemeinschaftsebene legitimieren.

- Wegen der stärkeren Marktorientierung in der Abfallwirtschaft und die zu erwartenden lukrativen Geschäftsfelder, drängen nationale und internationale Konzerne in die Abfallwirtschaft ${ }^{375}$. Dies dürfte insbesondere für die Organisation der Sonderabfallentsorgung in der Bundesrepublik Deutschland weitreichende Folgen haben. Der Eintritt der privatwirtschaftlichen Entsorgungsunternehmen dürfte den Zwang zur EG-weiten Harmonisierung und Wettbewerbsverträglichkeit abfallrechtlicher Maßnahmen verstärken.

- Die Regelung der Abfallentsorgung auf Gemeinschaftsebene könnte zu Schwierigkeiten führen. Die deutlichen Unterschiede bei den bestehenden

375 Vgl. Studie des KL-TEAM zum Markt für Sonderabfall in NRW nach 1992, S. 31-33. 
Entsorgungsstandards der Mitgliedstaaten könnten zur Folge haben, daß die Entwicklung hinter dem technischen Fortschritt zurückbleibt. Im Zusammenhang mit solchen unerwünschten Entwicklungen könnte sich die Legitimationsbasis der Gemeinschaft als zu gering erweisen, um nötigenfalls korrigierend eingreifen zu können.

- Die großen Probleme, die sich bei der Abfallbewirtschaftung andeuten, ziehen eine solche Aufmerksamkeit auf sich, daß die nach Ansicht der Autoren zu favorisierende Strategie der Abfallvermeidung vernachlässigt wird. Als Beispiel kann das Glasrecycling gelten: Hohe Recyclingquoten werden als Erfolg gewertet, dabei wird allerdings außer acht gelassen, daß Mehrwegsysteme sowohl energiesparender als auch umweltschonender sind. Dies zeigt sich insbesondere an dem Dilemma der Umweltpolitik in der Bundesrepublik Deutschland, das sich so umreißen läßt: Die Deutschen sind zwar führend im Umweltrecht, aber gleichzeitig einer der größten Produzenten von Schmutzfrachten in der Gemeinschaft.

- Es deutet sich immer mehr an, daß ein völlig neuer Ansatz zur rechtlichen Behandlung der Abfallproblematik erforderlich ist. Hinweise auf eine solche Neuausrichtung geben die auf nationaler und internationaler Ebene in Arbeit befindlichen Regelungen zur Haftung für durch Abfälle verursachte Schä$\operatorname{den}^{376}$.

376 Vgl. die diesbezüglichen Zwischenergebnisse der ad hoc-Arbeitsgruppe der UNEP zur Regelung der zivilrechtlichen Haftung für durch Abfälle verursachte Schäden und den Entwurf zu einer entsprechenden EG-Richtlinie. 


\section{Zusammenfassung}

\section{Situation}

Die Abfallentsorgung steht im Brennpunkt des öffentlichen Interesses. Ihre Auswirkungen betreffen die Menschen heute und in Zukunft. Die Lösungen der anstehenden Probleme erfordern eine Zusammenarbeit von Wissenschaft, Politik, Umweltverbänden und Industrie. In der Bundesrepublik Deutschland übertreffen die anfallenden Abfallmengen seit Jahren bei weitem die zur Verfügung stehenden Entsorgungskapazitäten. Deren Ausweitung stößt wegen des gestiegenen Umweltbewußtseins auf starke Widerstände. Zudem lassen sich geeignete Standorte insbesondere für Deponien und Verbrennungsanlagen kaum noch ausweisen. Folge der weiter steigenden Abfallmengen bei knappen Entsorgungskapazitäten ist ein umfangreicher Abfallexport.

\section{Ursachen}

Das veränderte Umweltbewußtsein resultiert aus den vielfältigen und in ihren Auswirkungen nicht mehr zu übersehenden Beeinträchtigungen der Umwelt und damit der menschlichen Lebensbedingungen. Das gestiegene Abfallaufkommen und die Entsorgung von Abfällen bildet hierbei einen besonderen Problemkreis. Die hohen Entsorgungsstandards und -kosten in der Bundesrepublik Deutschland haben bis heute nicht zu einer Verringerung der Abfallmengen geführt, weil die Ausfuhr von Abfällen, die nicht im Inland entsorgt werden können, zulässig und oft auch noch kostengünstiger ist. Abfallvermeidung und -verwertung bleiben weiterhin deutlich hinter der endgültigen Beseitigung durch Deponierung oder Verbrennung zurück.

\section{Erkenntnisse}

Die grenzüberschreitende Abfallentsorgung ist kein sinnvoller Ansatz zur Lösung von Kapazitätsengpässen, bedeutet sie doch sehr oft die Entsorgung in Staaten mit niedrigen Entsorgungsstandards und damit eine regionale Verschiebung der Umweltbelastungen. Zusätzliche Umweltbelastungen und -gefahrenpotentiale entstehen durch die Transportvorgänge. Solange die Engpässe der Entsorgungskapazitäten nicht zu einer Einschränkung abfallverursachender Wirtschaftsvorgänge führen, ist eine konsequente Vermeidung von Abfällen nicht zu erwarten. Die Abfallvermeidung ist jedoch die einzige, die Umwelt nicht belastende Form der „Entsorgung“. Aus diesem Grund muß zukünftig für den gesamten Produktions- und Nutzungszyklus von Produkten systematisch Vermeidungsmöglichkeiten gesucht und diese konsequent genutzt werden. 


\section{Rechtliche Rahmenbedingungen}

In der Bundesrepublik Deutschland existiert mit dem Abfallgesetz des Bundes, den jeweiligen Landesabfallgesetzen und den ergänzenden Verordnungen ein in weiten Teilen nahezu vollständiges Instrumentarium zur Regelung der Abfallentsorgung und der Abfallwirtschaft. Diesem Regelungssystem ist das des EWG-Abfallrechts überlagert, ihm kommt in Konfliktfällen ein Anwendungsvorrang gegenüber mitgliedstaatlichem Recht zu. Der Regelungsumfang beider Rechtssysteme ist als weitestgehend gleich anzusehen; die Regelungsdichte des EWG-Rechts ist jedoch (noch) deutlich geringer und bedarf in vielen Bereichen einer weitergehenden Präzisierung.

Die im EWG-Vertrag durch gemeinschaftliches Primärrecht garantierten wirtschaftlichen Grundfreiheiten gelten nach Ansicht der Verfasser für Abfallentsorgung und Abfallwirtschaft. Die Entsorgung von Abfällen ist bis auf wenige Spezialfälle als Dienstleistung anzusehen. Daher müssen sich diesbezügliche Regelungen zum Abfall und seiner Entsorgung wie auch Maßnahmen von Gemeinschaft und Mitgliedstaaten an den Bestimmungen zur Dienstleistungsfreiheit messen lassen. Für die grenzüberschreitende Verbringung gefährlicher Abfälle besteht auf der Ebene des sekundären Gemeinschaftsrechts mit der Richtlinie 84/631/EWG eine abschlieBende Regelung. Für den Bereich der Haushaltsabfälle und hausmüllähnlichen Abfälle kündigt sich mit der Neufassung der Richtlinie 75/442/EWG eine entsprechende Entwicklung an. In Bezug auf Transportrisiken bestehen umfangreiche internationale Vereinbarungen, die zum einen technische Fragen klären und zum anderen die zivilrechtliche Haftung für Schäden aus Transportvorgängen regeln.

\section{Erschwernisse}

Das im Zusammenhang mit der Errichtung des EG-Binnenmarktes zum 31. Dezember 1992 prognostizierte europaweite Wirtschaftswachstum wird mit sehr hoher Wahrscheinlichkeit ein weiteres Anwachsen der Abfallmengen zur Folge haben. Die im Binnenmarktrecht enthaltenen Freizügigkeitsgarantien haben dabei unmittelbare Auswirkung auf das Abfallrecht in der Gemeinschaft und damit auch der Bundesrepublik Deutschland. Umweltpolitisch wünschenswerte Einschränkungen der EWG-vertraglichen Grundfreiheiten bedürfen der Rechtfertigung. Diese ist auf mitgliedstaatlicher Ebene nur noch in Ausnahmefällen gegeben. Eine EG-rechtliche Rechtfertigung von Maßnahmen zur Beschränkung der grenzüberschreitenden Verbringung von Abfällen seitens der Gemeinschaft ist zudem allein dort gegeben, wo sie aus Gründen des Umweltschutzes geboten erscheint. 


\section{Entwicklung}

Die bei der Abfallentsorgung auftretenden nationalen und übernationalen Probleme führen aus zwingenden umweltpolitischen und wettbewerbspolitischen Gründen zu zunehmenden Rechtsetzungsaktivitäten der Europäischen Gemeinschaft. Die von der Gemeinschaft verfolgte Strategie für die Abfallwirtschaft setzt bei der Abfallentsorgung auf regionale Konzepte, die sich nicht an Ländergrenzen orientieren. Die Folge ist, daß die grenzüberschreitende Zusammenarbeit und die Verbringung von Abfällen über Landesgrenzen im Rahmen einer gemeinschaftsweiten integrierten Abfallentsorgungsinfrastruktur auf hohem technischen Niveau eine umweltpolitische Notwendigkeit darstellt. Damit jedoch eine gemeinschaftsweite Zusammenarbeit auch tatsächlich funktionieren kann, ist die Abstimmung nationaler Maßnahmen und Entsorgungspläne auf europäischer Ebene unbedingt erforderlich. Soweit das für das deutsche Abfallrecht geltende Prinzip der Inlandsentsorgung nicht bereits heute im Hinblick auf die Wirkung des EWG-Vertrags der Korrektur bedarf, wird es spätestens mit der Verwirklichung des Binnenmarktes nicht mehr haltbar sein. Eine umweltpolitische Rechtfertigung staatlicher Entsorgungsgarantien läßt sich nur für Haushaltsabfälle aufstellen. Besteht darüber hinaus auch eine Entsorgungsgarantie für Produktionsabfälle, so steht dies im Widerspruch zum Verursacherprinzip, da mögliche Potentiale zur Abfallvermeidung nicht ausgeschöpft werden. Eine staatliche Entsorgungsgarantie für Produktionsabfälle käme einer Subventionierung der einheimischen Wirtschaft gleich, sie ist damit EGrechtlich unzulässig. Eine Verbesserung der gemeinschaftsweiten Umweltsituation ließe sich nur durch die Verpflichtung erreichen, im Ausland eine mindest gleichwertige Anlage aufzusuchen. Darüber hinaus müssen Überwachung und Kontrolle der Abfallströme und der gegenseitige Informationsaustausch konsequent genutzt und ausgebaut werden. Erfolgsaussichten hat die von der Gemeinschaft propagierte Strategie für die Abfallwirtschaft jedoch nur dann, wenn die im Entwurf zur Neufassung der Richtlinie 75/442/EWG aufgestellte Priorität der Vermeidung von Abfällen auch zu einschneidenden Maßnahmen in dieser Richtung führen. Ein zusätzlicher stärkerer Anreiz zur Abfallvermeidung könnte sich für die gewerblichen Abfallerzeuger aus der in der Entwicklung befindlichen Haftungsrichtlinie ergeben. Strengere Haftungsregelungen können zudem bewirken, daß schon bei der Konzeption neuer Produktionsverfahren und der Planung von neuen Produkten, die Vermeidung von Abfällen und deren gefahrlose Entsorgung in stärkerem Umfang Beachtung findet. 
Bert Rürup and Uwe H. Schneider - 978-3-631-75109-1

Downloaded from PubFactory at 01/11/2019 08:13:45AM

via free access 


\section{E. Literaturverzeichnis}

Backes, Christoph: Das neue Abfallgesetz des Bundes und seine Entstehung, in: DVBl 1987, S. 333.

Beutler, Bengt/Bieber, Roland/Pipkorn, Jörn: Die Europäische Gemeinschaft: Rechtsordnung und Politik, 3. Aufl., Baden Baden 1987.

Beyerlin, Ulrich: Die „neu“" Umweltpolitik der Europäischen Gemeinschaften, in: UPR 1989, S. 361.

BMU: - Pressemitteilungen - 78/90, Bonn 1990, S. 1.

Breuer, Rüdiger: EG-Richtlinien und deutsches Wasserrecht, in: WiVerw 1990, S. 79.

Doose, Ulrich: Rechtsvorschriften der Abfallentsorgung, in: Abfall und Abfallentsorgung (Walprecht, Dieter, Hrsg.), Köln u.a. 1990, S. 39-55.

EG-Bulletin 3-1989: Baseler Abkommen, Brüssel 1989, S. 40.

EG-Bulletin 9-1989: Gemeinschaftstrategie für die Abfallwirtschaft, Brüssel 1988, S. 8.

Europäische Stiftung zur Verbesserung der Lebens- und Arbeitsbedingungen:

Transport gefährlicher Abfälle, Luxemburg 1987.

Friedrich, Helmut Martin: Rechtsprobleme der nationalen, völkerrechtlichen und europarechtlichen Regelungen der grenzüberschreitenden Abfallverbringung, in: UPR 1988, S. 4.

Gassner, Erich: Die medien- und verfahrensübergreifende Umweltverträglichkeitsprüfung, in: UPR 1990, S. 361.

Gleiß, Alfred/Hirsch, Martin: Kommentar zum EWG-Kartellrecht, 3. Aufl., Heidelberg 1978.

Götz, Volkmar: JZ 1989, S. 1021.

Grabitz, Eberhard: Kommentar zum EWG-Vertrag, München, Stand September 1989. 
v.d. Groeben, Hans/Thiesing, Jochen/Ehlermann, Claus-Dieter: Kommentar zum EWG-Vertrag, Art. 36, Rdnr. 25-31 und Vorbemerkungen zu Art. 59 bis 66, Rdnr. 3, Baden Baden, Stand Februar 1984.

Hansmann, Klaus: Inhalt und Reichweite der Reststoffvorschrift des § 5 I

Nr. 3 BImSchG, in: NVwZ 1990, S. 409.

Herkommer/Kreßel/Wollenschläger: Rechtsprobleme bei der Genehmigung von

Anlagen zur Verwertung fester Verbrennungsrückstände aus der Hausmüllverbrennung, in: UPR 1989, S. 257.

Himmel, Joachim: Das Abfallrecht in 23 Schaubildern, Darmstadt 1990.

Holtmeier, Ernst-Ludwig: Rechtsprobleme des grenzüberschreitenden Transports gefährlicher Abfälle, Berlin 1985.

Hoschützky, Arnold/Kreft, Hansjürgen: Recht der Abfallwirtschaft, Köln u.a., Stand September 1989.

Hösel, Gottfried/Freiherr von Lersner, Heinrich: Recht der Abfallbeseitigung, Bd. 2, Berlin, Stand Dezember 1988.

Institut für gewerbliche Wasserwirtschaft und Luftreinhaltung e.V.: Referatesammlung zum Thema Umweltschutz im EG-Binnenmarkt, Köln 1989.

Ipsen, Hans Peter: Europäisches Gemeinschaftsrecht, Tübingen 1972.

Jakobi, Hans/Schenkel: Werner, Abfallbeschreibung, Klassifizierung der Sonderabfälle, in: Abfall und Abfallentsorgung (Walprecht, Dieter, Hrsg.), Köln u.a. 1989.

v. Kempis, Karl: Überlegungen zu der Vereinbarkeit des Grundsatzes der Abfallbeseitigung im Inland mit dem EWG-Vertrag, in: UPR 1985, S. 354.

Kloepfer, Michael: Umweltrecht, München 1989.

KL-TEAM, Gesellschaft für Planung und Training $m b H$ : Markt für Sonderabfälle in NRW nach 1992, Frankfurt (M.)/Hamburg 1989.

Knaur: Das deutsche Wörterbuch, München 1985.

v. Köller, Henning: Die neue Abfallverbringungsverordnung, in: Entsorga-Magazin 10/1988, S. 12.

Königs, Barbara: Der Müllberg wird leichter, aber gleichzeitig voluminöser, in: FAZ-Sonderdruck, Artikelreihe „Abfall“, Folge 1, Frankfurt, 1990. 
Kommunaler Abfallentsorgungsverband Saar (KABV)/Institut für Wassergüte- und Abfallwirtschaft: Binnenmarkt 1992 - Auswirkungen auf die Abfallwirtschaft -, Referatesarnmlung zum 10. abfallwirtschaftlichen Kolloqium, Saarbrücken 1990.

Krämer, Hans R.: Rechtliche Aspekte und Probleme der Vollendung des EGBinnenmarktes, Kiel 1987.

Krämer, Ludwig: Zur innerstaatlichen Wirkung von Umweltrichtlinien der EWG, in: WiVerw 1990, S. 138.

Küfner, Georg: Geringere Kosten und engere Deponieräume: Motive für den Müllexport, in: FAZ-Sonderdruck, Artikelreihe „Abfall“, Folge 5, Frankfurt 1990.

Landerausschusses für Immissionsschutz: Musterentwurf des Länderausschusses für Immissionsschutz für eine Verwaltungsvorschrift zu § 5 Abs. 1 Nr. 3 BImSchG, in: NVwZ 1989, S. 130.

Messinger, Anke: Den Müll will keiner vor der Haustür, in: FAZ-Sonderdruck, Artikelreihe „Abfall“, Folge 3, Frankfurt 1990,

Molkenbur, Gerhard: Umweltschutz in der Europäischen Gemeinschaft, in: DVBI. 1990, S. 677.

Müller-Graff, Peter-Christian: Binnenmarktziel und Rechtsordnung, Bergisch Gladbach/Köln 1989.

Müller/Schmitt-Gleser: Handbuch der Abfallentsorgung, München 1989.

v. Münch, lngo: Grundgesetzkommentar Bd. 1, Art. 24, Rdnr. 9-23 und Rdnr. 41-49.

O.V.: EuGH: Urteile zum Begriff des Abfalls, in: EuZW 1990, S. 109.

O.V.: „Einmal Abfall“" muß nicht ,immer Abfall bleiben“, in: HB vom 13. 6. 1990, S. 22.

Offerrnann-Clas, Christel: Das Abfallrecht der Europäischen Gemeinschaften, in: DVBl. 1981, S. 1125.

Oldenburg, Andreas: Die unmittelbare Wirkung von EG-Richtlinien, München 1984.

Pernice, Ingolf: Auswirkungen des europäischen Binnenmarktes auf das Umweltrecht Gemeinschafts(verfassungs-)rechtliche Grundlagen, in: NVwZ 1990, S. 201. 
Ders.: Gestaltung und Vollzug des Umweltrechts im europäischen Binnenmarkt

- Europäische Impulse und Zwänge für das deutsche Umweltrecht, in: NVwZ 1990, S. 414.

Pflugradt, H. J.: Neues Abfallrecht in Hessen und Synoptische Einführung in das Länderabfallrecht, in: Birn/Jung, Abfallbeseitigungsrecht in der betrieblichen Praxis, Kissling, Stand Mai 1990.

Rat der Europäischen Gemeinschaften - Generalsekretariat: Mitteilungen an die Presse 6715/90 (Presse 81), Brüssel 1990.

Rehbinder, Eckard: Abfallrechtliche Regelungen im Bundes-Immissionsschutzgesetz, in: DVBl 1989, S. 496.

Roller, Gerhard: Die neuere Entwicklung des Umwelthaftungsrechts - Internationale, gemeinschaftsrechtliche und nationale Regelungen und Vorschläge, in: PHI 1990, S. 154.

Ruchay, Dietrich: Vermeidungs- und Verwertungsstrategien, in: Abfall und Abfallentsorgung (Hrsg. D. Walprecht), Köln u.a. 1989, S. 15-23.

Salje, Peter: Deutsche Umwelthaftung versus europäische Abfallhaftung, in: DB 1990, S. 2053.

Schlabach, Erhard: Das 3. Änderungsgesetz zum Bundes-Immissionsschutzgesetz, in: UPR 1990, S. 250.

Schneider, Michael: Zum Transport gefährlicher Abfälle - rechtspolitische Konsequenzen aus der Suche nach den „Seveso-Fässem“, in: UPR 1983, S 253.

Schröder, Meinard: Grundlagen des europäischen Abfallrechts, in: WiVerw 1990, S. 118.

Spill, Elvira/Wingert, Erdmann (Hrsg.): Brennpunkt Müll, Hamburg 1990. Sondermann, Wolf: TA-Abfall im Dialog, in: VDI Berichte 789, Köln 1990.

Spetzler, Eugen: Die Kollision des Europäischen Gemeinschaftsrechts mit nationalem Recht und deren Lösung, in: RIW 1990, S. 286.

Stüer, Bernhard: Dreizehnte Umweltrechtliche Fachtagung der Gesellschaft für Umweltrecht, in: DVB1 1990, S. 197.

Szelinski, Bert-Axel: Grenzüberschreitende Abfallentsorgung, in: Handwörterbuch des Umweltrechts (Hrsg. Kimminich/v. Lersner/ Storm), Bd. 1, Berlin 1988, S. 677-682.

Ders.: Nationale, internationale und EG-rechtliche Regelungen der grenzüberschreitenden Abfallverbringung, in: UPR 1984, S. 364.

S. G.: Abfall - Kein Thema für die Wissenschaft?, in: THD-Intern, Nr. 4 1990, S. 1. 
Töpfer, Klaus (Hrsg): Meldung über die Ergebnisse der Ratstagung vom 7. Juni 1990 in Luxemburg, in: Informationen des BMU, Nr. 7/1990/S. 332.

v. Wilmowsky, Peter: Grenzüberschreitende Abfallentsorgung: Ressourcenkonflikt im gemeinsamen Markt, in: NVwZ 1991, S. 1.

Ders.: Gemeinsamer Markt für Abfälle

- Zugang zu den natürlichen und öffentlichen Ressourcen anderer Mitgliedstaaten, Diss. jur. (unveröffentlichte Fassung), Frankfurt (M.) 1989. 


\section{SOZIALÖKONOMISCHE SCHRIFTEN}

Herausgegeben von Professor Dr. Dr. h.c. Bert Rürup

Band 1 Marietta Jass: Erfolgskontrolle des Abwasserabgabengesetzes. Ein Konzept zur Erfassung der Gesetzeswirkungen verbunden mit einer empirischen Untersuchung in der $\mathrm{Pa}$ pierindustrie. 1990.

Band 2 Frank Schulz-Nieswandt: Stationäre Altenpflege und "Pflegenotstand" in der Bundesrepublik Deutschland. 1990.

Band 3 Helmut Böhme, Alois Peressin (Hrsg.): Sozialraum Europa. Die soziale Dimension des Europäischen Binnenmarktes. 1990.

Band 4 Stephan Ruß: Telekommunikation als Standorttaktor für Klein- und Mittelbetriebe. Telekommunikative Entwicklungstendenzen und regionale Wirtschaftspolitik am Beispiel Hessen. 1991.

Band 5 Reinhard Grünewald: Tertiärisierungsdefizite im Industrieland Bundesrepublik Deutschland. Nachweis und politische Konsequenzen. 1992.

Band 6 Bert Rürup, Uwe H. Schneider (Hrsg.): Umwelt und Technik in den Europäischen Gemeinschaften. Teil I: Die grenzüberschreitende Entsorgung von Abfällen. Bearbeitet von: Thomas Kemmler, Thomas Steinbacher. 1993. 


\section{Andreas Schröer}

\section{Kommunaler Umweltschutz in Europa}

Frankfurt/M., Berlin, Bern, New York, Paris, Wien, 1992. LI, 210 S.

Europäische Hochschulschriften: Reihe 2, Rechtswissenschaft. Bd. 1269

ISBN 3-631-45180-6

br. DM 74.--

Umweltschutz auf der einen Seite und die Europäischen Gemeinschaften auf der anderen Seite sind zwei hochaktuelle Themenbereiche, deren kommunale Bedeutung in der vorliegenden Arbeit hinterfragt wird. Nach Darstellung, inwieweit Umweltschutz überhaupt kommunale als auch gemeinschaftliche Aufgabe ist, beschäftigt sich die Untersuchung im Kernbereich mit dem Einfluß des umweltorientierten europäischen Gemeinschaftsrechtes auf die kommunalen Aufgabenbereiche im Umweltschutz (Abfall-, Wasser-, Immissionsschutz-, Strahlenschutz-, Naturschutz- und Baurecht, Öffentliches Auftragswesen, Umweltverträglichkeitsprüfung, Zugang von Einzelpersonen zu behördlichen Umweltdaten), Umsetzungsprobleme und -defizite werden aufgezeigt. Es wird die Problematik diskutiert, wie im Falle von Differenzen zwischen nationalem und gemeinschaftsrechtlichem Umweltrecht von Seiten der Kommunalverwaltungen zu verfahren ist. $\mathrm{Ob}$ die Garantie der kommunalen Selbstverwaltung durch gemeinschaftliches Umweltrecht beeinträchtigt wird und eine Berufung der Kommunen auf diesen Verfassungsgrundsatz möglich ist, wird abschließend erörtert.

Aus dem Inhalt: Umweltschutz als Aufgabe der Kommunen der Bundesrepublik Deutschland nach nationalem Verfassungsrecht - Umweltschutz als Aufgabe der Europäischen Wirtschaftsgemeinschaft (Rechtsgrundlagen, Implementations- und Vollzugsdefizit) - Einfluß des Umweltschutzrechts und der Umweltpolitik der Europäischen Gemeinschaften auf die Umweltschutzaufgaben der Kommunen der Bundesrepublik Deutschland (Abfall-, Wasser-, Immissionsschutz-, Strahlenschutz-, Naturschutz-, Baurecht, öffentliches Auftragswesen, UVP, Zugang von Einzelpersonen zu behördlichen Umweltdaten) - Europafestigkeit von Art. 28 Abs. 2 GG

\section{V}

Verlag Peter Lang Frankfurt a.M. Berlin $\cdot$ Bern $\cdot$ New York $\cdot$ Paris $\cdot$ Wien Auslieferung: Verlag Peter Lang AG, Jupiterstr. 15, CH-3000 Bern 15 Telefon (004131) 9411122, Telefax (004131) 9411131

- Preisänderungen vorbehalten - 
Bert Rürup and Uwe H. Schneider - 978-3-631-75109-1

Downloaded from PubFactory at 01/11/2019 08:13:45AM

via free access 